\title{
Evolution of anuran assemblages in the Late Cretaceous of Utah, USA
}

\author{
Zbyněk Roček • Jeffrey G. Eaton • James Gardner • \\ Tomáš Přikryl
}

Received: 5 January 2010 /Revised: 4 April 2010 /Accepted: 17 June 2010 /Published online: 2 September 2010

(C) The Author(s) 2010. This article is published with open access at Springerlink.com

\begin{abstract}
Several hundred isolated anuran bones recovered from 37 localities in southern Utah, USA, provide a relatively continuous record of the evolution of anuran assemblages in the central part of the North American Western Interior that spans almost 25 million years, from the early Cenomanian to the late Campanian. Although it is difficult to associate isolated anuran bones from different parts of the skeleton with each other, it is possible to identify distinctive morphs for certain bones (e.g., ilia, maxillae) that can be used to make inferences about the taxonomic diversity of fossil assemblages. Because the samples document a relatively long interval of time, they can also be used to recognize trends in the anatomical evolution of
\end{abstract}

Z. Roček $\cdot$ T. Přikryl

Department of Palaeobiology, Institute of Geology, Academy of

Sciences of the Czech Republic,

Rozvojová 135 ,

CZ 16500 Prague 6, Czech Republic

Z. Roček $(\bowtie)$

Department of Zoology, Charles University,

Viničná 7 ,

CZ 12844 Prague 2, Czech Republic

e-mail: Rocek@gli.cas.cz

J. G. Eaton

Department of Geosciences, Weber State University,

2507 University Circle,

Ogden, UT 84408-2507, USA

J. Gardner

Royal Tyrrell Museum of Palaeontology,

Drumheller, Alberta, Canada T0J OY0

T. Přikryl

Department of Palaeontology, Charles University,

Albertov 6,

CZ 12843 Prague 2, Czech Republic anurans and in the evolution of anuran assemblages. Smallbodied anurans prevailed until the early Campanian, then beginning in the late Campanian, larger-bodied anurans began dominating assemblages. Using iliac morphs as a proxy for taxonomic diversity, it is apparent that some local assemblages were surprisingly diverse. When coupled with previously reported fossils, the new specimens from Utah help document when certain anatomical features appeared and radiated among anurans. Ilia in the majority of early anurans (including the earliest anuran Prosalirus) had an oblique groove on the dorsal margin but lacked a dorsal tubercle. Through the Late Cretaceous, there is a trend towards an increasing majority of ilia having a welldeveloped dorsal tubercle; this osteological change could be associated with changes in locomotor behavior. Procoelous vertebrae are already present in the Cenomanian samples, which indicates that this derived anuran vertebral condition must have appeared before the Late Cretaceous.

Keywords Anura · Evolution · Late Cretaceous · Fossil frogs $\cdot$ Utah $\cdot$ Stratigraphy

\section{Introduction}

The Mesozoic record of anurans in North America consists of three-dimensionally preserved, disarticulated and rare semi-articulated bones. Except for one occurrence each in New Jersey and Baja California, the North American Mesozoic anuran record is geographically limited to the Western Interior of the USA, from Texas north to Montana and North Dakota, and into southern Alberta and Saskatchewan, Canada. This record is also stratigraphically patchy, with occurrences in the middle Early Jurassic (Pliensbachian), in the late Late Jurassic 
(Kimmerdgian, ?Tithonian), and then a relatively continuous sequence from the late Early Cretaceous to the K/T boundary (latest Aptian/early Albian-Maastrichtian). The Mesozoic record of frogs in Utah extends from the Early/Late Cretaceous boundary to the end of the Maastrichtian. In an attempt to put the Utah record into context, below we briefly review the Mesozoic record of North American anurans.

The geologically oldest anuran fossils from anywhere in the world date from the Early Jurassic (Pliensbachian) of North America. At the Gold Springs Quarry in the Kayenta Formation of northeastern Arizona, hand quarrying produced three silty slabs that contain the mostly disarticulated skull and postcranial bones from several individuals (Shubin and Jenkins 1995; Jenkins and Shubin 1998), and subsequent screen-washing of the spoil pile produced an isolated humerus and five ilia (Curtis and Padian 1999). The quarried specimens were described as belonging to Prosalirus bitis Shubin and Jenkins, 1995, whereas the screen-washed specimens were identified by Curtis and Padian (1999: 23) only as "Anura". Sufficient material of Prosalirus is available to permit a partial reconstruction of the skeleton (Shubin and Jenkins 1995: Fig. 3a, d) and to demonstrate that it is a basal anuran, although its exact position relative to other basal anurans is uncertain (e.g., Gao and Wang 2001; Borsuk-Białynicka and Evans 2002). Some of the bones from Gold Springs Quarry (especially the premaxilla, maxilla, vertebrae, urostyle, scapula, and ilium) can be used for comparisons with anuran bones from younger North American Mesozoic localities.

The next oldest occurrences are from the Late Jurassic (Kimmeridgian-?Tithonian), from two localities in the upper part of the Morrison Formation: Como Bluff in Wyoming and the Rainbow Park Microsite in Utah. Eobatrachus agilis Marsh, 1887 (see also Moodie 1912, 1914) and Comobatrachus aenigmaticus Hecht and Estes, 1960, were both named for partial humeri from Como Bluff; neither taxon is currently accepted (e.g., Estes and Sanchíz 1982; Evans and Milner 1993; Henrici 1998a, b). Sanchíz (1998) considered both of them nomina vana. An incomplete ilium from Como Bluff was assigned by Evans and Milner (1993) to the Pelobatidae sensu lato, but J.-C. Rage (pers. comm. in Roček 2000: 1302) suggested it may instead be referable to the Discoglossidae sensu lato. Enneabatrachus hechti Evans and Milner, 1993 is known by an incomplete ilium (holotype) from Como Bluff (Evans and Milner 1993) and by an urostyle and an incomplete skeleton from the Rainbow Park Microsite (Henrici 1998b); most workers (e.g., Evans and Milner 1993; Henrici 1998a, b; Sanchíz 1998; Roček 2000; Holman 2003) include Enneabatrachus within the Discoglossidae sensu lato. Henrici (1998a) described Rhadinosteus parvus based on nine incomplete skeletons and some isolated bones, from metamorphosing larvae to young postmetamorphic individuals, that are preserved on mudstone slabs from the Rainbow Park Microsite. Henrici (1998a) interpreted Rhadinosteus as a member of the Pipoidea, which makes it the earliest record for that clade, and possibly a member of the Rhinophrynidae. Finally, based on distinctive ilia from the Rainbow Park Microsite, Henrici (1998b) also reported a possible discoglossid sensu lato and two indeterminate genera and species.

The oldest Cretaceous anuran fossils are isolated skull and postcranial bones from about a dozen localities of late Aptian-middle Albian age (Winkler et al. 1990; Cifelli et al. 1997) in the following units of the Trinity Group: the upper and middle parts of the Antlers Formation in, respectively, northcentral Texas (e.g., Zangerl and Denison 1950; Hecht 1963; Winkler et al. 1990; Gardner 1995) and southeastern Oklahoma (Cifelli et al. 1997) and the Twin Mountains and Paluxy formations in central Texas (Winkler et al. 1989, 1990). Specimens from the Antlers Formation have not been formally described. Based on the ornamentation of skull bones from the Antlers Formation of northcentral Texas, Hecht (1963) suggested those might be referable to the Leptodactylidae sensu lato, but this identification was questioned by Lynch (1971) in his monographic treatment of that family. Winkler et al. (1990) described a small number of isolated bones from several localities in central Texas. Those authors tentatively assigned a humerus and urostyle, both from the Twin Mountains Formation, and a sacral vertebra from the Paluxy Formation to the Discoglossidae sensu lato and regarded the remaining specimens (maxillae from both formations; vertebrae and tibiofibulae from the Paluxy Formation) as being from indeterminate anurans. Based on Winkler et al's (1990) published account of the central Texas specimens, Roček and Nessov (1993) and Roček (2000) suggested that the maxillae and vertebrae might pertain to the Gobiatidae, which otherwise are known only from the Late Cretaceous of Central Asia (e.g., Roček and Nessov 1993; Roček, 2000, 2008).

The next youngest North American anurans are of latest Albian-earliest Cenomanian age, and are known by isolated bones and several incomplete, partially articulated skeletons from the uppermost part of the Cedar Mountain Formation in central Utah (Gardner 1995; Cifelli et al. 1999a). Slightly younger anurans have been reported (Winkler and Jacobs 2002) from the middle Cenomanian Woodbine Formation of Texas. Specimens from both formations have yet to be formally described.

Intensive screen-washing programs over the past 25 years in southern Utah have yielded hundreds of anuran bones from a statigraphically extensive series of localities in the Dakota Formation (Cenomanian), the Smoky Hollow (Turonian) and John Henry (ConiacianSantonian) members of the Straight Cliffs Formation, the Wahweap (middle Campanian), Iron Springs Formation 
(Santonian or Campanian), and Kaiparowits Formation (late Campanian) (e.g., Eaton et al. 1999a, b; Gardner et al. 2009). The first detailed report on these collections is contained in the main part of this paper.

All but one of the remaining Late Cretaceous anuran records in North America are from outside Utah and most of these consist of isolated skull and postcranial bones. The oldest of these occurrences is in the Deadhorse Coulee Member (late Santonian) in the upper part of the Milk River Formation of southeastern Alberta (Fox 1972, 1976b). Anurans are next known from the following seven units of middle-late Campanian age: Aguja Formation in Texas (Rowe et al. 1992); "Mesaverde" Formation in Wyoming (Breithaupt 1985; DeMar and Breithaupt 2006, 2008); Judith River Formation in Montana (Sahni 1972; Blob et al. 2001); Foremost, Oldman, and Dinosaur Park formations in Alberta (Fox 1976b; Brinkman 1990; Gardner 2000, 2005; Peng et al. 2001; Eberth et al. 2001); and Dinosaur Park Formation in Saskachewan (Eberth et al. 1990). Regarding specimens from the Judith River Formation of Montana, Sahni (1972) recognized several morphs of maxillae, ilia, and humeri that he assigned to the Discoglossidae sensu lato and Pelobatidae sensu lato, and Blob et al. (2001) reported on three unusual ilia that they described as belonging to a new anuran taxon, Nezpercius dodsoni. Gardner (2000, 2005) provisionally recognized two new, but unnamed anuran taxa from the Dinosaur Park Formation of Alberta. The next youngest anuran fossils are rare, isolated bones from the late Campanian Fruitland Formation of New Mexico (Armstrong-Ziegler 1980; Hunt and Lucas 1993) and from the late Campanian-early Maastrichtian Horseshoe Canyon Formation of Alberta (Eberth et al. 2001; Gardner 2005; Larson et al. in press). There are two reports of North American Campanian anurans from outside of the Western Interior: in the "El Gallo Formation" of Baja California (Lillegraven 1976; Estes and Sanchíz 1982) and in the Marshalltown Formation of New Jersey (Denton and O’Neill 1998).

The youngest North American Mesozoic anurans are from the late Maastrichtian. Anurans of this age have been reported from the Frenchman Formation in Saskatchewan (Fox 1989; Tokaryk 1997), the lower part of the Scollard Formation in Alberta (Eberth et al. 2001), and the lower part of the North Horn Formation in Utah (Cifelli et al. 1999 b), but are best known from the Lance Formation in Wyoming (Estes 1964, 1969, 1970; Fox 1976a; Breithaupt 1982, 1985; Estes and Sanchíz 1982) and the Hell Creek Formation in Montana and North Dakota (Estes 1969; Estes et al. 1969; Estes and Sanchíz 1982; Bryant 1989; Pearson et al. 2002). The Bug Creek Anthills locality in the upper part of the Hell Creek Formation in Montana has produced numerous anuran bones - including the holotype of Scotiophryne pustulosa Estes, 1969-and initially was considered to be late Maastrichtian in age (e.g., Estes 1964, 1969, 1970; Estes et al. 1969; Fox 1976b; Breithaupt 1982, 1985; Estes and Sanchíz 1982; Bryant 1989; Sanchíz 1998; Gardner 2000; Holman 2003). This locality is now interpreted as containing a mix of lowermost Paleocene and reworked upper Maastrichtian fossils (Lofgren 1995; Cifelli et al. 2004; Kielan-Jaworowska et al. 2004). Fortunately, all the anuran taxa known from the Bug Creek Anthills also occur in the Lance Formation, which is unquestionably late Maastrichtian in age. Additionally, thanks to intensive collecting efforts over the past decade, numerous anuran-bearing localities have been identified in unreworked portions of the Hell Creek Formation (e.g., Pearson et al. 2002). Until recently, five anuran species in three families were recognized from the Lance and Hell Creek formations: the palaeobatrachid Palaeobatrachus? occidentalis Estes and Sanchíz, 1982; the discoglossids sensu lato Scotiophryne pustulosa Estes, 1969 and Paradiscoglossus americanus Estes and Sanchíz, 1982; an unidentified species of the pelobatid sensu lato Eopelobates; and the incertae sedis taxon Theatonius lancensis Fox, 1976a (Estes 1964, 1969, 1970; Estes et al. 1969; Fox 1976a; Estes and Sanchíz 1982; Breithaupt 1982, 1985; Bryant 1989; Holman 2003). In the most recent treatment of anurans from the Lance and Hell Creek formations, Gardner (2008) accepted the same five species, but argued that Scotiophryne, Paradiscoglossus, and the Eopelobateslike species could not be assigned to any known family and noted that previous reports of Scotiophryne and Theatonius (Armstrong-Ziegler 1980; Estes and Sanchíz 1982; Breithaupt 1985; Fox 1989; Hunt and Lucas 1993; Denton and O'Neill 1998) in geologically younger formations could not be substantiated. Based on the presence in the Lance Formation of five distinctive maxillary morphs and two distinctive iliac morphs, none of which could be associated with one another or with any of the previously recognized taxa, Gardner (2008) also suggested that the diversity of anurans in that unit might be much higher than previously thought, with perhaps as many as 12 taxa.

Here, we report on several hundred isolated anuran bones recovered from 37 localities in southern Utah. These fossils document a relatively continuous record of the evolution of anuran assemblages in the central part of the North American Western Interior that spans almost 25 million years, from the early Cenomanian to the late Campanian. Other than para-contemporaneous localities in Central Asia (e.g., Roček and Nessov 1993), the Utah sequence contains the earliest records of locally diversified Late Cretaceous anuran assemblages. Although we suspect that certain of the specimens reported herein pertain to distinct taxa, we refrain from formally erecting any new anuran genera or species for two reasons. First, it is difficult to reliably associate isolated anuran bones, especially ones 
from different parts of the skeleton-for example, skull bones with ilia or vertebrae. Second, because some elements bear peculiar anatomical features not found in contemporary anurans (e.g. maxillae of Theatonius have a longitudinal canal in the interior of their orbital margin), it would be difficult to assign them to any recognized family. Instead, we employ a more typological approach that identifies and describes distinctive morphs for each of the bones. Some of these bones (e.g., maxillae, prearticulars, humeri, ilia, and urostyles) can, however, provide limited taxonomic information. Where appropriate, we use that information as a guide for estimating taxonomic diversities. Finally, because our samples document a relatively long interval of time, we also attempt to recognize some trends in the anatomical evolution of anurans during the Late Cretaceous.

\section{Localities, their ages, geological setting, and depositional environments}

A wide geographic (Fig. 1) and stratigraphic (Fig. 2, Table 1) range of localities have produced specimens of anurans that span almost 25 million years of anuran evolution in the Late Cretaceous. The justifications for ages and some information on the deposition environments of localities are provided below, organized by formation in ascending order (with the exception of the Iron Springs Formation, see below). The timescale of Gradstein et al. (2004) is used here. Detailed locality data is available to qualified researchers from the Utah Museum of Natural History, Salt Lake City.
The geologic setting in which the anuran-containing strata were deposited is a foreland basin that developed east of the Sevier orogenic fold and thrust belt. This rapidly subsiding basin had high sedimentary rates (e.g., Jinnah et al. 2008) and there was no opportunity for significant reworking of older specimens; in any case, the available source rocks are largely marine and Paleozoic and, thus, would not contain any anuran fossils. The frogs recovered from these rocks are mostly tiny and their bones very delicate, so it is unlikely there was significant transport of these specimens. Many of the localities are in mudstones that contain complete ostracods and gastropods, suggesting little transport of specimens, if any at all. Most of these localities represent riparian to floodplain habitats; relatively rare pond deposits also occur. A few of the localities (particularly from the Dakota Formation, see below) consist of sandy stream lags and proximal overbank deposits and in these cases there may be more extensive habitat mixing. There are inherent limitations in palaeoecologic interpretation and faunal comparisons when considering time-averaged localities that resulted from different taphonomic processes (e.g., Wilson 2008).

\section{Iron Springs Formation}

The Iron Springs Formation is present on the Markagunt Plateau in Parowan Canyon and to the west in the Pine Valley Mountains (Fig. 1). The currently known age range of the 1,000-m-thick formation is from the late Albian [based on a ${ }^{40} \mathrm{Ar}-{ }^{39} \mathrm{Ar}$ date of $101.7 \pm 0.42 \mathrm{Ma}$ (million years ago) in Dyman et al. 2002] to the Campanian (based on a ${ }^{40} \mathrm{Ar}-{ }^{39} \mathrm{Ar}$ date of $83.0 \pm 1.1$ Ma from Eaton et al.

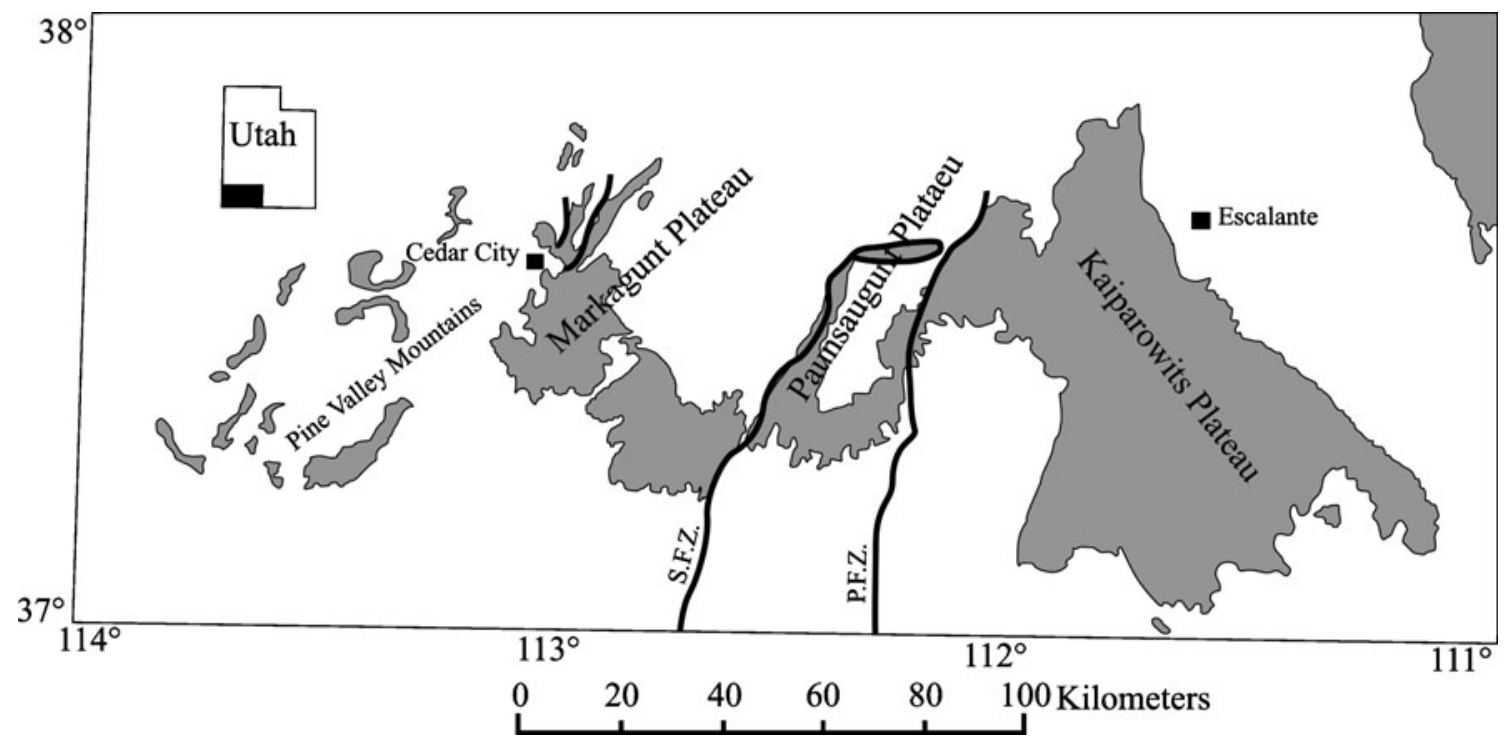

Fig. 1 Cretaceous outcrops (shaded gray) and plateaus of southwestern Utah. S.F.Z. The Sevier fault zone, P.F.Z. the Pausaugunt fault zone 
1999b, earliest Campanian, a date recovered from a biotite ash $213 \mathrm{~m}$ below the top of the formation in Parowan Canyon; see Eaton et al. 2001). The single locality from the Iron Springs Formation that has produced anurans is UMNH Locality 12 (MNA 1230). This locality is not shown in Fig. 2 because it is the only Iron Springs locality included here and its absolute stratigraphic position is unknown. The locality is a dark mudstone very high in the
Iron Springs Formation. In this area, the Iron Springs is unconformably overlain by the Eocene Claron Formation, but there is no way to be certain of how much Iron Springs strata has been removed by erosion during the approximately 20 million years represented by the unconformity. In Parowan Canyon, the Iron Springs Formation is also unconformably overlain the Claron Formation and an earliest Campanian radiometric date $(83.0 \pm 1.1 \mathrm{Ma}$; Eaton

Fig. 2 Approximate stratigraphic position and correlation of localities. M.P. Markagunt Plateau, P.P. Paunsaugunt Plateau, K.P. Kaiparowits Plateau (see Fig. 1), CS Capping Sandstone Member of the Wahweap Formation. All except MNA 1004 are UMNH VP localities

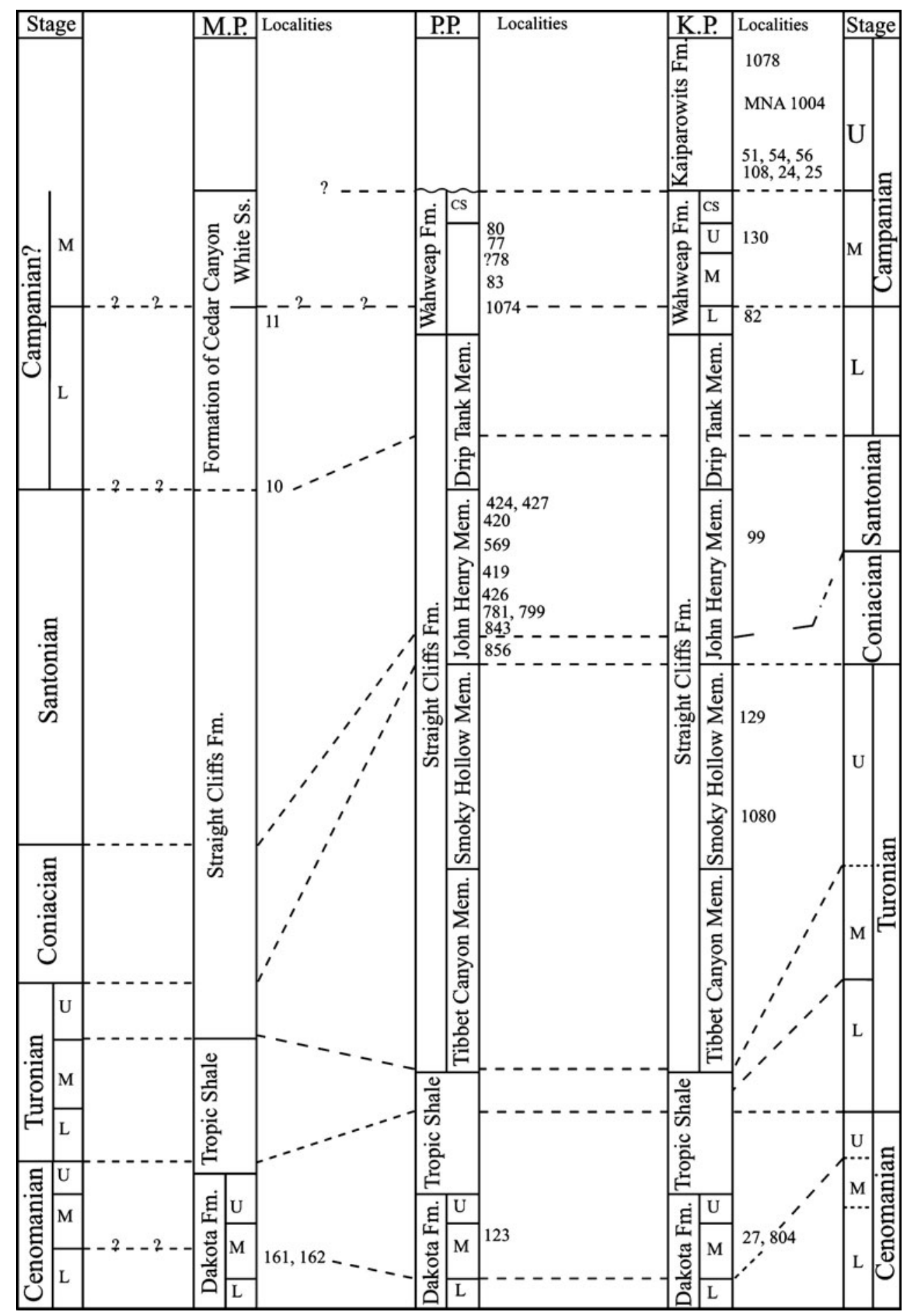


Table 1 List of localities

\begin{tabular}{|c|c|c|c|c|}
\hline Stage & Locality no. & Locality name & Formation & Member \\
\hline \multicolumn{5}{|c|}{ Upper Campanian } \\
\hline & UMNH 1078 & Howard's uppermost Kaiparowits locality & Kaiparowits Fm. & \\
\hline & MNA 1004 & South Rim & Kaiparowits Fm. & \\
\hline & UMNH 108 & The Blues & Kaiparowits Fm. & \\
\hline & UMNH 56 & Fossil Ridge & Kaiparowits Fm. & \\
\hline & UMNH 54 & Fossil Ridge & Kaiparowits Fm. & \\
\hline & UMNH 51 & Fossil Ridge & Kaiparowits Fm. & \\
\hline & UMNH 25 & Blue Wash Quarry & Kaiparowits Fm. & \\
\hline & UMNH 24 & Blue Wash Quarry & Kaiparowits Fm. & \\
\hline \multicolumn{5}{|c|}{ Lower-Mid Campanian } \\
\hline & UMNH 11 & Websters Flat & ?Wahweap Fm. & \\
\hline & UMNH 80 & Campbell Canyon & Wahweap Fm. & \\
\hline & UMNH 78 & Johnson Bench & ?Wahweap Fm. & \\
\hline & UMNH 77 & Campbell Canyon & Wahweap Fm. & \\
\hline & UMNH 130 & Barker Reservoir Rd. & Wahweap Fm. & \\
\hline & UMNH 83 & Mill Creek & Wahweap Fm. & \\
\hline & UMNH 1074 & Bulldog Hollow & Wahweap Fm. & \\
\hline & UMNH 82 & White Flats Rd. & Wahweap Fm. & \\
\hline \multicolumn{5}{|c|}{ Campanian? } \\
\hline & UMNH 12 & Pinto Flats & Iron Springs Fm. & \\
\hline \multicolumn{5}{|c|}{ Upper Santonian or Lower Campanian } \\
\hline & UMNH 10 & Paul's locality & uncertain & \\
\hline \multicolumn{5}{|c|}{ Upper Santonian } \\
\hline & UMNH 427 & North side of Pasture Wash & Straight Cliffs Fm. & John Henry M. \\
\hline & UMNH 424 & North ide of Pasture Wash & Straight Cliffs Fm. & John Henry M. \\
\hline & UMNH 420 & Hat Shop & Straight Cliffs Fm. & John Henry M. \\
\hline & UMNH 569 & Hat Shop Aquatic & Straight Cliffs Fm. & John Henry M. \\
\hline \multicolumn{5}{|c|}{ Middle Santonian } \\
\hline & UMNH 843 & Divide between Noon and Mud Creeks & Straight Cliffs Fm. & John Henry M. \\
\hline & UMNH 781 & Casey’s Shell Hash Loc. & Straight Cliffs Fm. & John Henry M. \\
\hline & UMNH 99 & Henderson Canyon & Straight Cliffs Fm. & John Henry M. \\
\hline & UMNH 419 & Old Merrill Ranch & Straight Cliffs Fm. & John Henry M. \\
\hline \multicolumn{5}{|c|}{ Lower Santonian } \\
\hline & UMNH 799 & Casey’s Concretionary Horizon & Straight Cliffs Fm. & John Henry M. \\
\hline & UMNH 426 & Sheep Creek & Straight Cliffs Fm. & John Henry M. \\
\hline \multicolumn{5}{|c|}{ Coniacian } \\
\hline & UMNH 856 & Heward Creek & Straight Cliffs Fm. & John Henry M. \\
\hline \multicolumn{5}{|c|}{ Turonian } \\
\hline & UMNH 1080 & Slickrock Bench 11 & Straight Cliffs Fm. & Smoky Hollow M. \\
\hline & UMNH 129 & Jimmy Canyon & Straight Cliffs Fm. & Smoky Hollow M. \\
\hline \multicolumn{5}{|c|}{ Upper Cenomanian } \\
\hline & UMNH 123 & Alton & Dakota Fm. & \\
\hline & UMNH 27 & Bulldog Bench & Dakota Fm. & \\
\hline & UMNH 804 & Bulldog Bench & Dakota Fm. & \\
\hline \multicolumn{5}{|c|}{ Middle? Cenomanian } \\
\hline & UMNH 162 & Cedar Canyon & Dakota Fm. & \\
\hline & UMNH 161 & Cedar Canyon & Dakota Fm. & \\
\hline
\end{tabular}


et al. 1999b) occurs $213 \mathrm{~m}$ below the contact. For this reason, but with caution, we consider the age of Locality 12 to be early Campanian, perhaps a little older than faunas recovered from the Wahweap Formation.

\section{Dakota Formation}

All vertebrate nonmarine fossils were recovered from the middle member of the Dakota Formation. The upper member is well dated as late Cenomanian based on ammonites (Cobban 1984; Tibert et al. 2003). As the middle member becomes increasing brackish up-section reflecting the rapid transgression of the Western Interior Seaway it seems likely that the middle member is also late Cenomanian, or at oldest, middle Cenomanian. Kowallis et al. (1989) provided ${ }^{40} \mathrm{Ar}^{-39} \mathrm{Ar}$ dates from low in the overlying Tropic Shale of $94.7 \pm 0.2 \mathrm{Ma}$ and $94.5 \pm 0.1 \mathrm{Ma}$, which would suggest that the upper member of the Dakota Formation is late Cenomanian. Bohor et al. (1991) had reported a ${ }^{40} \mathrm{Ar}-{ }^{39} \mathrm{Ar}$ date from the base of the formation of $92.9 \pm 0.2 \mathrm{Ma}$ and $90.5 \pm$ from near the top of the formation, but these ages would place the Dakota Formation in the Turonian and such a date is not possible based on ammonites in the upper member. Dyman et al. (2002) also considered the upper member to be of late Cenomanian age, and published a ${ }^{40} \mathrm{Ar}^{39}{ }^{39} \mathrm{Ar}$ date of $96.06 \pm 0.30 \mathrm{Ma}$ date for the middle member which would place the middle member in the late early Cenomanian. Eaton (personal observation) examined the horizon that was sampled by Dyman et al. (2002) and concluded that the rock is not an airfall ash but a bentonitic mudstone; this casts doubt on the late early Cenomanian age reported by Dyman et al. (2002).

The lower member of the Dakota Formation is a conglomerate that rests unconformably on Jurassic rocks. The middle member is relatively thick, up to $50 \mathrm{~m}$ on the Kaiparowits Plateau (Bulldog Bench, where both Kaiparowits Plateau localities are located), and was probably deposited in a relatively brief period of time ( $\sim 1$ million years, the middle and late Cenomanian together only span a little over 2 million years; Gradstein et al. 2004). As such, sedimentary rates were relatively high and there is no evidence of extensively reworked materials. Specimens recovered from UMNH Locality 27 (MNA 1067) clearly underwent some transport as the locality represents overbank fill adjacent to a levee. Specimens from UMNH Locality 804 (MNA 1064) also underwent some transport as they were recovered from a channel lag. Similarly, UMNH Locality 123 (MNA 939) on the Paunsaugunt Plateau represents a channel lag.

The two localities (UMNH localities 161, 162) on the Markagunt Plateau are from Cedar Canyon. Both are "blind wash" (Eaton 2004) mudstone localities that contain complete gastropods and ostracods and there is no evidence of extensive reworking. There are well over $100 \mathrm{~m}$ of the middle member in Cedar Canyon (see Eaton et al. 2001) and it is possible that subsidence began earlier to the west adjacent to the thrust belt than in the KaiparowitsPaunsaugunt area. The mammals from these localities appear somewhat more primitive than those from the Dakota Formation of the Kaiparowits Plateau and could be a bit older, but certainly not older than early Cenomanian (Eaton 2010).

\section{Straight Cliffs Formation, Smoky Hollow Member}

Peterson (1969) named the Smoky Hollow Member and divided it into three parts: (1) a lower coal zone which has considerable brackish water influence; (2) a barren middle zone representing floodplain deposits; and (3) an upper conglomeratic bed that he referred to as the Calico bed. The fossils reported here come from the middle barren unit. There have as yet been no radiometric dates generated from the Smoky Hollow Member. Peterson (1969) dated the underlying Tibbet Canyon Member based on the late middle Turonian index fossil Inoceramus howelli White, 1876 which indicates the upper part of the late middle Turonian Prionocyclis hyatti zone of Obradovich and Cobban (1975). As there is no marked unconformity between the Tibbet Canyon and Smoky Hollow members it is likely that the Smoky Hollow is late Turonian in age.

The only significantly productive localities that contain anurans are from the barren middle zone of the Smoky Hollow Member on the Kaiparowits Plateau. UMNH Locality 129 (MNA 995) is in a mudstone and represents a floodplain accumulation. UMNH 1080 (MNA 1212) is in a friable sandstone found low in the middle member that may represent a crevasse splay deposit.

\section{Straight Cliffs Formation, John Henry Member}

Peterson (1969) reported Volviceramus involutus from low in the John Henry Member, a taxon considered to represent the middle Coniacian (e.g., Merewether et al. 2007, Fig. 5). Taxa from the middle and upper part of the member, including the ammonite Desmoscaphites, suggest that the upper part of the John Henry Member does not extend beyond the Santonian (Eaton 1991). As such, the member ranges from middle Coniacian to possibly late Santonian.

Most of the localities reported here from the John Henry Member represent floodplain or pond mudstones. Several of the most significant localities (e.g., UMNH localities $424,427)$ are blind wash sites and contain delicate mammal jaws and complete ostracods. UMNH Locality 856 is present very low in the John Henry Member on the Paunsaugunt Plateau and is $21.5 \mathrm{~m}$ above the top of the Smoky Hollow Member and may be, due to its low stratigraphic position within the member, Coniacian in age. This locality is a very 
poorly sorted and may represent a proximal crevasse splay setting.

\section{Wahweap Formation}

This formation is over $400 \mathrm{~m}$ thick on the Kaiparowits Plateau. Radiometrically datable ashes are rare, although Jinnah et al. (2008) reported a ${ }^{40} \mathrm{Ar}^{39} \mathrm{Ar}$ date from about $60 \mathrm{~m}$ above the base of the formation of $80.1 \pm 0.3 \mathrm{Ma}$. A radiometric date of $75.96 \pm 0.14 \mathrm{Ma}$ for the overlying lower unit of the Kaiparowits Formation and estimates of depositional rates suggest the upper age limit on the Wahweap Formation is 76.1 Ma (Roberts et al. 2005). This suggests the age of the Wahweap Formation is middle Campanian. Eaton and Cifelli (1988) originally correlated the mammalian fauna from the Wahweap Formation with the fauna from the Milk River Fauna in Alberta, Canada (Aquilan North American Land-Mammal "Age"); however, later studies (Eaton 2006a) of mammals from the upper part of the John Henry Member of the Straight Cliffs Formation (Santonian) revealed a stronger correlation of that fauna to the Milk River fauna than to the Wahweap fauna. A Santonian age for the upper member (which contains all the vertebrate fossils in the formation) of the Milk River Formation has been well documented on the basis of palynomorphs (Braman 2002) and U-Pb geochronology (Payenberg et al. 2002). As such, the Wahweap fauna is younger than the Santonian Aquilan Land-Mammal "Age" and older than the late Campanian Judithian Land-Mammal "Age."

UMNH Locality 82 is a lag deposit very low in the Wahweap Formation of the Kaiparowits Plateau, whereas UMNH Locality 130 is a floodplain mudstone in the upper member which contains abundant delicate gastropods. Localities on the Paunsaugunt Plateau represent a mixture of sandstone lags (UMNH localities 77, 80) or floodplain mudstones (UMNH localities 83 (MNA 1073), 118, 807, 1074). Locality 78 is in a floodplain mudstone that has been thrust into position, so its stratigraphic position can only be roughly estimated.

Two localities on the Markagunt Plateau (Cedar Canyon) may be from strata equivalent to the Wahweap Formation (see Eaton et al. 2001; Eaton 2006b), but here the term "Formation of Cedar Canyon" is used following the suggestion by Moore et al. (2004). Locality 10 is from just above a conglomeratic horizon considered by some to be the Drip Tank Member of the Straight Cliffs Formation (see discussion in Eaton et al. 2001, p.343; Moore et al. 2004) and therefore would be a locality equivalent to the basal Wahweap Formation. A locality more than $250 \mathrm{~m}$ higher, UMNH Locality 11, does appear to be Campanian in age (Eaton 2006b) and may also be from strata equivalent to the Wahweap Formation.
Kaiparowits Formation

The Kaiparowits Formation is about $855 \mathrm{~m}$ thick (Eaton 1991; $860 \mathrm{~m}$ in Roberts et al. 2005), consists of fluvial rocks and is only present on the Kaiparowits Plateau (although the base of the formation is present to the east in the "beds on Tarantula Mesa" in the Henry Basin; Eaton 1990). Radiometric dates (Roberts et al. 2005) and mammalian faunas (e.g., Eaton and Cifelli 1988; Eaton 2002) have suggested a late Campanian (but not latest) age for the Kaiparowits Formation. The youngest ${ }^{40} \mathrm{Ar}^{-39} \mathrm{Ar}$ reported from the Kaiparowits Formation is $74.21 \pm 0.18 \mathrm{Ma}$ (Roberts et al. 2005) which places the Kaiparowits Formation in the early part of the late Campanian. Most of the anuran assemblages are from localities in the lower $400 \mathrm{~m}$ of the formation, with the exception of two localities higher up in the unit: locality TB8 (see Eaton 1991, Fig. 16) and UMNH Locality 1082; the latter was discovered in 2008 at $747 \mathrm{~m}$ above the base of the formation and, as yet, no mammals have been studied from the locality. Depositional rates and poor soil development suggest very rapid deposition and a rate as high as $\sim 41 \mathrm{~cm} / \mathrm{ka}$ has been suggested by Jinnah et al. (2008).

Most of the localities (localities 24, 25, 56, 57, 108) are in floodplain mudstones that preserve delicate material often accompanied by abundant and well-preserved fresh water invertebrates. Locality 1078 is a claystone that is packed with complete gastropods and bivalves. Although there is breakage in these localities, it is likely that there has been little transport of specimens. Localities 51 and 54 are sandy mudstones with abundant freshwater invertebrate shell fragments, suggesting a higher degree of transport than at the other localities.

\section{Palaeoecology}

The Upper Cretaceous rocks of southern Utah were deposited in relatively close proximity to or within the Western Interior Seaway (e.g., Roberts and Kirschbaum 1995). The upper part of the Dakota Formation, the Tropic Shale, and part of the Straight Cliffs Formation were deposited in the seaway. This seaway connected the Arctic Ocean to the Gulf of Mexico and had a stabilizing effect on the climate of the Western Interior of North America. The climate throughout this interval appears to have been subtropical or, at least, very wet and warm temperate. This is established for the lowest unit in the sequence, the Dakota Formation, based on palynomorphs (May and Traverse 1973), to the top of the section, the Kaiparowits Formation, based on floras and paleosols (Roberts 2007). Angiosperms are diverse and the most common elements of the flora throughout the section. Coals are present in the 
Dakota Formation and in the Smoky Hollow and John Henry members of the Straight Cliffs Formation. Brackish water influence is also found throughout the section, except for the Kaiparowits Formation where there may be only rare brackish influence in the lower part (Roberts 2007). As such, the palaeoecology of the sequence from which the anurans were recovered was relatively consistent throughout the interval. Perhaps the greatest palaeoecologic variation is related to changes of elevation and groundwater tables west of the Kaiparowits Plateau region towards the Sevier thrust belt. This is reflected in relatively drab, organic-rich floodplain mudstones in the Kaiparowits region, as compared with the well-variegated equivalent floodplain deposits on the Paunsaugunt and Markagunt plateaus. This variation has not yet been assessed palaeoecologically, but there are certainly significant mammalian faunal differences when comparing the Paunsaugunt and Markagunt plateaus to the Kaiparowits Plateau (Eaton 1999, 2006b).

\section{Materials and methods}

All specimens were recovered by quarrying localities and then processing the rock by wet screen-washing. Most of the anuran bones (both tiny as well as larger ones) were broken but the broken surface can be both fresh as well as worn, presumably indicating various degrees of their secondary transport. In no way was the damage to the bones caused by the screen-washing process because broken bones were recovered even when very gentle agitation was applied.

Dermal bones of the skull, such as the frontoparietals, maxillae, parasphenoid and squamosals, are the most significant for anuran taxonomy. Unfortunately, some of these bones may be small and delicate; thus, they are rarely abundant in the fossil record. Among postcranial elements, the most frequently used are the humeri and ilia. However, because the lateral and medial cristae of the humeri serve as insertion areas of muscles used in amplexus, their degree of development may reflect sexual, not taxonomic, differences. The radioulnae and tibiofibulae may be quite common in the fossil record, yet those bones are morphologically uniform and, thus, provide little or no taxonomic information. Those bones can, however, provide information about the sizes of animals.

Several hundred isolated bones (see graph in Fig. 3) were investigated, but only some of them could be assigned to previously described taxa. Although many of the remaining specimens likely represent different taxa, we decided not to establish any new taxa on the basis of disarticulated elements because we realize that it is difficult to reliably associate elements from different parts of the skeleton. Some localities (e.g., Paul's locality, see Fig. 11, below) produced large samples in which different morphs of particular elements, especially ilia, could be identified. Using these structural morphs as a proxy for taxonomic richness, it is possible to estimate the taxonomic diversities of anuran assemblages at a local scale. Finally, because of the extent of the geological time-span represented by the localities, we were able to identify some trends in the morphological transformations of anuran bones. In cases where osteological features are known to be related to a particular function (e.g., structures on the ilia serving for the insertion of muscles important for locomotion may provide information about the mode of locomotion), it was possible to draw conclusions on the way of life of these early frogs.

We followed the osteological nomenclature of Sanchiz (1998, pp.4-10). The most frequently used terms are illustrated in Fig. 3. Anglicized terms are used here and there throughout the text. Other terms are explained in the text.

Institutional abbreviations: MCZ - Museum of Comparative Zoology, Harvard University, Harvard, Massachusetts, USA; MNA - Museum of Northern Arizona, Flagstaff, Arizona, USA; UMNH - Utah Museum of Natural History, Salt Lake City, Utah, USA. Except where indicated otherwise, all locality numbers are UMNH localities and all specimen numbers denote UMNH specimens.

\section{Description of the material}

Middle? Cenomanian (Fig. 4)

Dakota Formation, Cedar Canyon, localities 161, 162

Material: 3 prearticulars (12927, Fig. 4p; 12933, Fig. 4q; 13170, Fig. 4o); 9 maxillae (12909, Fig. 4h-1,2; 12910, Fig. 4f-1,2; 12924, Fig. 4k-1,2; 12925, Fig. 4n-1,2; 12926, Fig. 4j-1,2; 18427, Fig. 4g-1,2; 18408, Fig. 4m-1,2; 18428, Fig. 4i-1,2; 18429, Fig. 4l-1,2); 5 humeri (12894, Fig. 4a; 12929, Fig. 4d; 12934, Fig. 4e; 12938, Fig. 4c; 13006, Fig. 4b), 2 ilia (12936, Fig. 4r-1,2; 12983, Fig. 4s), 1 presacral vertebra $(18420$, Fig. $4 \mathrm{w}) ; 1$ sacral vertebra (18418, Fig. 4x-1-3); 3 urostyles (12932, Fig. 4t; 12944, Fig. 4u; 12954, Fig. 4v-1-4).

Description: Three types of prearticulars occur in the Dakota Formation of Cedar Canyon. UMNH 13170 (Fig. 4o) is characterized by a short but prominent coronoid process directed dorsomedially. From the level of this process posteriorly, Meckel's groove is not roofed and is represented only by a horizontal ledge. UMNH 12927 (Fig. 4p) differs from UMNH 13170 in having Meckel's 


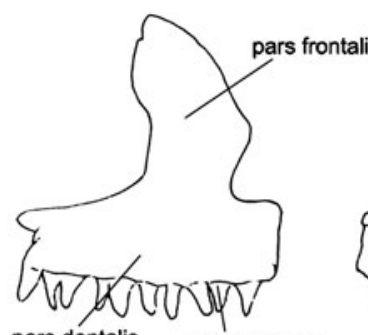

pars dentalis crista dentalis

a-1 sulcus dentalis a-2
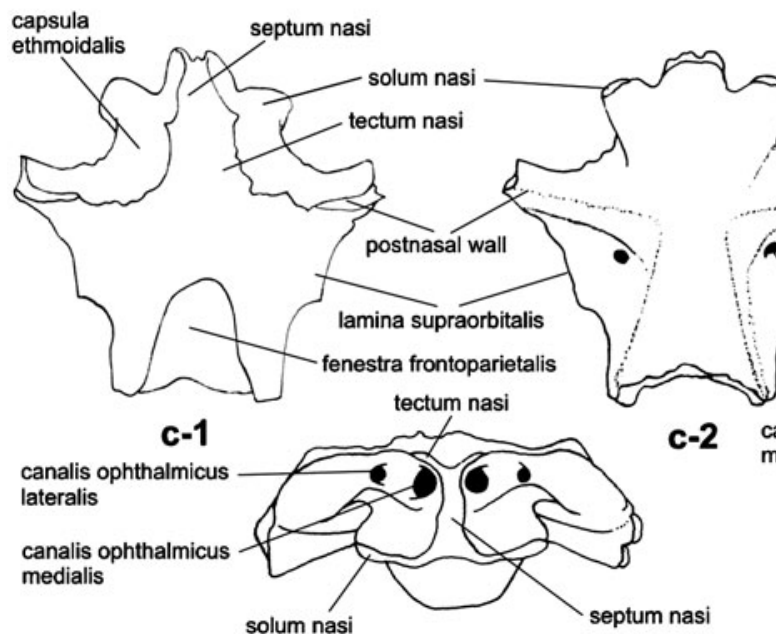

fossa condyloidea

c-3

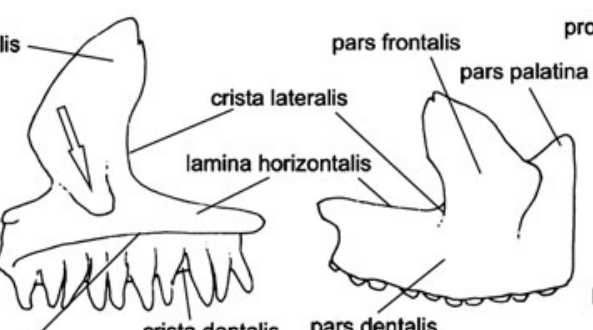

a-3

canalis ophthalmicus medialis

processus posterior

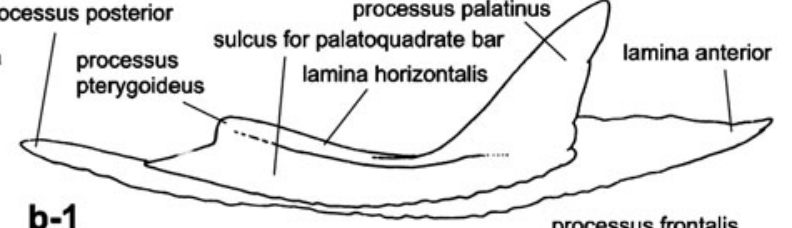

b-1

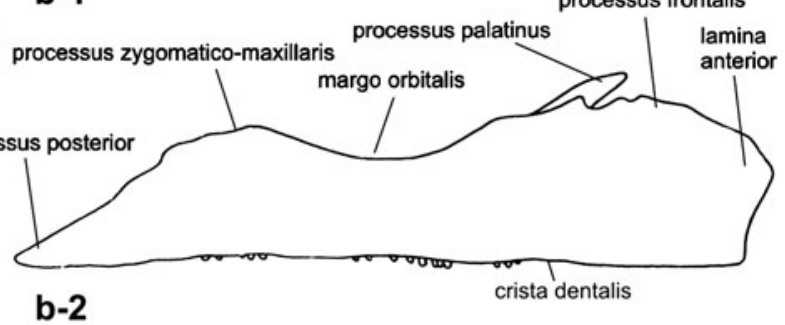

b-2

processus palatinus sulcus for palatoquadrate bar
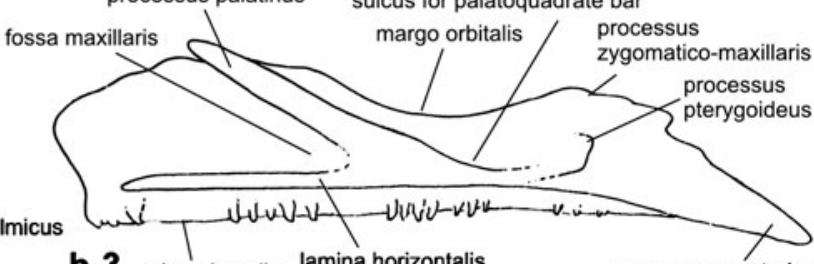

b-3 crista dentalis lamina horizontalis

processus posterior pars ascendens

tuber superius

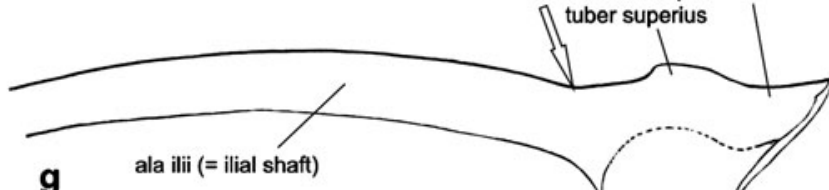

canalis neuralis

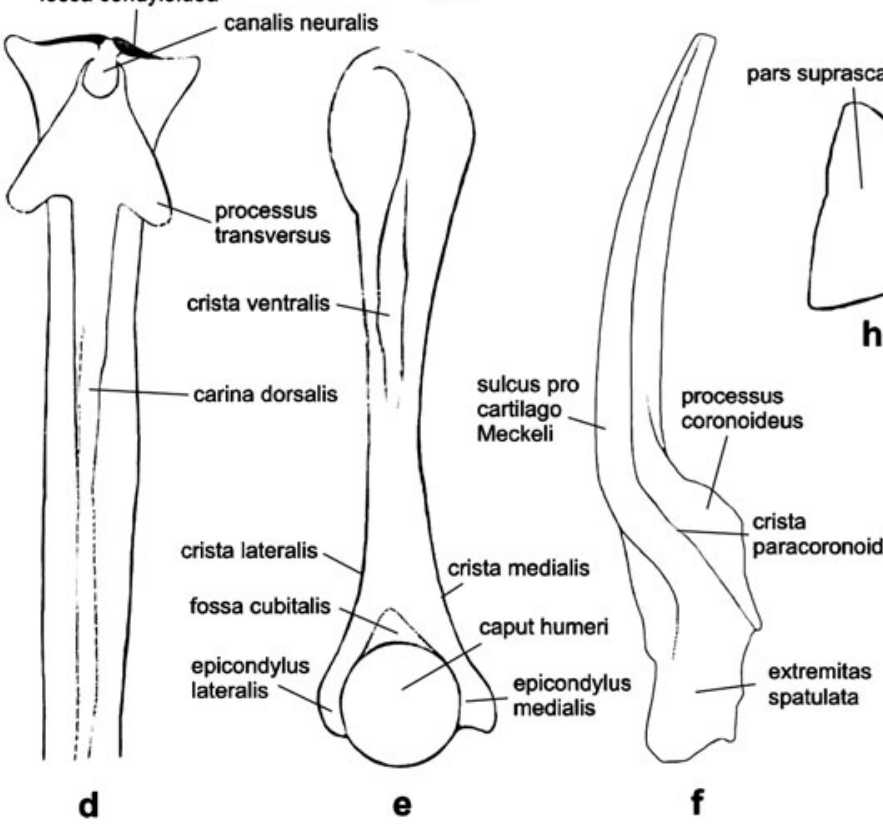

g

ala ini (= ilial shaft)

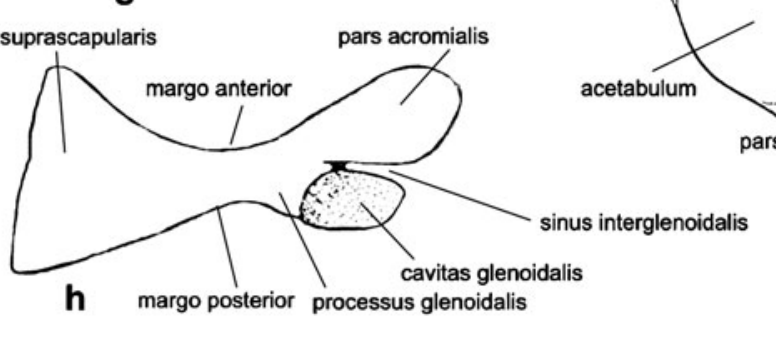

processus glenoidalis

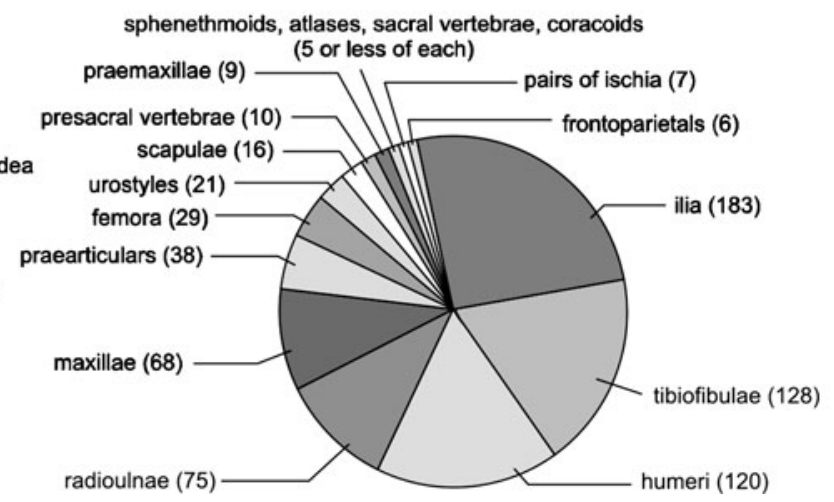

Fig. 3 Anatomical terms used in text and investigated material. a Right premaxilla in outer (a-1), inner (a-2) and dorsal (a-3) views. The recess for the lower prenasal cartilage (cartilago praenasalis inferior) marked by arrow. b Right maxilla in dorsal (b-1), outer (b-2) and inner (b-3) views. c Sphenethmoid in dorsal (c-1), ventral (c-2) and anterior

(c-3) views. d Urostyle in dorsal view. e Right humerus in ventral view. f Left angular in dorsal view. $\mathrm{g}$ Left ilium in lateral view. Location of the oblique groove across the dorsal margin of the bone in some taxa marked by arrow. h Right scapula in outer view. Graph depicts numbers of investigated bones 
groove well delimited dorsally by a sharp crista paracoronoidea which clearly separates it from the similarly well delimited depression on the dorsal surface of the coronoid process; the process is only moderately prominent medially. Also, UMNH 12933 (Fig. 4q) has its Meckel's groove well delimited by the crista paracoronoidea, but the dorsal surface of the coronoid process is convex.

Basically, two types of maxillae occur in the sample. Sculptured maxillae are mostly larger, whereas smooth maxillae are smaller. The larger maxillae are represented by UMNH 12910 (Fig. 4f-1,2) which is a fragment from the anterior portion of the right maxilla. Its inner surface slants down from the upper margin of the bone towards the margin of the lamina horizontalis. Posteriorly (to the right in Fig. 4f-1), the margin of the horizontal lamina becomes thinner and more extended medially, whereas it is thick and widely rounded in its anterior part. The outer surface of the bone is sculptured, except for a strip along the lower margin of the bone. The sculpture consists mostly of pits of various size and depth which, towards the lower part of the bone, tend to be larger; the rounded ridges separating them sometimes protrude as tubercles. UMNH 18427 (Fig. 4g-1,2) is another large, sculptured maxilla, represented by a fragment of the middle part of the bone. In contrast to UMNH 12910, its outer surface is covered by pitted sculpture. On the inner side of the bone, the tip of the pterygoid process is broken off. A comparatively deep sulcus for the palatoquadrate bar is delimited ventrally by a rounded horizontal lamina and dorsally by a ridge running parallel to the orbital margin. The latter is broad and slightly declined medially. UMNH 18429 (Fig. 41-1,2) represents a comparatively large maxilla which bears reticular sculpture on its outer surface. It includes the pterygoid process (marked by arrow in Fig. 4l-1) but differs from other maxillae by its horizontal lamina which is, at least in its posterior section, represented by a thin ledge.

Other maxillae are represented by small, unsculpted morphs. UMNH 12909 (Fig. 4h-1,2) is a posterior part of the right maxilla with posterior teeth. The horizontal lamina terminates abruptly (with no trace of the pterygoid process), its posteriorly facing edge is slightly concave and nearly perpendicular to the inner surface of the bone. The dorsal surface of the horizontal lamina is the bottom of the groove for the palatoquadrate bar, the roof of which is produced by the vertical part of the bone somewhat declined medially. The outer surface of the bone is smooth. UMNH 12926 (Fig. 4j-1,2) appears to be the anterior part of the left maxilla the dorsal edge of which is intact. Its horizontal lamina is thick and broadly rounded, the outer surface is smooth. UMNH 12924 (Fig. 4k-1,2) has its dorsal part entirely broken off but apparently it is the posterior part of the left maxilla at the level of the posterior end of the horizontal lamina. The latter tapers posteriorly and has no pterygoid process. The outer surface of the bone is smooth.

There are also several maxillae in the sample, which represent transitions between the two morphotypes described above. UMNH 18408 (Fig. 4m-1,2), although also sculptured on its outer surface, represents a small frog. Its outer surface is covered by irregular pitted sculpture; the pits sometimes tend to fuse into grooves, and their ridges may produce moderately prominent pustules here and there. The arrow in Fig. $4 \mathrm{~m}-2$ marks the margin where the palatine process is broken off. On the inner surface of the bone, there is a shallow depression which may be interpreted as the fossa maxillaris. The remaining part of the inner side is a smooth surface extending onto the lamina horizontalis which, as a result, is not well delimited dorsally. UMNH 18428 (Fig. 4i-1,2) is the posterior part of a large right maxilla which is rather worn, so it cannot be determined whether it had a posterior outgrowth for articulation with the quadratojugal. Its outer surface is covered only by a faint irregular rugosity, so it cannot be included among sculptured taxa. On the inner surface, the horizontal lamina is comparatively thin and not terminated by the pterygoid process. Instead, the lamina terminates rather abruptly on the inner surface of the bone. Between the orbital margin and horizontal lamina is a broad horizontal depression that extends onto the inner surface of the posterior part of the bone. Also, UMNH 12925 (Fig. $4 n-1,2$ ), which is the anterior part of the right maxilla, represents a larger species. It is characterized by a thick and rounded horizontal lamina, and by a smooth outer surface.

All humeri are, disregarding size, rather uniform in their asymmetrical structure: the lateral epicondyle is absent or, as in the specimens where the distal part of the bone is damaged (UMNH 12894, Fig. 4a; UMNH 13006, Fig. 4b), it was developed to a much lesser degree. Two larger humeri have their lateral and medial cristae either absent (UMNH 12894, Fig. 4a) or weakly developed (UMNH 12934, Fig. 4e). In those specimens where the caput is preserved, the fossa cubitalis is deep but narrow. Only in UMNH 12894 does it seem to be triangular in shape. UMNH 13006 (Fig. 4b) and 12938 (Fig. 4c) are small (estimated length about $3 \mathrm{~mm}$ ), their medial crista is indistinct but the lateral crista, although short, is thickened along its margin (see arrows in Fig. $4 \mathrm{~b}$ and c). UMNH 12929 (Fig. 4d), which is intermediate in size between the smaller UMNH 13006 and 12938 and 12894 and the larger UMNH 12934, has its lateral crista well preserved, terminating on the lateral surface of the articular head. Both of its cristae are thickened along their margins, and a deep rounded ridge continues onto the ventral surface of the medial epicondyle. UMNH 12934 (Fig. 4e) has its medial epicondyle confluent with the articular head. 


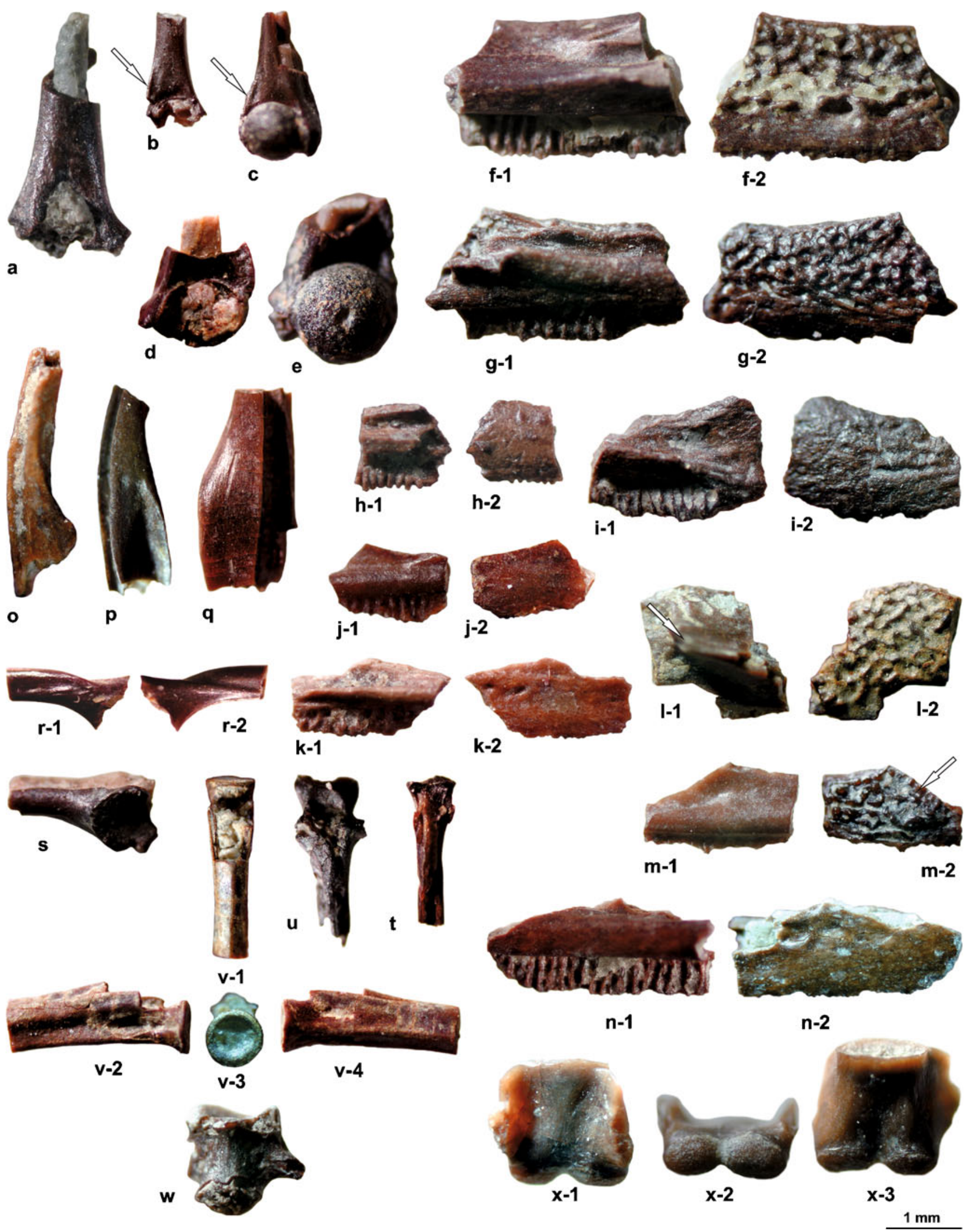


Fig. 4 Cedar Canyon, middle? Cenomanian. a Right humerus (12894) in ventral view. b Right humerus (13006) in ventral view. c Right humerus (12938) in ventral view. d Left humerus (12929) in ventral view. e Left humerus (12934) in ventral view. f Right maxilla (12910) in inner (f-1) and outer (f-2) views. $\mathbf{g}$ Left maxilla (18427) in inner (g-1) and outer (g-2) views. h Right maxilla (12909) in inner (h1) and outer (h-2) views. i Right maxilla (18428) in inner (i-1) and outer (i-2) views. $\mathbf{j}$ Left maxilla (12926) in inner (j-1) and outer (j-2) views. k Left maxilla (12924) in inner (k-1) and outer (k-2) views. I Maxilla (18429) in inner (l-1) and outer (l-2) views. Arrow marks the pterygoid process. m Maxilla (18408) in inner (m-1) and outer (m-2) views. Arrow marks the level where palatine process was broken off. n Right maxilla (12925) in inner (n-1) and outer (n-2) views. o Left praearticulare (13170) in dorsal view. p Left praearticulare (12927) in dorsal view. q Right praearticular (12933) in dorsal view. $\mathbf{r}$ Left ilium (12936) in outer (r-1) and inner (r-2) views. s Left ilium (12983) in outer view. t Urostyle (12932) in dorsal view. u Urostyle (12944) in dorsal view. $\mathbf{v}$ Urostyle (12954) in dorsal (v-1), right lateral $(\mathbf{v}-2)$, anterior (v-3) and left lateral (v-4) views. $\mathbf{w}$ Presacral vertebra (18420) in ventral view. $\mathbf{x}$ Sacral vertebra (18418); centrum in dorsal $(\mathbf{x}-1)$, posterior (x-2) and ventral (x-3) views. All are at the same scale

Only two anuran ilia were recovered from the Dakota Formation of Cedar Canyon. UMNH 12936 (Fig. 4r-1,2) is small (estimated length about $3 \mathrm{~mm}$ ) and its characteristic features are absence of the dorsal tubercle ("tuber superius" in Fig. 3g), the acetabulum apparently not extending beyond the anteroventral outline of the bone, and a depression on the dorsal margin of the bone which continues as a distinct oblique groove onto its inner surface. The groove is delimited ventrally by a rounded ledge coming from the pars ascendens (Fig. 4r-2). UMNH 12983 (Fig. 4s) is characterized by an extensive acetabulum slightly extending anteroventrally beyond the outline of the bone.

All presacral vertebrae in the sample are fragmentary. UMNH 18420 (Fig. 4w) has the neural arches including zygapophyses broken off so it cannot be determined whether it was procoelous or opisthocoelous. The only feature which can be observed is a faint median keel on the ventral surface of the centrum.

The sacral vertebra UMNH 18418 (Fig. 4x-1-3) belongs to a larger frog which was procoelous, and its sacrourostylar articulation was bicondylar.

The urostyle UMNH 12932 (Fig. 4t) represents a small frog with bicondylar sacrourostylar articulation. In contrast, the more complete UMNH 12944 (Fig. 4u) has its articular cotyle in the shape of a horizontal ellipsoid, suggesting that the articulation was monocondylar. Also a pair of stout transverse processes were developed. UMNH 12954 (Fig. 4v1-4) was also monocondylar, but its articulation cotyle was circular and apparently there were no diapophyses.

\section{Late Cenomanian (Fig. 5)}

Dakota Formation, Alton, Locality 123; Bulldog Bench, localities 804, 27

Material: 2 maxillae (13076, Fig. 5h; 13102); 4 prearticulars (13124, Fig. 5b; 13155, Fig. 5a; 13182, 13183); 1
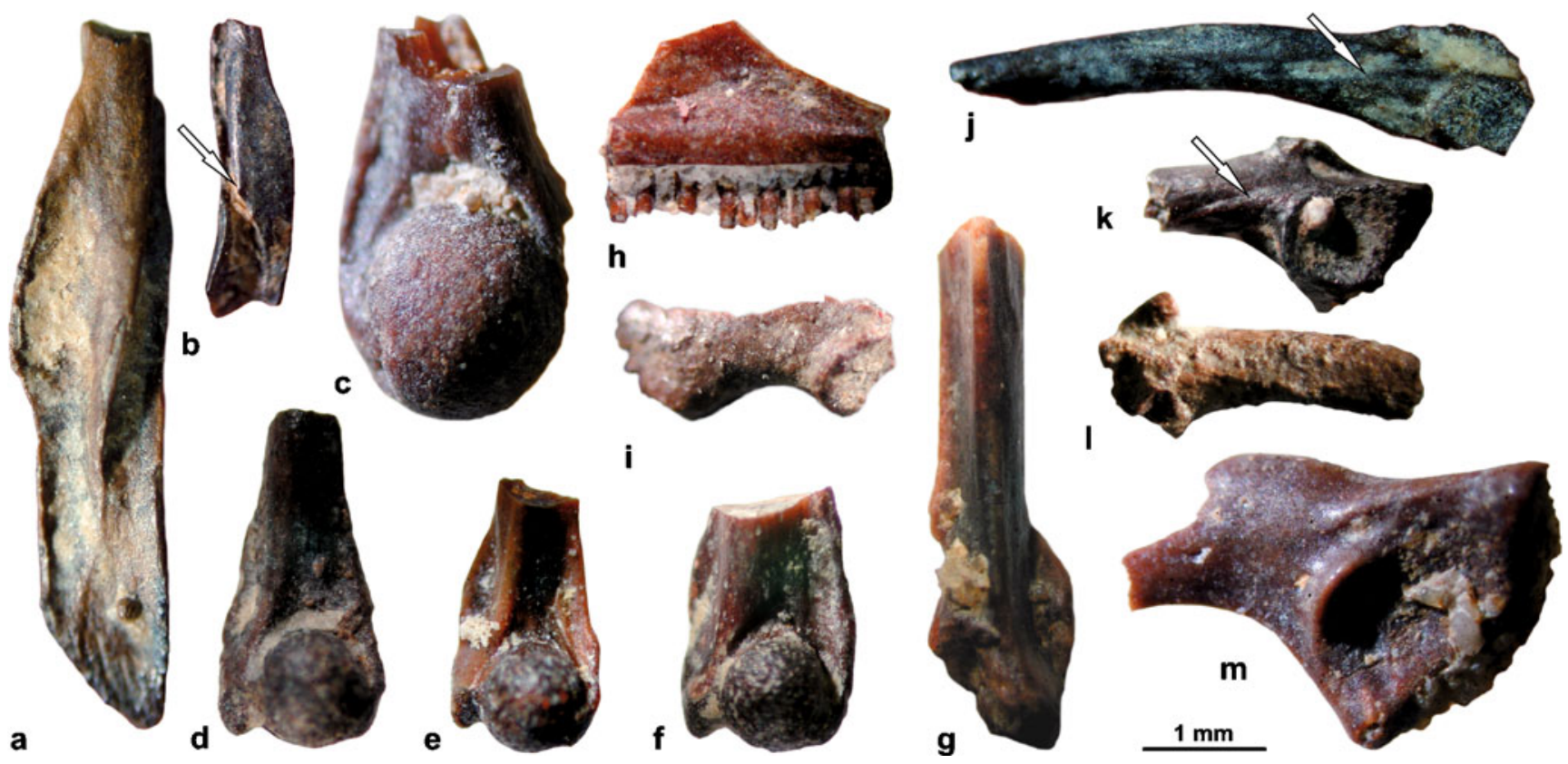

Fig. 5 Bulldog Bench, late Cenomanian. a Right praearticulare (13155) in dorsal view. b Left prearticular (13124) in dorsal view. Break of the dorsal margin of the sulcus Meckeli and crista paracoronoidea marked by arrow. c Right humerus (13074) in ventral view. d Left humerus (13160) in ventral view. e Left humerus (13077) in ventral view. f Left humerus (13163) in ventral view. g Right humerus (13121) in ventral

view. h Right maxilla (13076) in lingual aspect. i Right scapula (13161) in dorsal view (posterior margin below). $\mathbf{j}$ Left ilium (13156) in lateral view. Oblique groove filled with sediment marked by arrow. k Left ilium (13158) in lateral view. Oblique groove filled with sediment marked by arrow. I Right ilium (13159) in lateral view. m Left ilium (13071) in lateral view. All are at the same scale 
scapula (13161, Fig. 5i); 8 humeri (13074, Fig. 5c; 13077 , Fig. 5e; 13121, Fig. 5g; 13123; 13128; 13140; 13160, Fig. 5d; 13163, Fig. 5f); 1 radioulna (13122); 4 ilia (13071, Fig. 5m; 13156, Fig. 5j; 13158, Fig. 5k; 13159, Fig. 51); 1 pair of ischia (13162); 2 femora $(13139,13141) ; 15$ tibiofibulae (13125-13127, 13129-13138, 13142, 13151).

Description: Both maxillae are represented by only small fragments that have a thick and rounded horizontal lamina in the anterior portion of the bone (UMNH 13076, Fig. 5h) and a smooth outer surface.

The prearticular UMNH 13124 (Fig. 5b) is characterized by having its coronoid process widely convex medially, only moderately thickened along its margin, and that the dorsal crista delimiting Meckel's groove passes into the crista paracoronoidea by a sudden turn (see arrow in Fig. 5b). The dorsal surface of the coronoid process is smooth and flat. UMNH 13155 (Fig. 5a) is larger and its crista paracoronoidea disappears on the posterior part of the bone. The medial margin of the coronoid process is slightly elevated so the dorsal surface of the process is depressed. The depression and elevated margin extend nearly to the posterior end of the bone.

Only the posterior part of the right scapula UMNH 13161 (Fig. 5i) is preserved. The glenoid is large and prominent, but details of the sinus interglenoidalis and pars acromialis cannot be seen.

All the humeri are uniform in their total absence of the lateral epicondyle, and in having a deep fossa cubitalis that is restricted only to the narrow area adjacent to the caput. A distinct rounded ridge originates on the ventral surface of the humeral shaft and continues onto the medial epicondyle. Both the medial and lateral cristae are slightly thickened along their margins and neither expand beyond the outlines of the bone (UMNH 13160, Fig. 5d), or the medial crista is only slightly expanded and declined dorsally (UMNH 13077, Fig. 5e; 13163, Fig. 5f). Only in UMNH 13121 (Fig. 5g) is the margin of the medial crista convex. As evidenced by preserved humeral shafts UMNH 13121 (Fig. 5g), 13123, 13128, and 13140, the crista ventralis is simple and undivided. UMNH 13074 (Fig. 5c) is about twice as big as other humeri but is also asymmetrical, with the lateral epicondyle absent.

The ilia UMNH 13156 (Fig. 5j) and 13158 (Fig. 5k) are small (estimated total lengths less than $5 \mathrm{~mm}$ ). Their characteristic features are large acetabula with the anteroventral margin exceeding the outlines of the bone, and an indistinct shallow groove running from the lateral base of the dorsal tubercle anteroventrally along the outer surface of the iliac shaft (see arrows in Fig. 5j and k). On the inner surface of the bone, there is a crista running from the pars ascendens to the lower part of the inner surface of the shaft where it disappears; the crista is somewhat sharper in
UMNH 13158 than in UMNH 13156. The main difference between both ilia is that in UMNH 13156 (Fig. 5j) the dorsal tubercle is extensive but laterally compressed, thus resembling a convex crest with a sharp and irregular edge. Laterally, the dorsal tubercle is delimited by a wide groove separating it from the acetabulum; this is why the upper margin of the dorsal tubercle is slightly declined laterally. In UMNH 13158 (Fig. 5k), the dorsal tubercle has a long elevated base but only its middle part is prominent. It is also only minimally compressed laterally, meaning its dorsal margin is rounded and does not form a sharp edge.

UMNH 13159 (Fig. 51) is similar to UMNH 13156 and 13158 in size, but is different in having a smaller acetabulum (although its anteroventral margin far exceeds the outline of the bone) and in the asymmetrical shape of the dorsal tubercle, which is developed as a prominent knob declined anterolaterally. The anterior margin of the tubercle is located at the level of the anterior margin of the acetabulum.

The ilium UMNH 13071 (Fig. 5m) is markedly different, because it is about twice as large as the three previously described specimens and its acetabulum is a mere depression in the bone, except for a short anterior section that is elevated. The dorsal tubercle is absent. A distinctive feature is a short, rounded ridge running from the tip of the pars ascendens parallel to the upper margin of the acetabulum and terminating at the level of its anterior elevated rim.

The tibiofibulae bear no diagnostic features. UMNH 13127 and 13135 are small (estimated lengths 9-10 mm), with large foramen for the arteria tibialis antica; before entering the foramen, the artery was located in a well defined groove.

\section{Turonian (Fig. 6)}

Straight Cliffs Formation, Smoky Hollow Member, Jimmy Canyon, Locality 129; Slickrock Bench, Locality 1080

Material: 1 premaxilla (13463, Fig. 6s-1,2); 2 maxillae (13455, Fig. 6r-1,2; 18371, Fig. 6q); 1 ?frontoparietal (18370, Fig. 6o); 2 scapulae (13464, Fig. 6cc-1,2; 13465, Fig. 6bb-1,2); 18 humeri (13435, Fig. 6n; 13451, Fig. 6k; 13456; 18350, Fig. 6a; 18351, Fig. 6c; 18352, Fig. 6b; 18353, Fig. 6e; 18354, Fig. 6f; 18356, Fig. 6d; 18357, Fig. 6g; 18358; 18359, Fig. 6h; 18360, Fig. 6m; 18361, Fig. 61; 18362, Fig. 6j; 18363; 18364, Fig. 6i; 18365); 4 radioulnae $(13432 ; 13433 ; 13439 ; 13452) ; 9$ ilia (13457, Fig. 6aa; 13458, Fig. 6w-1,2; 13459, Fig. 6z; 13460, Fig. 6y; 13461, Fig. 6x-1,2; 13462; 18355, Fig. 6t; 18366, Fig. 6u; 18367, Fig. 6v-1,2); 1 pair of ischia (18372); 1 urostyle (18368, Fig. 6p); 1 radioulna (18369); 15 tibiofibulae (13434; 13437; 13438; 13443; 13453; 18240; 18375-18383). 


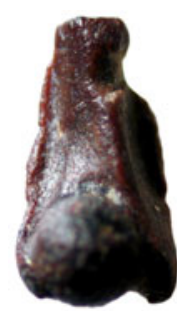

a

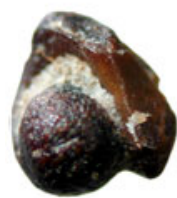

i

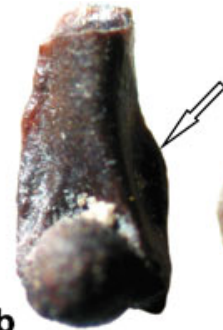

b

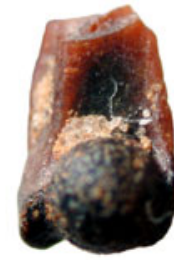

j

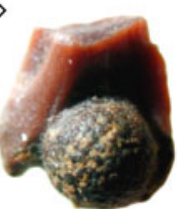

C

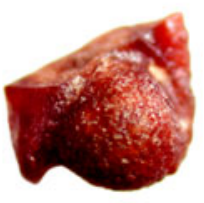

k

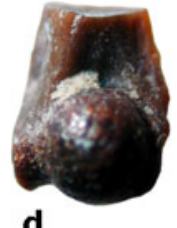

d

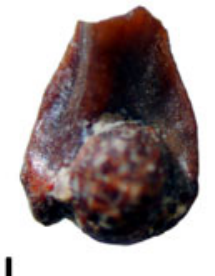

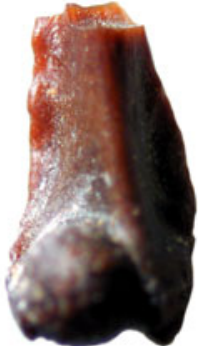

e

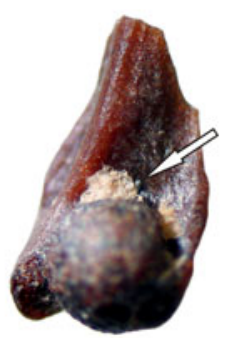

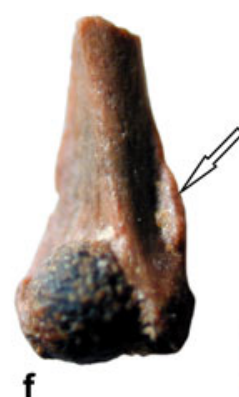

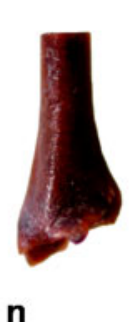

n

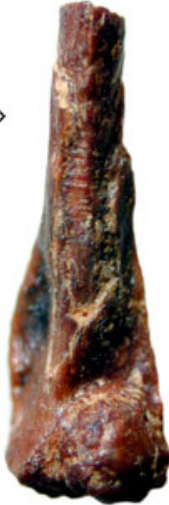

g

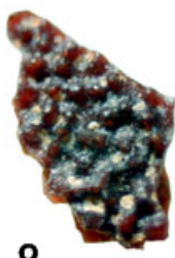

o

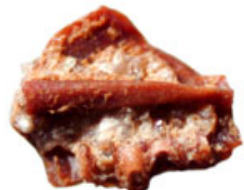

r-1<smiles>[AlH2][Al]1C=C[AlH]1</smiles>

v-2

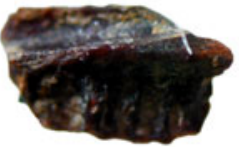

q

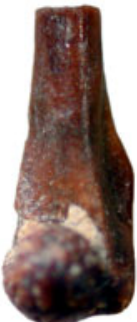

h

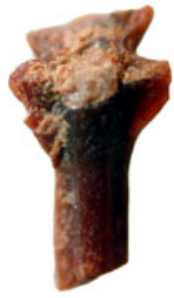

p

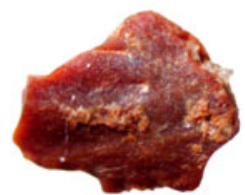

r-2 v-1

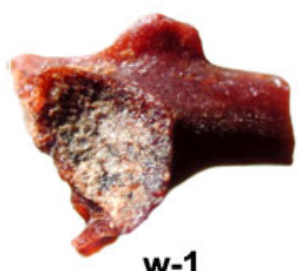

w-1

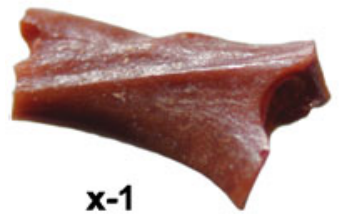

$x-1$

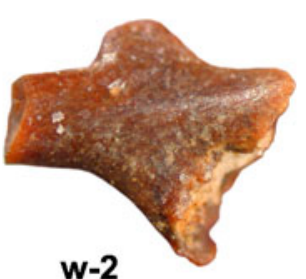

w-2
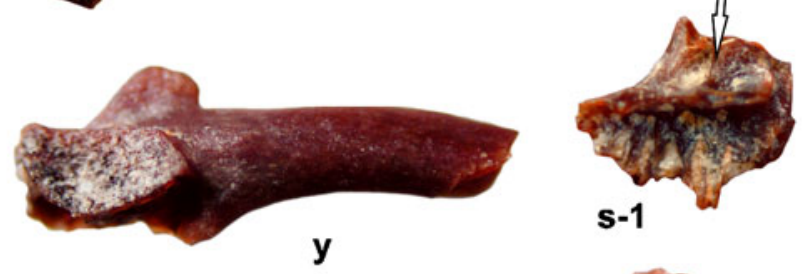

s-1

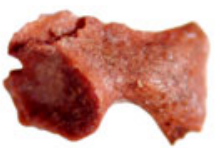

bb-1
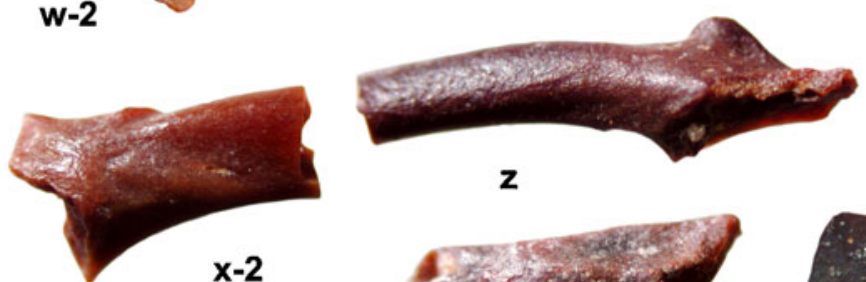

z

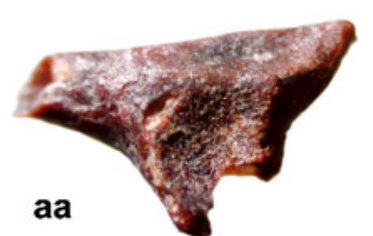

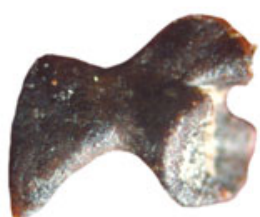

cc-1

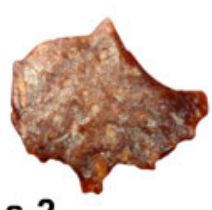

s-2

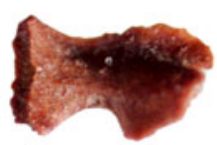

bb-2
$1 \mathrm{~mm}$

Fig. 6 Jimmy Canyon, Turonian. a Right humerus (18350). b Right humerus (18352). c Left humerus (18351). d Left humerus (18356). e Right humerus (18353). f Right humerus (18354). g Left humerus (18357). h Right humerus (18359). i Right humerus (18364). j Left humerus (18362). $\mathbf{k}$ Left humerus (13451). $\mathbf{l}$ Left humerus (18361). m Left humerus (18360). n Left humerus (13435). o Fragment of dermal bone (maxilla?) (18370). p Urostyle (18368) in adorsal view. q Maxilla (18371) in medial view. $\mathbf{r}$ Maxilla (13455) in medial (r-1) and lateral (r-2) views. s Premaxilla (13463) in medial (s-1) and lateral (s2 ) views. The partition in the recess for the inferior prenasal cartilage is marked by arrow. $\mathbf{t}$ Right ilium (18355) in lateral view. u Left ilium (18366) in lateral view. v Left ilium (18367) in lateral (v-1) and medial (v-2) views. w Right ilium (13458) in lateral (w-1) and medial (w-2) views. $\mathbf{x}$ Right ilium (13461) in medial (x-1) and lateral (x-2) views. $\mathbf{y}$ Right ilium (13460) in lateral view. $\mathbf{z}$ Left ilium (13459) in lateral view. aa Left ilium (13457) in lateral view. bb Right scapula (13465) in outer (bb-1) and inner (bb-2) views. cc Left scapula (13464) in outer (cc-1) and inner (cc-2) views. All are at the same scale. Humeri are in ventral view 
Description: Only the lower part of the premaxilla UMNH 13463 (Fig. 6s-1,2) is preserved but it is clear that its horizontal lamina was thin and extensive, and the recess for the inferior prenasal cartilage (marked by arrows in Fig. 3a2 and 6s-1) is subdivided by a vertical ridge. The outer surface of the bone is smooth. The estimated number of tooth positions is nine or ten.

The maxilla UMNH 13455 (Fig. 6r-1,2) is an anterior part of the bone, with a deep fossa on its inner side and a smooth outer surface. UMNH 18371 (Fig. 6q) is also a small fragment of the maxilla with a thin and dorsally rather concave horizontal lamina. Similar to UMNH 13455, it is smooth on its outer surface.

A small fragment of a dermal bone (UMNH 18370, Fig. 6o), covered by a pit-and-ridge scupture, could be a part of an anuran frontoparietal.

Two scapulae occur in the sample. In both, the processus glenoidalis is much more robust than the pars acromialis; however, UMNH 13464 (Fig. 6cc-1,2) is larger and its glenoid is semilunar and occupies only half of the glenoid process. On its inner surface is a rounded ridge (see arrow in Fig. 6cc-2) coming from the glenoid process; however, it does not continue onto the pars suprascapularis. UMNH 13465 (Fig. 6bb-1,2) also has its glenoid subdivided, although to a lesser degree than in UMNH 13464. The general morphology of these two scapulae may suggest that they belong to a single taxon or to closely related taxa.

Several types of humeri can be recognized in the Turonian samples. The smallest one is UMNH 13435 (Fig. 6n). Only the proximal part of its caput is preserved, but it is obvious that it was ossified (thus not representing an immature, juvenile individual), with no fossa cubitalis. Its medial and lateral cristae were poorly (if at all) developed. The ventral surface of the distal portion of the shaft is regularly rounded, and only a moderately elevated ridge joins the medial surface of the caput (thus not continuing onto the medial epicondyle, if the latter was present). UMNH 13456 is similar in size, but its caput is completely broken off. Both its medial and lateral cristae are moderately developed, and the fossa cubitalis is triangular.

The majority of the humeri are somewhat larger than the two described above and they are clearly asymmetrical, with a large medial epicondyle separated from the caput by a deep incision. In most specimens, there is a rounded ridge coming from the shaft onto the ventral surface of the medial epicondyle. The lateral crista does not terminate on the lateral epicondyle. Instead, it joins the lateral surface of the caput. The fossa cubitalis may be a narrow groove along the proximal surface of the caput (UMNH 13451, Fig. 6k) or an extensive depression (UMNH 18360, Fig. 6m) from which the caput is very prominent (observable in Fig. $6 \mathrm{~m}$ in which the humerus is in lateroventral view to show the extensive fossa cubitalis).
Some of the UMNH humeri (18350, Fig. 6a; 18353 , Fig. 6e; 18354, Fig. 6f; 18358; 18362, Fig. 6j; 18365; possibly also 18357 , Fig. $6 \mathrm{~g}$ ) each have the lateral epicondyle small, their cristae convex and swollen along their margins, and the fossa cubitalis shallow or absent because the rounded ridge coming from the crista ventralis turns towards the medial epicondyle, rather than being bifurcated. UMNH 18360 (Fig. 6m) and 18361 (Fig. 61) are similar, but the lateral epicondyle is completely absent and the lateral crista is bent ventrally so that an extensive depression arises proximolateral to the caput humeri (see arrow in Fig. 6m). UMNH 13451 (Fig. 6k), 18351 (Fig. 6c), 18352 (Fig. 6b), 18356 (Fig. 6d) and 18364 (Fig. 6i) also belong to this group. UMNH 18359 (Fig. 6h) seems to be a juvenile, but also belongs to this group.

The UMNH ilia 13458 and 13460 (Fig. 6w-1,2 and y, respectively) are each characterized by a large acetabulum with well-defined and elevated margins. The acetabulum almost completely occupies the dorsoventral diameter of the acetabular region of the ilium; its anteroventral portion slightly exceeds the outlines of the bone. The dorsal tubercle is prominent, compressed to form a comparatively thin lamina, moderately declined laterally and, if seen in lateral view, it is squarish and slightly declined anteriorly. UMNH 13459 (Fig. 6z) and possibly also UMNH 18355 (Fig. 6t) are similar in general morphology and in having a large acetabulum; the only difference is in shape of the dorsal tubercle which, although laterally compressed like in UMNH 13458 and 13460 (not as much in UMNH 18355), tapers towards its top and is rounded. It is also not declined laterally.

The second category of ilia is characterized by a complete absence of the dorsal tubercle. UMNH 13457 (Fig. 6aa) differs from all others in that the dorsal margin between the iliac shaft and the pars ascendens is straight. Its acetabulum is comparatively large. Two other ilia with no dorsal tubercle, UMNH 18366 and 18367 (Fig. 6u and v1,2 , respectively), are characterized by having their shaft separated from the posterior part of the bone by a shallow depression on the dorsal surface of the bone, which makes the shaft distinctly arch-like.

The ilium UMNH 13461 (Fig. 6x-1,2) is intermediate between the ilia with a prominent dorsal tubercle and those without a dorsal tubercle. In lateral view, its tubercle is only moderately prominent. There is an oblique groove running across the dorsal margin of the bone anteromedially just in front of the dorsal tubercle. A characteristic feature on the inner surface of the bone is a straight crista between the pars ascendens and lower margin of the iliac shaft (observable in Fig. 6x-1).

The urostyle UMNH 18368 (Fig. 6p) seems to be monocondylar. Its condyloid fossa is a horizontal ellipsoid filled with sediment; if there was a vertical partition, it is 
broken off or obscured by matrix. Both transverse processes are robust, but dorsoventrally compressed and continue posteriorly as a horizontal ledge.

\section{Coniacian (Fig. 7)}

Straight Cliffs Formation, John Henry Member, Heward Creek, Locality 856

Material: 2 scapulae (19370, Fig. 7c-1,2; 18978, Fig. 7d1,2); 3 ilia (19366, Fig. 7b; 19368; 19371; Fig. 7a-1,2); 1 femur (19365); 4 tibiofibulae (19363; 19364; 19367; 19369)

Description: UMNH 19370 (Fig. 7c-1,2) is a scapula that is missing on both its medial and lateral ends. In spite of this damage, it seems that its glenoid was declined lateroventrally, rather than laterodorsally. Its interglenoidal sinus is clearly seen in ventral aspect, but dorsally it is obscured by a thin lamina. On the outer surface of the bone, an oblique ridge runs from the posterior part of the sinus towards the posterior margin of the bone. UMNH 18978 (Fig. 7d-1,2) is larger, but also seems to have the interglenoidal sinus developed only on the outer side of the bone, whereas it is obscured on the inner side.

The ilium UMNH 19366 (Fig. 7b) has its shaft broken off, but its acetabular region is well preserved. The dorsal part of the acetabulum is a deep depression in the bone, whereas its anterior and anteroventral margins protrude as a vertical ridge. Consequently, the iliac portion of the acetabulum is strongly declined posteriorly. The dorsal margin of the pars ascendens is nearly a straight continuation of the dorsal margin of the iliac shaft. Anterior to the acetabulum is a distinct elevation, which is especially well delimited posteroventrally (see arrow in Fig. 7b). Anteriorly, the elevation continues onto the ventral surface of the iliac shaft. UMNH 19371 (Fig. 7a-1,2) is represented only by a shaft and anterior part of the acetabular portion of the bone. The acetabulum is declined posteriorly in the same way as in
UMNH 19366. It also has an elevation on the lateral surface of the shaft which is more extensive (reaching the dorsal margin of the shaft), and is similarly well delimited posteroventrally by a distinct oblique border (marked by arrow in Fig. 7a-1). On its inner surface, it is characterized by a welldeveloped oblique ledge delimiting a groove running anteroventrally towards the lower margin of the shaft.

\section{Early Santonian (Fig. 8)}

Straight Cliffs Formation, John Henry Member, Sheep Creek, Locality 426; Casey's Concretionary Horizon, locality 799

Material: 4 maxillae (18546; 18547, Fig. 8m-1,2; 18549; 18550); 1 prearticular (18560, Fig. 81); 5 humeri (18508, Fig. 8a; 18557, Fig. 8d; 18564; 18566, Fig. 8c; 18567, Fig. 8b); 1 radioulna (18543); 10 ilia (18293, Fig. 8f-1,2; 18294; 18299, Fig. 8h-1,2; 18509, Fig. 8i; 18544, Fig. 8e; 18556, Fig. 8g; 19270, Fig. 8j; 19271; 19272; 19273, Fig. 8k); 1 femur (18563); 9 tibiofibulae (18295; 18297; $18298 ; 18300 ; 18301 ; 18302 ; 18548 ; 18561 ; 18562) ; 1$ dermal bone (18510).

Description: The maxillae are fragmentary, but appear uniform. UMNH 18547 (Fig. 8m-1,2) represents the anterior portion of the right maxilla with its horizontal lamina tapering anteriorly. Its dorsal margin is broken off. Sculpture on the outer surface consists of faint horizontal rounded ridges and grooves, which are absent only along the lower margin of the bone. UMNH 18546 and 18550 are small fragments, with smooth outer surfaces.

The prearticular UMNH 18560 (Fig. 81) is large, with its coronoid process extensive and directed medially. It is moderately depressed on its dorsal surface. It appears that the groove for Meckel's cartilage widens posteriorly, so it presumably extended over the whole width of the bone.

The humeri are rather uniform and are best exemplified by UMNH 18508 (Fig. 8a). Its medial epicondyle is large
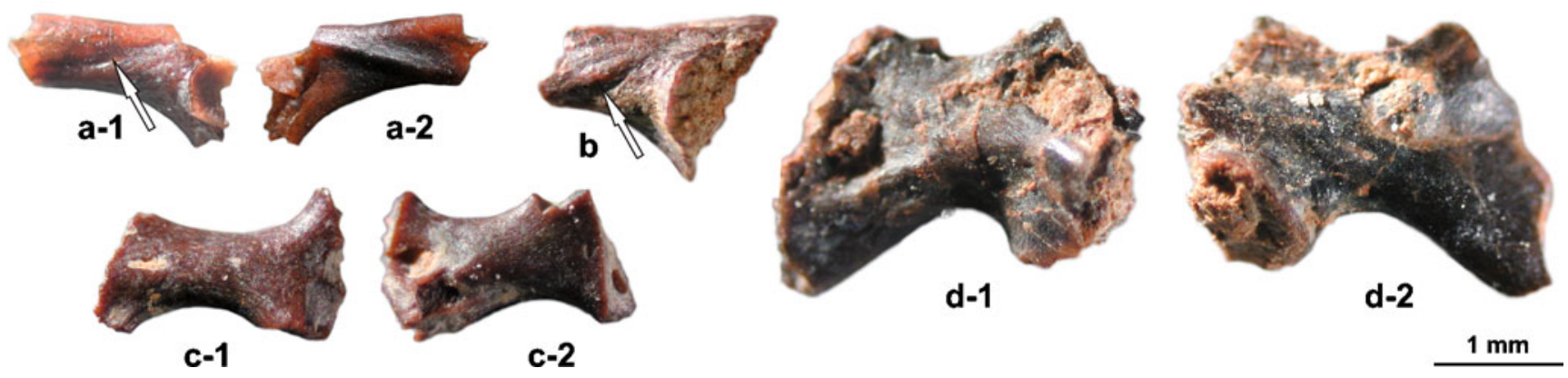

Fig. 7 Heward Creek, Coniacian. a Left ilium (19371) in lateral (a-1) and medial (a-2) views. b Left ilium (19366) in lateral view. c Left scapula (19370) in dorsal (c-1) and ventral (c-2) views. d Right scapula (18978) in ventral (d-1) and dorsal (d-2) views. All are at the same scale 


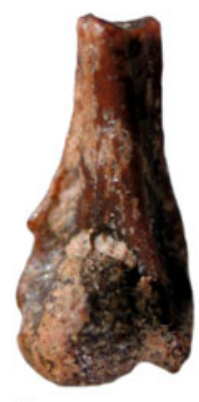

a

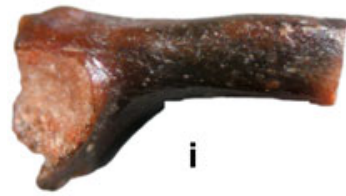

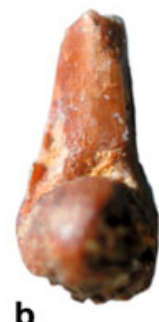
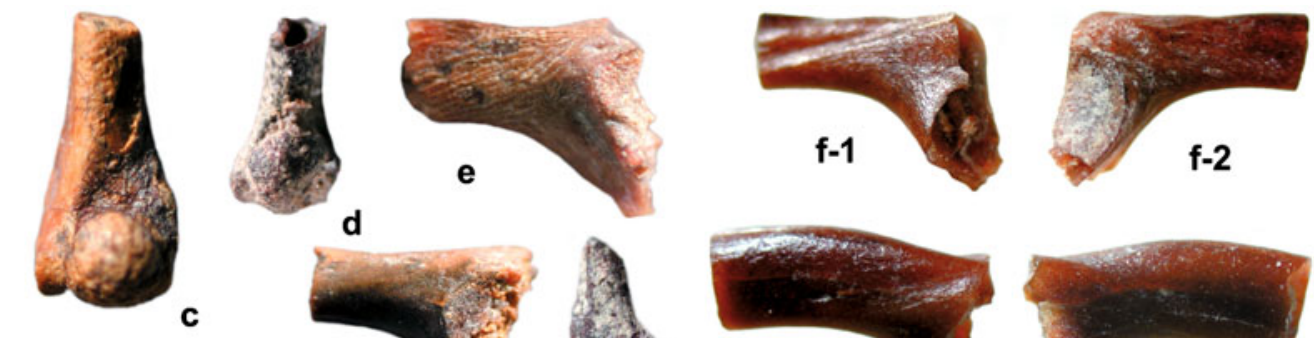

d

c

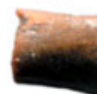

j

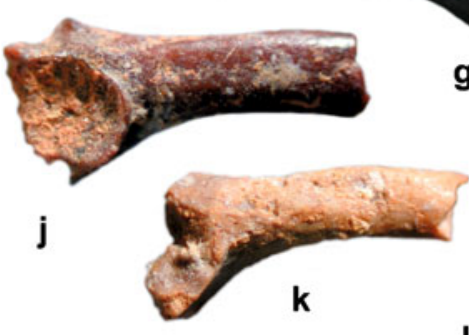

I

g

Fig. 8 Sheep Creek, Casey's Concretionary Horizon, early Santonian. a Right humerus (18508) in ventral view. b Right humerus (18567) in ventral view. c Left humerus (18566) in ventral view. d Left humerus (18557) in ventral view. e Left ilium (18544) in lateral view. f Right ilium (18293) in medial (f-1) and lateral (f-2) views. g Left ilium

and well separated from the caput, whereas the lateral epicondyle is absent so the lateral crista is confluent with the lateral surface of the caput. Neither the lateral nor the medial cristae are prominent relative to the corresponding margins of the humeral shaft and are only slightly swollen along their margins. The fossa cubitalis is deep, narrow, and declined ventrolaterally, due to a prominent rounded ridge continuing from the crista ventralis of the shaft to the medial epicondyle. UMNH 18567 (Fig. 8b) is similar (although its medial epicondyle is broken away) and the only difference is that the medial crista is not developed. UMNH 18566 (Fig. 8c) is also generally similar, but differs in that the keel on the medial epicondyle is not confluent with the medial ridge on the shaft and that the fossa cubitalis is shallow. Both the medial and lateral cristae are poorly developed. UMNH 18564 is similar, although much damaged.

The humerus UMNH 18557 (Fig. 8d) differs by virtue of its small size and that its lateral epicondyle appears to be better developed. The medial crista is absent and only the lateral one is developed.

Only ilia without a dorsal tubercle were recovered from the early Santonian strata. UMNH 18293 (Fig. 8f-1,2) has a comparatively large acetabulum which does not extend beyond the level of the anteroventral margin of the bone. The dorsal acetabular margin is moderately elevated and rounded, whereas the anteroventral margin is a prominent perpendicular edge. The dorsal margin of the bone is nearly straight. On the inner surface of the bone, there is a distinct but shallow oblique groove that runs anteroventrally towards the lower margin of the shaft; even though it is

much more fragmentary, UMNH 19271 has a similar oblique groove. UMNH 18556 is similar if observed in lateral aspect (Fig. 8g); however, its medial surface is smooth, without an oblique groove. UMNH 18509 (Fig. 8i), 19270 (Fig. 8j) and 19273 (Fig. 8k) are basically the same as UMNH 18556; the only slight differences are that the dorsal margin is moderately depressed in the transition between the acetabular portion of the bone and the iliac shaft and that the acetabulum is larger, with its margin reaching the level of the anteroventral margin of the bone. The oblique groove on the inner surface is indistinct or very faint. The seemingly developed dorsal tubercle (Fig. $8 \mathrm{i}$ and j) is an artefact caused by the posterior part of the dorsal margin of the bone having been broken away.

UMNH 18299 (Fig. 8h-1,2) is a fragment that represents the proximal portion of the iliac shaft. It has an oblique groove that traverses the dorsal margin of the bone, however, it does not continue onto the medial surface of the bone.

Middle Santonian (Fig. 9)

Straight Cliffs Formation, Old Merrill Ranch, locality 419; Henderson Canyon, locality 99; Casey's Shell Hash Locality, locality 781; Willis Creek, locality 821; Divide between Noon and Mud Creeks, locality 843

Material: 1 frontoparietal (19288, Fig. 9e-1,2); 7 maxillae (18513, Fig. 9b-1,2; 18525, Fig. 9c-1,2; 19279, Fig. 9f-1,2; 19287, Fig. 9a-1,2; 19299; 19360, Fig. 9d-1,2; 19362); 4 
prearticulars (18217, Fig. 9g; 18239; 18529; 19278, Fig. 9h); 1 atlas (18516, Fig. 9y-1-3); 1 urostyle (19289, Fig. 9ee-1,2); 1 scapula (18511); 8 humeri (18204; 18214, Fig. 9dd; 18216, Fig. 9aa-1,2; 18223, Fig. 9cc; 18225; 18234; 18512, Fig. 9z; 18541, Fig. 9bb); 7 radioulnae (18209, 18236, 18523, 18526, 18530, 18533, 19307); 26 ilia (18199; 18211, Fig. 9o; 18212, Fig. 9v; 18213, Fig. 9x; 18218, Fig. 9p; 18220, Fig. 9u; 18221, Fig. 9-n; 18222, 18224; 18226; 18227, Fig. 9k; 18228, Fig. 9s; 18229, Fig. 9i; 18230; 18231, Fig. 9j; 18232; 18233, Fig. 9t; 18235; 18237; 18539, Fig. 9w; 19293, Fig. 91; 19303, Fig. 9q; 19305; 19355, Fig. 9m; 19356, Fig. 9r; 19358); 4 femora $(18200,18205,19291 ; 19302) ; 31$ tibiofibulae (18193-18198, 18201, 18203, 18238, 18514, 18515, 18518-18520, 18527, 18528, 19277; 19281-19285, 19292, 19294-19298, 19300, 19301; 19359).

Description: The frontoparietal UMNH 19288 (Fig. 9e$1,2)$ was paired, with a smooth dorsal surface and straight orbital margin. It is slightly broader across its parietal portion than across its frontal portion. In ventral aspect, a low, rounded crista runs along the lateral margin of the bone. The frontoparietal incrassation (see Fig. 9e-1), which is a thickened part of the frontoparietal that in the articulated skull fits into the large foramina in the roof of the braincase (Jarošová and Roček 1982), is separated from the rounded crista by an irregular groove running parallel to the margin of the bone.

Most of the maxillae have smooth outer surfaces. UMNH 18513 (Fig. 9b-1,2) was slender and long. Its posterior part was of the same depth as its orbital section and the zygomaticomaxillar process only moderately protrudes from the dorsal margin of the bone. The horizontal lamina tapers towards its posterior end, but does not terminate in a distinct pterygoid process; instead, it terminates as a thin and posteriorly convex edge that is attached to the vertical part of the bone. The tooth row extends by two or three tooth positions beyond the level of the posterior end of the lamina horizontalis. UMNH 18525 and 19360 (Fig. 9c-1,2 and d1,2 ) are each similar to UMNH 18513, but their zygomaticomaxillar process is even less prominent and their orbital margin is markedly declined medially.

Other maxillae are sculptured. UMNH 19287 (Fig. 9a$1,2)$ is the middle part of a left maxilla. Its horizontal lamina is robust, with a widely rounded margin; however, towards the posterior (left in Fig. 9a-2), it is gradually extended by a thin, dorsomedially declined lamina that is terminated by the pterygoid process. The outer surface of the bone, except for its lower margin, is covered by faint pit-and-ridge sculpture. UMNH 19279 (Fig. 9f-1,2) is similar, but it is larger and the lower part of its sculptured area is covered by horizontal ridges, rather than by pits and ridges.
The two prearticulars in the sample differ markedly from one another. UMNH 18217 (Fig. 9g) preserves the complete coronoid process, which has a convex and slightly elevated margin; this is why there is an extensive depression between the coronoid process and crista paracoronoidea. In contrast, UMNH 19278 (Fig. 9h) has a narrow coronoid process, with a straight and markedly swollen margin. The rounded dorsal surface of the bone anterior to the coronoid process becomes flattened posteriorly and declined medioventrally into a groove running parallel with the margin of the process. Meckel's groove is deep and delimited dorsally and ventrally by sharp cristae; it is located on the lateral surface of the bone at the level of the posterior part of the coronoid process.

The atlas UMNH 18516 (Fig. 9y-1-3) has both anterior cotyles widely separated, with a small pit in the midline. There is a posterior cotyle which, together with the anterior pit, suggests amphicoelous centrum. The centrum, however, is not pierced by the notochordal canal. The neural arches are broken off.

The urostyle UMNH 19289 (Fig. 9ee-1,2) is broken both posteriorly and anteriorly, so it is difficult to determine whether its articulation with the sacral vertebra was monocondylar or bicondylar. However, because the notochordal canal enters the body of the urostyle, we infer that the articulation likely was monocondylar. On both sides is a narrow, horizontal ledge extending anteriorly as a small, dorsoventrally compressed lateral process roofing a small intervertebral foramen. The dorsal margin of the bone is rounded with no keel.

UMNH 18511 is a central part of a short and robust scapula that is too fragmentary to be used for diagnostic purposes.

All humeri in the sample are clearly asymmetrical. The presence of the medial and lateral epicondyles cannot be ascertained for those specimens in which only the shaft is preserved (e.g., UMNH 18512, Fig. 9z; UMNH 18541, Fig. 9bb). It also seems that the medial and lateral cristae are poorly developed. The preserved distal part of UMNH 18214 (Fig. 9dd) is small and lacks the larger part of the caput, but its lateral epicondyle is completely absent (although the lateral crista is well developed, delimiting a large depression with the fossa cubitalis; the latter is represented by a deep groove adjacent to the caput). The medial epicondyle apparently did not reach distally to the same level as the caput. UMNH 18204 is only a proximal section of the humerus. Its ventral crista is prominent, extending onto the epiphysis. UMNH 18216 (Fig. 9aa-1,2) is apparently the humerus of a juvenile, in which the caput was not ossified and therefore not preserved. Both the medial and lateral cristae are only moderately developed. Asymmetry of the distal part of the bone is, however, apparent (it seems that the caput has shifted laterally), and 


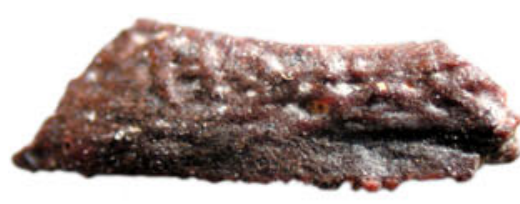

a-1

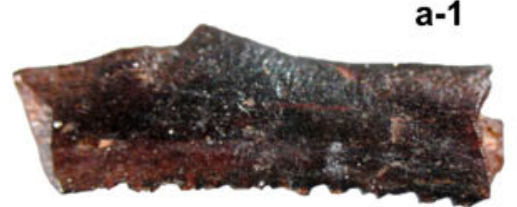

b-1

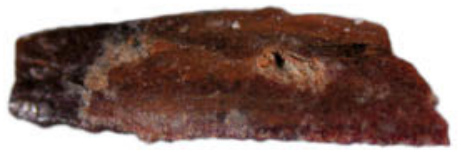

c-1

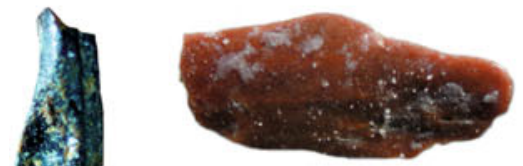

d-1

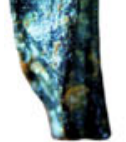

g

h

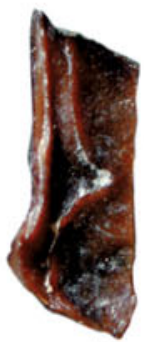

e-1

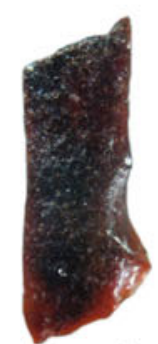

e-2
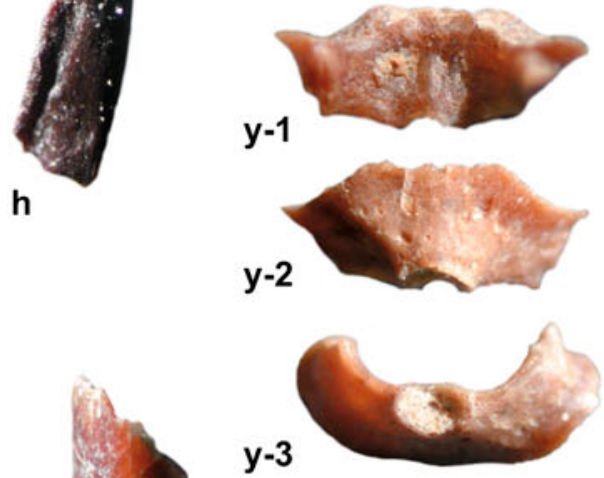

z

黑 Springer

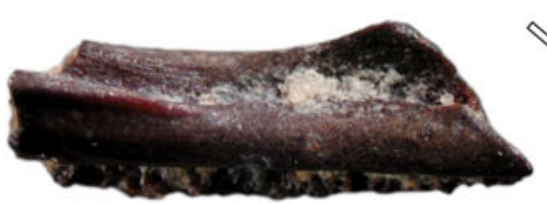

a-2

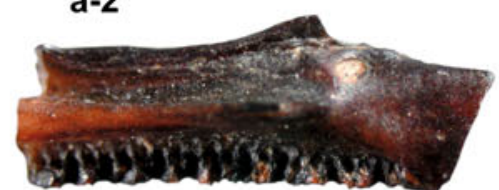

b-2

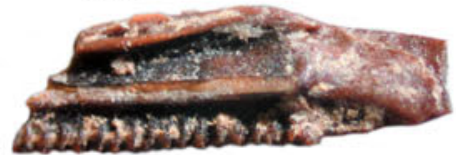

c-2

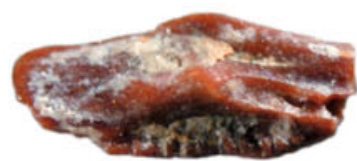

d-2
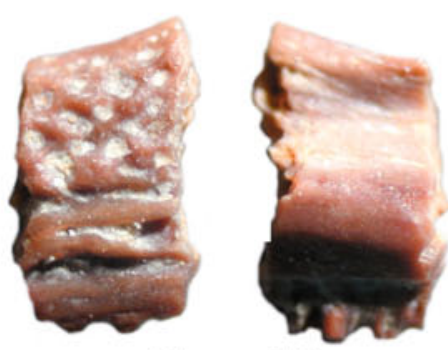

$f-1 \quad f-2$

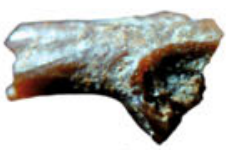

j

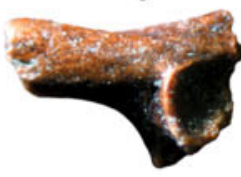

k
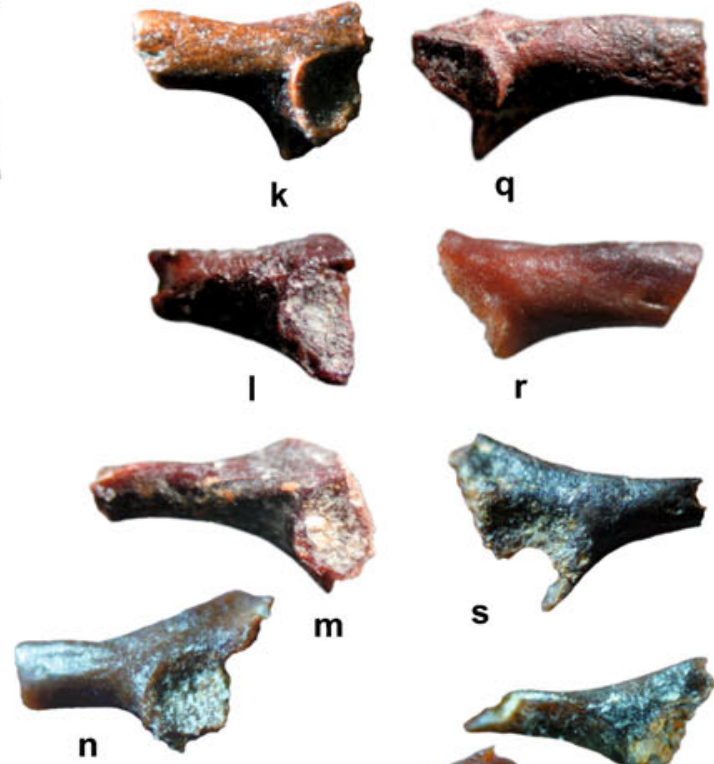

$\mathbf{S}$
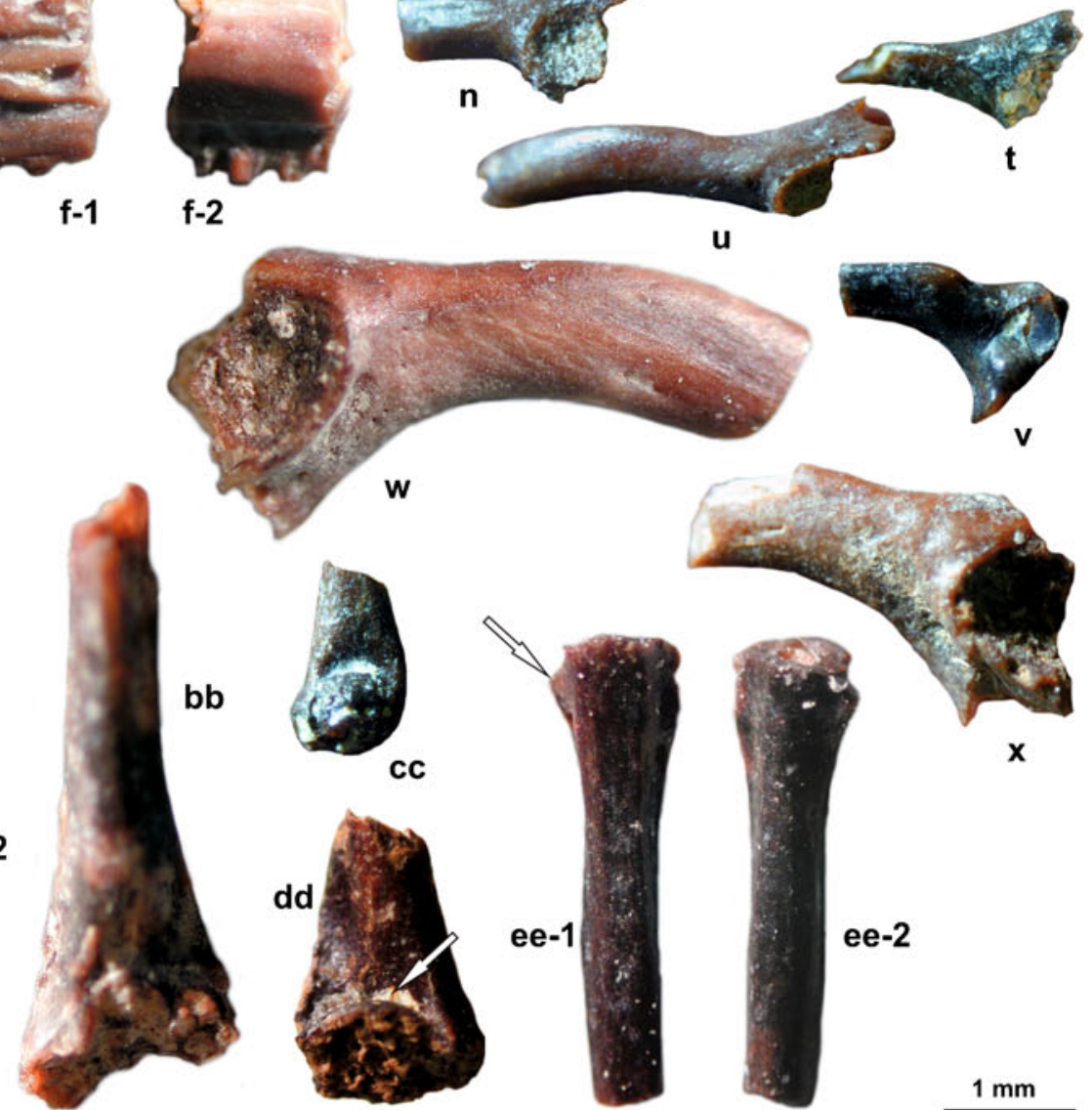

$\mathbf{u}$
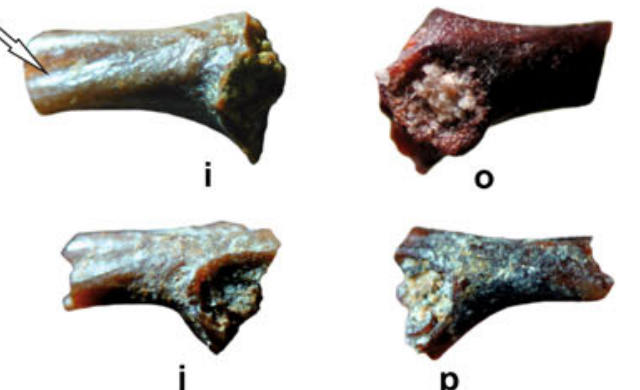
Fig. 9 Old Merrill Ranch, Henderson Canyon, Casey's Shell Hash Loc., Divide between Noon and Mud Creeks, middle Santonian. a Right maxilla (19287) in labial (a-1) and lingual (a-2) views. b Right maxilla (18513) in labial (b-1) and lingual (b-2) views. c Right maxilla (18525) in labial (c-1) and lingual (c-2) views. d Left maxilla (19360) in labial (d-1) and lingual (d-2) views. e Right frontoparietal (19288) in ventral (e-1) and dorsal (e-2) views. f Left maxilla (19279) in labial (f-1) and lingual (f-2) views. g Right praearticulare (18217) in dorsal view. h Right praearticulare (19278) in dorsal view. i Left ilium (18229) in lateral view. j Left ilium (18231) in lateral view. k Left ilium (18227) in lateral view. I Left ilium (19293) in lateral view. m Left ilium (19355) in lateral view. n Left ilium (18221) in lateral view. o Right ilium (18211) in lateral view. p Right ilium (18218) in lateral view. q Right ilium (19303) in lateral view. r Right ilium (19356) in lateral view. s Right ilium (18228) in lateral view. t Left ilium (18233) in lateral view. u Left ilium (18220) in lateral view. v Left ilium (18212) in lateral view. w Right ilium (18539) in lateral view. x Left ilium (18213) in lateral view. $\mathbf{y}$ Atlas (18516) in dorsal (y-1), ventral $(\mathbf{y}-2)$ and posterior (y-3) views. $\mathbf{z}$ Right humerus (18512) in ventral view. aa Left humerus (18216) in ventral (aa-1) and dorsal (aa-2) views. bb Left humerus (18541) in ventral view. cc Left humerus (18223) in ventral view. dd Right humerus (18214) in ventral view. ee Urostyle (19289) in dorsal (ee-1) and ventral (ee-2) views. All are at the same scale

the crista ventralis is present (marked by arrow in Fig. 9aa1). The humerus UMNH 18223 (Fig. 9cc) is similar to UMNH 18216 in that it has both cristae only moderately developed (in fact, they are more or less rounded) and that its lateral epicondyle is entirely absent. The fossa cubitalis is well developed, as it is in other humeri. UMNH 18234, despite consisting of only the distalmost part of the bone, also represents a clearly asymmetrical humerus in which the lateral epicondyle is entirely lacking whereas the medial epicondyle is well developed and reaching the level of the distalmost margin of the caput. There is a deep incision between the caput and medial epicondyle.

None of the ilia in the sample has a dorsal tubercle. The ilium UMNH 18211 (Fig. 9o), although very small, may be characterized by a medium-sized acetabulum with only moderately elevated margins dorsally and anteriorly; anteroventrally, the margin of the acetabulum extends slightly beyond the outlines of the bone.

The ilium UMNH 18227 (Fig. 9k) is characterized by a relatively small acetabulum, the anteroventral margin of which is raised, so that the acetabulum is declined posteriorly. However, in other features it is similar to those ilia in the sample whose posterior part has a dorsal margin rising towards the pars ascendens. The ilia UMNH 18539 and 18213 (Fig. 9w and $\mathrm{x}$, respectively) are basically similar to UMNH 18227 (Fig. 9k), except they are larger. UMNH 19293 (Fig. 91) also resembles UMNH 18227, but differs in its large acetabulum that extends to or slightly beyond the anteroventral outline of the bone.

The ilia UMNH 18218 (Fig. 9p) and 18224 are characterized by their almost straight dorsal margin and by an acetabulum that is a mere depression in the bone, rather than a structure with elevated margins. UMNH 18218 (Fig. 9p) is a small ilium that could belong to a juvenile, but judging by other ilia of the same size in this sample (UMNH 18221 and 18233; Fig. 9n and t, respectively) its general morphology corresponds to that of adults. UMNH 18224 is similar in that its dorsal margin is nearly straight and the acetabulum is a relatively small depression with low margins.

The ilia UMNH 18228 (Fig. 9s) and 18233 (Fig. 9t) each have a comparatively large and triangular acetabular region that gradually tapers into the iliac shaft. Their acetabula are only shallow depressions in the bone. UMNH 18228 has its pars ascendens markedly extended posterodorsally.

UMNH 18229 (Fig. 9i), 18231 (Fig. 9j) and, perhaps, 19356 (Fig. 9r) and 19358 are similar to one another in having the proximal part of their shaft straight, with an elongated depression on its outer surface. At the posterior end of this depression, there is a small foramen (marked by arrow in Fig. 9i). The acetabulum is large, reaching anteroventrally beyond the outlines of the bone.

The ilia UMNH 18220 (Fig. 9u), 18221 (Fig. 9n) and, possibly, 18230 are characterized by having the dorsal margin of the acetabular region declined posteriorly towards the pars ascendens (the latter is considerably declined posterodorsally) and separated from the dorsal margin of the iliac shaft by a broad depression, and in having a large acetabulum whose anteroventral portion extends beyond the outlines of the bone. The upper margin of the bone is broadly rounded, with no trace of an oblique groove crossing over the dorsal margin. Because the anterior portion of the acetabulum is raised, it is facing posterolaterally, rather than laterally. UMNH 18222 is similar, but larger.

UMNH 19355 (Fig. 9m) is intermediate between UMNH 18220 (Fig. 9u) and 18221 (Fig. 9n) because it also has a large and probably triangular acetabular region, and between UMNH 18229 (Fig. 9i) and 18231 (Fig. 9j) in having a prominent though rounded ledge running from the dorsal margin of the acetabulum anteriorly and slightly ventrally on the shaft. The shaft is comparatively slender.

UMNH 18212 (Fig. 9v), although its size fits within the range of variation of other small anuran ilia, is anomalous. The shaft and presumed acetabulum are somewhat distorted; these may be a result of a healed injury or developmental malformation.

Late Santonian (Fig. 10A, B)

Straight Cliffs Formation, Hat Shop Aquatic, locality 569; Hat Shop, locality 420; North Side of Pasture Wash, localities 424 and 427

Material: 1 premaxilla (18482, Fig. 10Bgg-1,2); 9 maxillae (18401, Fig. 10Aa-1,2; 18402-18407; 19341, Fig. 10Ab-1,2; 
19342, Fig. 10Ac-1,2); 2 prearticulars (18318, Fig. 10Ae1,$2 ; 18492$, Fig. 10Ad); 6 trunk vertebrae (18386, Fig. 10Al1-3; 18388, Fig. 10Am-1-3; 18390, Fig. 10Ak-1,2; 18392, Fig. 10Ah-1,2; 18470, Fig. 10Ai-1-3; 18472, Fig. 10Aj-14); 2 sacral vertebrae (18391, Fig. 10Ag-1,2; 18500, Fig. 10Af-1-3); 2 urostyles (18384, Fig. 10Bcc-1-3; 18385, Fig. 10Bdd-1-3); 1 scapula (18491, Fig. 10Bff-1,2); 18 humeri (18317; 18397, Fig. 10Bx; 18398; 18399, Fig. 10Bq; 18400, Fig. 10Bn; 18453; 18454, Fig. 10Bu; 18455, Fig. 10Bs; 18456, Fig. 10Bv; 18469, Fig. 10Bt; 18478, Fig.10Bm; 18481, Fig. 10Br; 18488-18490; 18503, Fig. 10Bo; 18504, Fig. 10Bw; 18505, Fig. 10Bp); 8 radioulnae (18464, 18465, 18468, 18493-18497); 18 ilia (18314, Fig. 10Bz-1,2; 18344, Fig. 10Bd-1,2; 18394, Fig. 10Ba-1,2; 18395, Fig. 10Bc-1,2; 18396, Fig. 10Bbb-1-3; 18471, Fig. 10Bb-1,2; 18473, Fig. 10Baa-1,2; 18474, Fig. 10Bi; 18475, Fig. 10Bg; 18476, Fig. 10Bk; 18477, Fig. 10Be; 18479, Fig. 10Bf; 18480, Fig. 10Bh; 18483, Fig. 10Bj; 18484, Fig. 10Bl; 18486; 18499; 18506, Fig. 10By;); 1 pair of ischia (18501, Fig. 10Bee); 4 femora (18316; 18459; 18463; 18466); 7 tibiofibulae $(18315 ; 18393 ; 18460-18462$; $18467 ; 18498)$.

Description: The premaxilla UMNH 18482 (Fig. 10Bgg1,2 ) is smooth on its outer surface, with only a short and widely rounded frontal process that was connected by a suture with its counterpart from the opposite side of the skull. On its inner surface, there is a thin horizontal lamina that broadens laterally.

The maxilla UMNH 18401 (Fig. 10Aa-1,2) belonged to a much larger frog. Its posterior process is broken off; however, its zygomaticomaxillar process seems to be preserved in its original shape (i.e. with a straight horizontal margin). The pterygoid process is directed medially, rather than posteriorly, and the horizontal lamina connecting its tip with the inner vertical surface of the bone is pierced by a foramen (see arrow in Fig. 10Aa-1). The sculpture on the outer surface of the bone tends to be tubercular, rather than pit-and-ridge. UMNH 18402 is the anterior part of the similar-sized maxilla, but with the dorsal margin broken off. Its outer surface is nearly smooth, except for few horizontal grooves along the lower part of the bone.

In contrast to the previous two maxillae, UMNH 19341 (Fig. 10Ab-1,2) is even larger. Its horizontal lamina is somewhat flattened dorso-ventrally on its margin, and becomes thinner towards the posterior. The vertical part of the bone (the fragment presumably preserves its middle or orbital section) is declined medially, over the shallow groove on the upper side of the horizontal lamina. Although the posterior part of the bone is broken away, it seems that its upper margin is interrupted by an oblique groove. The outer surface of the bone is nearly smooth.
Fig. 10 A Hat Shop, North Side Pasture Wash, late Santonian. a Left maxilla (18401) in medial (a-1) and lateral (a-2) views. b Right maxilla (19341) in medial (b-1) and lateral (b-2) views. c Right maxilla (19342) in inner (c-1) and outer (c-2) views. d Right prearticular (18492) in dorsal view. Sulcus Meckeli marked by arrow, its roof is partly broken off. e Right prearticular (18318) in dorsal (e-1) and dorsomedial (e-2) views. Processus coronoideus marked by arrows. f Sacral vertebra (18500) in ventral (f-1), posterior (f-2) and anterior (f-3) views. $\mathbf{g}$ Sacral vertebra (18391); centrum in dorsal (g-1) and ventral (g-2) views. h Trunk vertebra (18392) in anterior (h-1) and posterior (h-2) views. i Trunk vertebra (18470) in ventral (i-1), posterior (i-2) and anterior (i-3) views. $\mathbf{j}$ Trunk vertebra (18472) in ventral $(\mathbf{j}-1)$, dorsal $(\mathbf{j}-2)$ posterior $(\mathbf{j}-3)$, and anterior $(\mathbf{j}-4)$ views. $\mathbf{k}$ Trunk vertebra (18390) in anterior (k-1) and ventral (k-2) views. $\mathbf{I}$ Trunk vertebra (18386) in anterior (l-1), ventral (l-2), and dorsal (l-3) views. $\mathbf{m}$ Trunk vertebra (18388) in anterior $(\mathbf{m}-1)$, ventral $(\mathbf{m}-2)$, and posterior (m-3) views. All are at the same scale. B Hat Shop Aquatic, North Side Pasture Wash, late Santonian. a Left ilium (18394) in lateral (a-1) and medial (a-2) views. b Right ilium (18471) in medial (b-1) and lateral (b-2) views. Arrows mark healed fracture. c Right ilium (18395) in medial (c-1) and lateral (c-2) views. d Left ilium (18344) in lateral (d-1) and medial (d-2) views. e Left ilium (18477) in lateral view. f Right ilium (18479) in lateral view. g Left ilium (18475) in lateral view. h Right ilium (18480) in lateral view. i Left ilium (18474) in lateral view. $\mathbf{j}$ Left ilium (18483) in lateral view. $\mathbf{k}$ Left ilium (18476) in lateral view. I Scotiophryne pustulosa. Left ilium (18484) in lateral view. m Left humerus (18478). n Right humerus (18400). o Right humerus (18503). p Right humerus (18505). q Right humerus (18399). r Right humerus (18481). s Left humerus (18455). t Left humerus (18469). u Left humerus (18454). v Left humerus (18456). w Left humerus (18504). x Left humerus (18397). y Right ilium (18506). $\mathbf{z}$ Right ilium (18314) in medial (z-1) and lateral (z-2) views. aa Right ilium (18473) in medial (aa-1) and lateral (aa-2) views. bb Right ilium (18396) in dorsal (bb-1), medial (bb-2) and lateral (bb-3) views. cc Urostyle (18384) in dorsal (cc-1), ventral (cc2), and left lateral (cc-3) views. dd Urostyle (18385) in dorsal (dd-1), ventral (dd-2), and left lateral (dd-3) views. ee Ischia (18501) in dorsal view. ff Left scapula (18491) in outer (ff-1) and inner (ff-2) views. gg Right premaxilla (18482) in outer (gg-1) and inner (gg-2) views. All are at the same scale

UMNH 19342 (Fig. 10Ac-1,2) is characterized by a robust horizontal lamina with widely rounded margin. The base of the frontal process is preserved and has a deep fossa maxillaris (see arrow in Fig. 10Ac-1). The outer surface is covered by indistinct pitted sculpture. UMNH 18403 , $18404,18405,18406$, and 18407 are fragmentary and of different sizes, but resemble UMNH 19342 in having a horizontal lamina that is narrow horizontally, but deep vertically, and widely rounded margin. The outer surface of UMNH 18405 is rugose, with no distinct sculpture, whereas UMNH 18406 and 18407 bear indistinct pits that tend to fuse together to form grooves.

The prearticular 18318 (Fig. 10Ae-1,2) lacks its posteriormost part, yet the coronoid process is preserved. The process is directed medially and was not extensive (marked by arrows in Fig. 10Ae-1,2). Its dorsal surface is flat, rather than concave.

Only the middle part of the right prearticular 18492 (Fig. 10Ad) is preserved, and on this specimen the crista paracoronoidea obliquely traverses the bone. Meckel's 


\section{A}

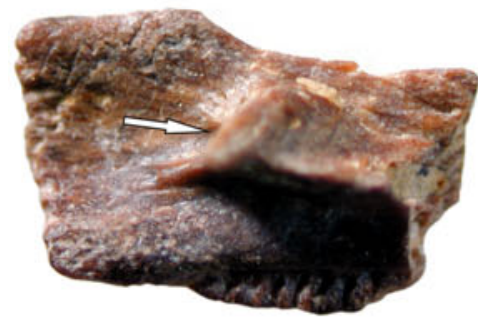

a-1

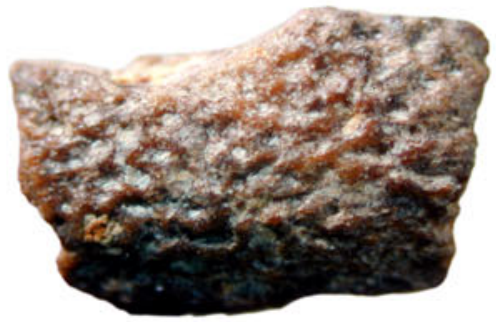

a-2
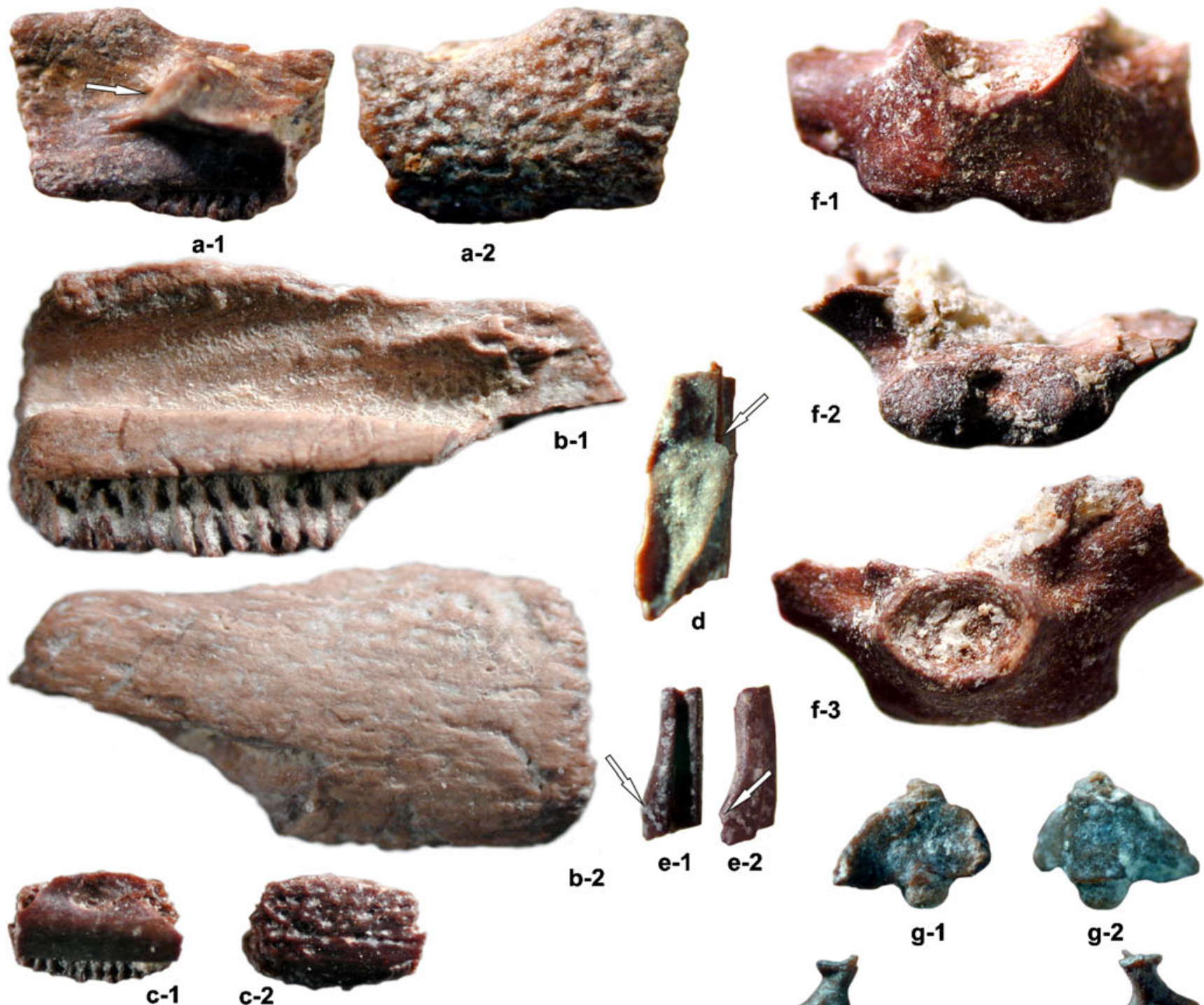

b-2
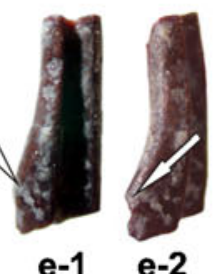

f-3

f-2
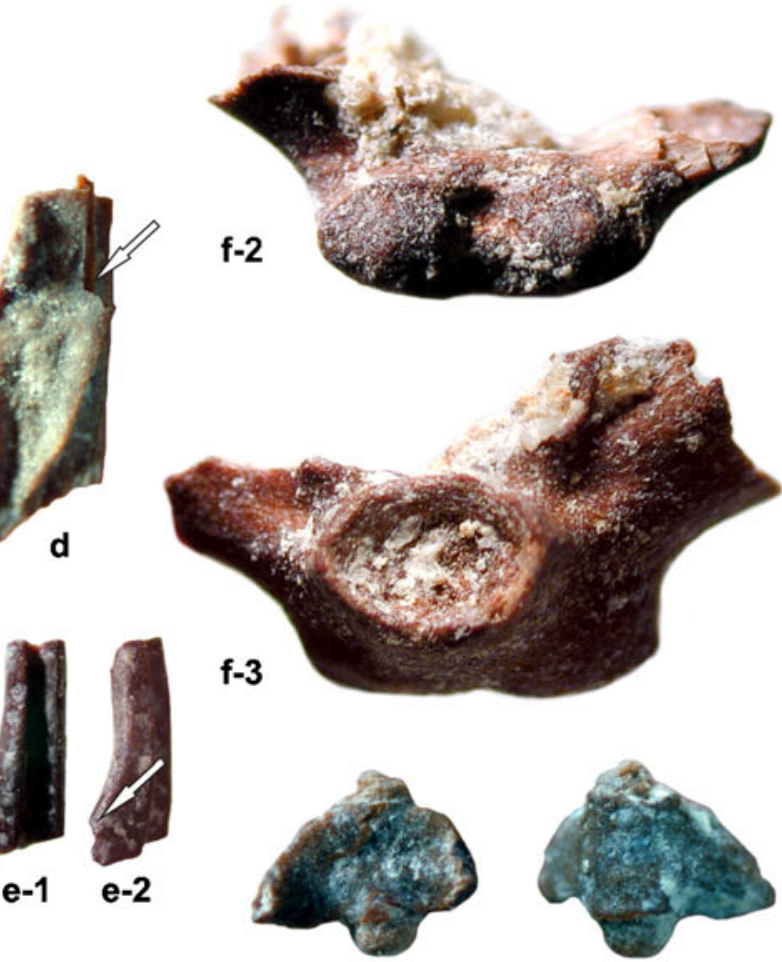

g-1

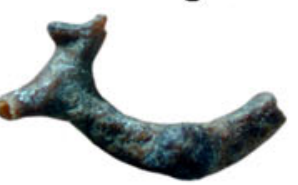

h-1

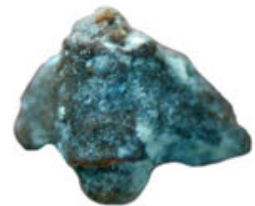

g-2

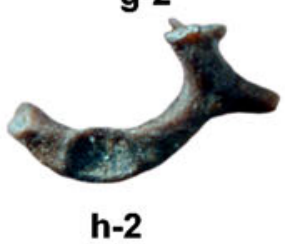

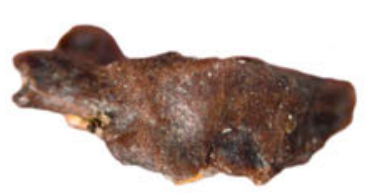

i-1

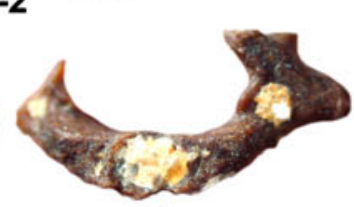

i-2

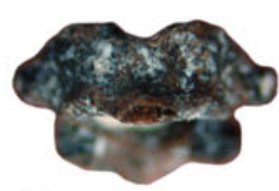

j-1

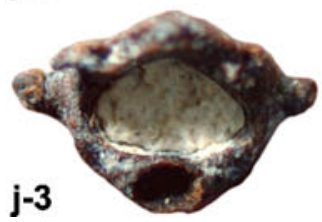

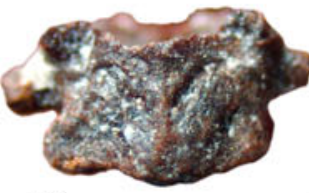

j-2

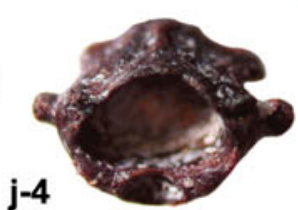

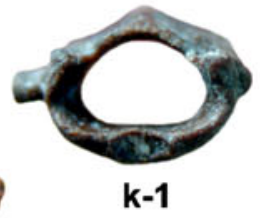

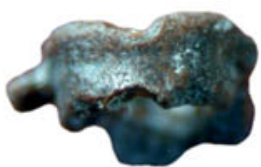

k-2

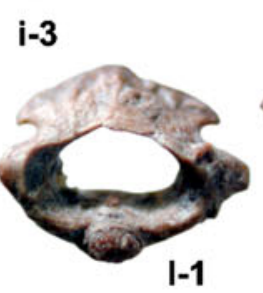

I-1

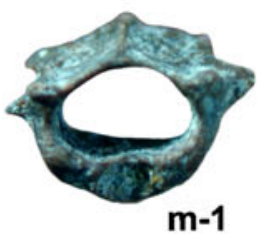

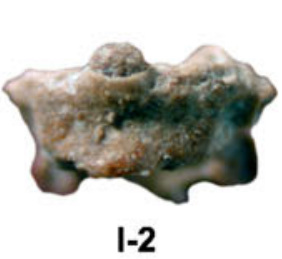

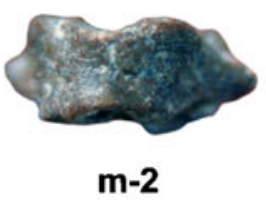

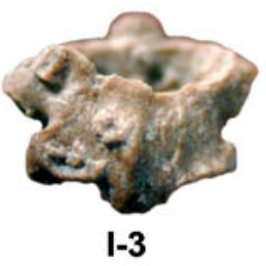

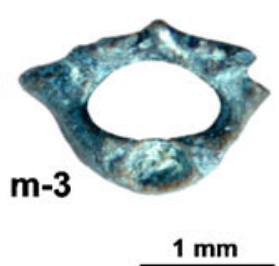


B
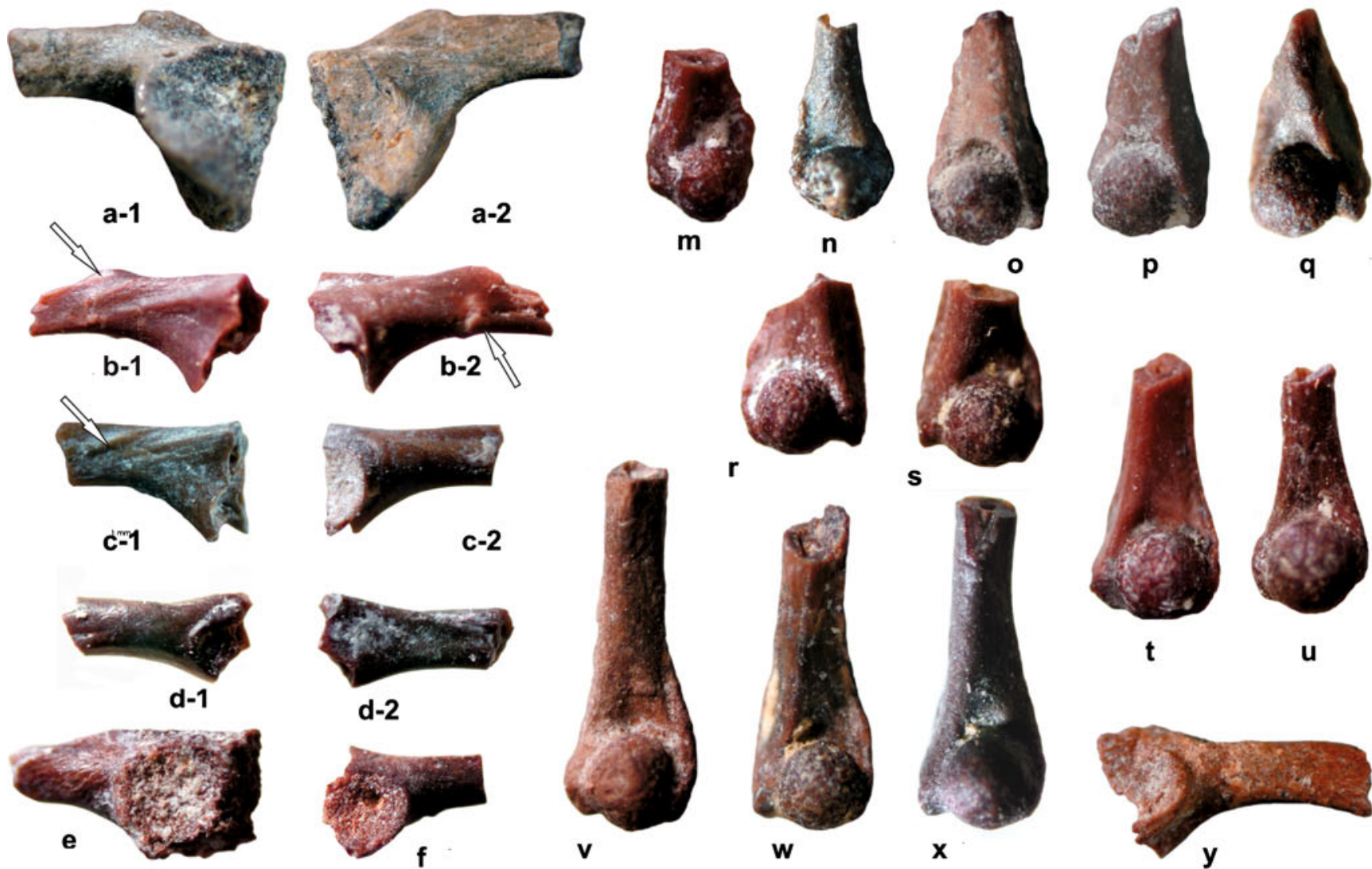

p
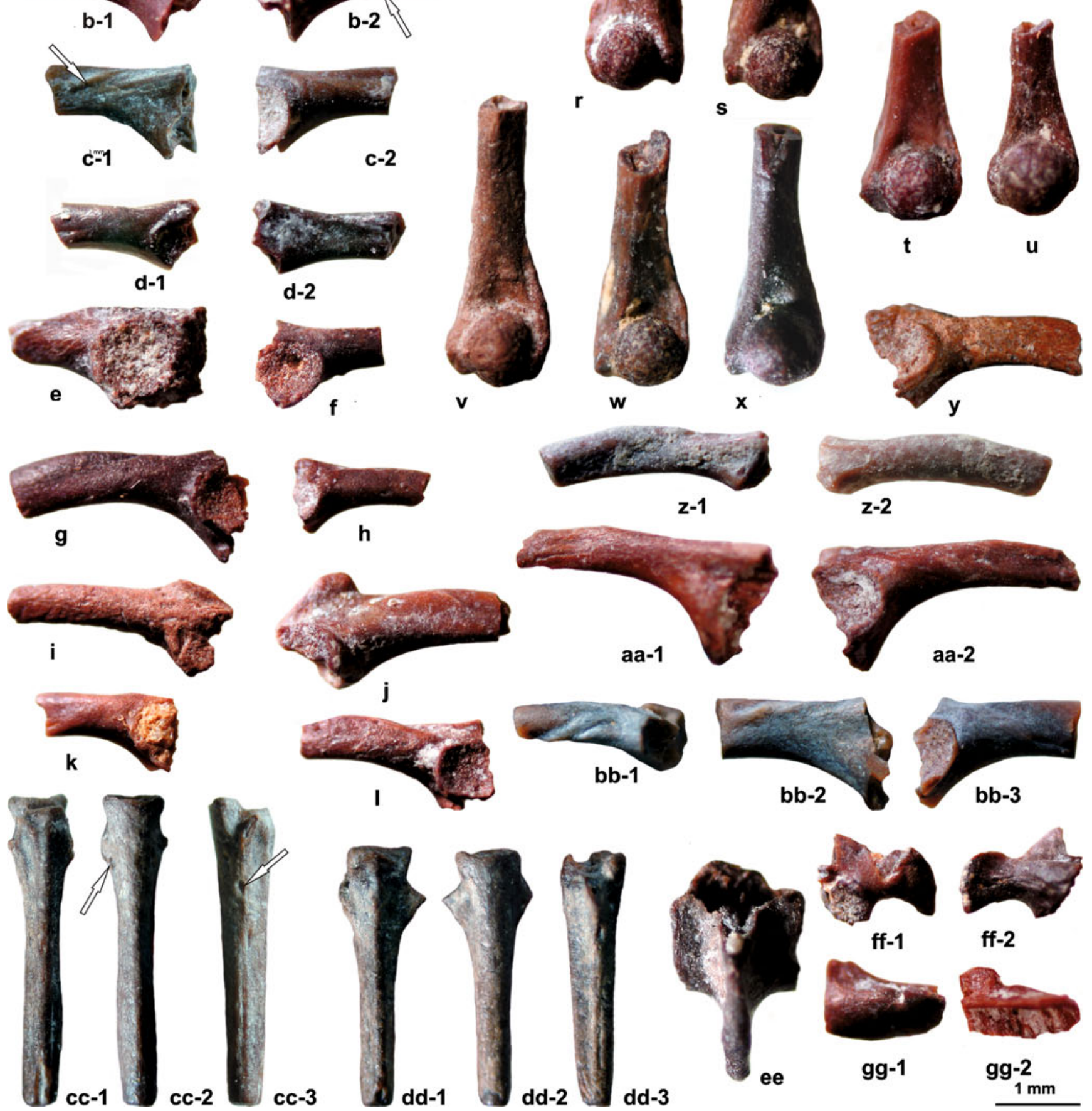

ff-1

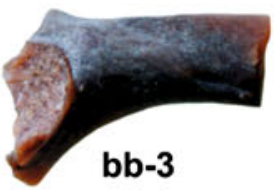

Fig. 10 (continued) 
groove (marked by arrow in Fig. 10Ad) originally had a roof, but this has been broken off. In spite of the comparatively large size of this specimen, the coronoid process is just an irregular tubercular elevation on the medial margin of the bone (at the level of the arrow) and posteriorly the medial margin of the bone is raised dorsally so that between this margin and the crista paracoronoidea there is a deep depression.

The trunk vertebra UMNH 18386 (Fig. 10Al-1-3) is clearly opisthocoelous and imbricate. Although its transverse processes are broken off, it is obvious that they were slightly declined posteriorly. The neural spine obviously was widely rounded and did not extend much beyond the posterior margin of the neural arches, and the sagittal ridge was indistinct. UMNH 18392 (Fig. 10Ah-1,2) is also an opisthocoelous trunk vertebra, with rather narrow bases of the neural arches. Its posterior articular concavity is shaped like a moderately horizontal ellipsoid; however, it is not as elongated as in UMNH 18386. The preserved proximal part of the transverse process suggests that the process was slightly declined anteriorly.

Other trunk vertebrae are amphicoelous. UMNH 18388 (Fig. 10Am1-3) is nearly complete, with moderately imbricate neural arches, and with the cotyles almost circular. UMNH 18472 (Fig. 10Aj-1-4) and 18470 (Fig. 10Ai-1-3) are similar, although the latter is slightly larger. UMNH 18390 (Fig. 10Ak-1,2) is also similar, but differs slightly in that its cotyles are more compressed ellipsoids. The preserved part of the transverse process is declined posteriorly.

Two different sacral vertebrae occur in the sample. UMNH 18500 (Fig. 10Af-1-3) is large, with the articular concavity facing anteriorly, whereas posteriorly there are two condyles suggesting that the sacro-urostylar articulation was bicondylar. The shape of the proximal part of its left transverse process suggests these processes were rather long. The second sacral in the sample (UMNH 18391, Fig. 10Ag-1,2) is peculiar in having condyles both anteriorly and posteriorly. Its neural arches are broken off close to the centrum but despite this it is clear that the proximal part of the transverse processes had to be rather narrow. The size of this vertebra, as well as shape of its condyles, correspond with both the monocondylar urostyles and the amphicoelous vertebrae in the sample.

The urostyle UMNH 18384 (Fig. 10Bcc-1-3) was monocondylar and its anterior concavity has the shape of horizontal elipsoid. There are a pair of dorsoventrally compressed transverse processes, but neither of them is complete. They do not continue along the sides of the bone as a significant ledge; however, there is a posteriorly facing foramen on either side (posterior to the process on the left side; see arrow in Fig. 10bcc-3) and below the process on the right side (see arrow in Fig. 10Bcc-2). The urostyle UMNH
18385 (Fig. 10Bdd-1-3) is similar, but there are three foramina on the left side and two on the right side. It seems that the transverse processes were triangular, and moderately declined anteriorly. Although both urostyles are not complete, they are similar to each other in their basic features.

The left scapula (UMNH 18491, Fig. 10Bff-1,2) is short, with the glenoid cavity and acromial part comparatively large. The suprascapular portion of the bone is extensive. The bone, though fully ossified, is very small (only slightly exceeding $1 \mathrm{~mm}$ ), suggesting a very small anuran.

Three types of humeri may be distinguished in the sample. One, represented by UMNH 18399 (Fig. 10Bq), is characterized by a large medial epicondyle and the complete absence of a lateral epicondyle. The medial crista extends slightly beyond the outline of the bone, whereas the lateral margin is straight. The fossa cubitalis is a narrow depression between the caput and the rounded ridge extending onto the medial epicondyle. Similar, but with their medial crista and medial epicondyle less developed, are UMNH 18397 (Fig. 10Bx), 18503 (Fig. 10Bo), 18504 (Fig. 10Bw), and 18505 (Fig. 10Bp). UMNH 18469 (Fig. 10Bt) may also belong in this category; however, its medial epicondyle protrudes less distally. Nevertheless, all these humeri are distinctly asymmetrical.

There is a group of humeri in which the medial epicondyle is large, but the lateral crista either has a small lateral epicondyle or terminates distinctly on the lateral side of the caput. This is evident on specimens UMNH 18455 (Fig. 10Bs), 18456 (Fig. 10Bv) and 18481 (Fig. 10Br).

Finally, there is a group of humeri in which the medial epicondyle is weakly developed and, thus, nearly the same size as the lateral epicondyle. Therefore, these humeri are almost symmetrical. This morphology is present in three specimens: UMNH 18454 (Fig. 10Bu), which also lacks both the medial and lateral cristae; UMNH 18400 (Fig. 10Bn) which, in contrast to UMNH 18454, has both cristae well developed as swollen margins; and in UMNH 18478 (Fig. 10Bm). Some of these humeri are small, so it is possible that they may have belonged to juveniles.

The humeral shafts UMNH 18317, 18488 and 18489, although each has their caput broken off, have a prominent and rounded ventral crista.

The ilium UMNH 18394 (Fig. 10Ba-1,2) is distinct in its proportions - the shaft is slender and straight, but the acetabular region is large. This is due to an extremely large acetabulum which reaches the dorsal margin of the bone (the pars ascendens is not developed), and whose anteroventral margin extends laterally. There is also a distinct and prominent dorsal tubercle on the dorsal margin of the bone.

The ilia UMNH 18395 (Fig. 10Bc-1,2), 18396 (Fig. 10Bbb-1-3), and 18471 (Fig. 10Bb-1,2) are similar to each other in having two parallel oblique ridges (see arrow in Fig. 10Bc-1) on the inner surface of the posterior 
section of the iliac shaft; these ridges are also evident in dorsal view (Fig. 10Bbb-1). Their acetabula are large, but do not extend anteroventrally beyond the margin of the bone. The dorsal tubercle is absent. The profile of the dorsal surface of the bone is moderately depressed in the transition between the iliac shaft and pars ascendens. The ilium UMNH 18471 was obviously broken and subsequently healed in life, as evidenced by secondary deposition of bone tissue on the dorsal and lateral surfaces (marked by arrows in Fig. 10Bb-1,2).

The ilium UMNH 18506 (Fig. 10By) and the much more fragmentary UMNH 18507 each have the anteroventral margin of the acetabulum markedly prominent, with an extensive fossa below it, whereas its dorsal margin is just the margin of a depression in the bone. The proximal section of the shaft is comparatively slender. The margin of the pars ascendens is declined posterodorsally; this margin continues on the inner surface of the bone as a low, oblique ridge which disappears before reaching the lower margin of the shaft. UMNH 18314 (Fig. 10Bz-1,2) is a broken shaft, so that the acetabular region is lacking. However, it is very similar to UMNH 18506 in that it obviously has no dorsal tubercle and the proximal section of the shaft was slender.

UMNH 18344 (Fig. 10Bd-1,2) is characterized by its acetabulum which is just a depression in the bone and lacks elevated margins. The acetabulum is rather small (a strip of whitish matrix adjoining it antero-dorsally lies outside the boundaries of the acetabulum; see Fig. 10Bd-1). On the inner surface of the bone, there is rather conspicuous ridge running anteroventrally from the pars ascendens.

The ilium UMNH 18477 (Fig. 10Be) has a large acetabulum reaching nearly the level of the dorsal and anteroventral margin of the bone, but its shaft is slender. It is similar to the ilium UMNH 18394 (Fig. 10Ba-1,2) in size and most aspects of its structure, except that it lacks a dorsal tubercle. UMNH 18479 (Fig. 10Bf) also has an extremely large acetabulum extending anteroventrally beyond the margins of the bone, but the bone itself is much smaller.

The following ilia have much smaller acetabula; however, the positions of their acetabula may vary. UMNH 18473 (Fig. 10Baa-1,2) has no dorsal tubercle, the dorsal margin of the pars ascendens and the dorsal margin of the shaft are straight, and only further to the anterior is the shaft curved ventrally. The ilia UMNH 18475 (Fig. 10Bg), 18476 (Fig. 10Bk), and 18480 (Fig. 10Bh) are similar in the proportions of their acetabula relative to other parts of the bone, in having a depressed transition between the shaft and the pars ascendens, and in having the shaft regularly curved. However, they differ in size and have either a distinct oblique ridge (UMNH 18480) or an oblique groove on the medial surface (UMNH 18476).
UMNH 18484 (Fig. 10Bl) is similar to the previous three ilia in its general morphology; however, it differs markedly in having an oblique groove on its dorsal surface, which runs from the dorsal margin of the acetabulum, but disappears on the inner surface of the bone. It can be referred to Scotiophryne. UMNH 18486 also has an oblique groove along its dorsal surface; in addition, its acetabulum is shifted ventrally beyond the outlines of the bone and is markedly declined posteriorly.

UMNH 18474 (Fig. 10Bi) is peculiar in that it has a nearly straight shaft, bears an extensive dorsal tubercle that is compressed laterally and slightly swollen along its dorsal margin, and lacks the pars ascendens. Instead, the dorsal margin of the bone joins the margin of the acetabulum.

The ilium UMNH 18483 (Fig. 10Bj) is, besides UMNH 18394 (Fig. 10Ba-1,2) and UMNH 18474 (Fig. 10Bi), the only other ilium in the sample which has a prominent dorsal tubercle. The tubercle is rounded and rather declined anteriorly. The inner surface of the bone is featureless.

The UMNH ischia 18501 (Fig. 10Bee) bear no taxonomically informative features, although they do indicate the presence of a large anuran in the sample.

Late Santonian or Early Campanian (Figs. 11 and 12)

Formation uncertain, Paul's locality, locality 10; Iron Springs Formation, Pinto Flats, locality 12

Material: 2 premaxillae (13547, Fig. 11c-1,2; 13565); 4 maxillae (13486, Fig. 11a-1,2; 13548, Fig. 11b-1,2; 13553; 13558); 4 prearticulars $(13489 ; 13505 ; 13527 ; 13531$, Fig. 11u); 6 urostyles (13502, Fig. 11mm; 13524, Fig. 11jj-1-3; 13526, Fig. 111l-1,2; 13530, Fig. 11kk; 13533, Fig. $11 \mathrm{nn} ; 13549$, Fig. 11ii-1-3); 2 scapulae (13476, Fig. 11t; 13477); 26 humeri (13474, Fig. 11z; 13475; 13478, Fig. 11ff; 13479; 13491, Fig. 11aa; 13492, Fig. $11 \mathrm{bb} ; 13503 ; 13506$, Fig. 11gg; 13508; 13509; 13510, Fig. 11dd; 13512-13519; 13521, Fig. 11cc; 13528, Fig. 11ee; 13529; 13532; 13542; 13550; 13564); 7 radioulnae $(13520 ; 13535 ; 13540 ; 13541 ; 13545 ; 13555$; 13556); 32 ilia (13480, Fig. 11d; 13481, Fig. 11m; 13482, Fig. 11x; 13483, Fig. 11w; 13484, Fig. 111; 13485, Fig. 11h; 13487, Fig. 11e; 13488, Fig. 11r; 13493, Fig. 11f; 13494, Fig. 11y; 13495, Fig. 11n; 13496, Fig. 11p; 13497, Fig. 11hh; 13498, Fig. 11j; 13499, Fig. 11q; 13500, Fig. 11o; 13501, Fig. 11k; 13504, Fig. 11s; 13507; 13511, Fig. 11i; 13516; 13522; 13523, Fig. 11g; 13525; 13546; 13551, Fig. 11v; 13554; 13566; 18553, Fig. 12a; 18552, Fig. 12b; 18554, Fig. 12c; 18555, Fig. 12d); 1 pair of ischia (13560); 4 femora (13543; 13552 ; 13557; 13568); 7 tibiofibulae (13534; 13536$13539 ; 13559 ; 13567)$. 
Description: The premaxilla UMNH 13547 (Fig. 11c-1,2) belongs to a large anuran and, based on its size, can be associated with the maxillae UMNH 13486 (Fig. 11a-1,2) and 13548 (Fig. 11b-1,2). Its outer surface is smooth and passes into the dorsal surface as a rounded dorsal crista. The dorsal surface slants down laterally from the base of the pars frontalis, and the rounded dorsal crista slants down accordingly. The pars frontalis is a laterally compressed thin lamina that is slightly declined posterolaterally. Its medial surface slants down towards the pars palatina which, in life, was in contact with its counterpart on the opposite praemaxilla. The second premaxilla in the sample (UMNH 13565) is smaller; its pars frontalis is slightly less prominent and is confluent with the smooth outer surface of the bone. Its horizontal lamina is thin and slightly convex at the level of the pars frontalis. In terms of their size and structure, both praemaxillae are clearly distinct from one another.

The maxilla UMNH 13486 (Fig. 11a-1,2) is from a large anuran. On its outer surface, it bears irregular pit-and-ridge sculpture reaching dorsally to the margo orbitalis, but leaving a smooth strip along the ventral margin. On its inner surface is a deep and rounded horizontal lamina whose dorsal surface extends laterally and posteriorly in a thin horizontal plate. Because the posterior part of the bone is broken off it is not clear whether the posterior termination of this thin lamina is natural (i.e., without processus pterygoideus) or an artifact. The horizontal lamina delimits ventrally a groove for the palatoquadrate bar (partly filled with sediment; see arrow in Fig. 11a-2), the dorsal margin of which is extended by a thin lamina opposite to that on the ventral margin of the groove. A rounded ridge running down from the medial wall of the zygomaticomaxillar process onto the inner surface of the bone delimits a groove on the orbital margin of the process. It is possible that this groove served for articulation with the squamosal. UMNH 13548 (Fig. 11b-1,2) is a fragment from the middle part of the maxilla that is similar in size and sculpture to UMNH 13486. The horizontal lamina is deep and widely rounded, and the orbital margin is broad and declined medially. Between both areas there is a deep groove for the palatoquadrate bar. The maxilla UMNH 13558 has the same type of sculpture as UMNH 13486 and 13548 and has a rather pointed pterygoid process, the dorsal surface of which continues anteriorly as a broad, shallow groove. These three maxillae may belong to the same taxon.

The maxilla UMNH 13553 is much larger than those described above. It has a distinct pterygoid process and the same type of sculpture as the three maxillae described in the previous paragraph, which may suggest a close relationship. Unfortunately, the dorsal part of the maxilla is broken off. Judging by their comparable sizes, this maxilla and the ilium UMNH 13551 (Fig. 11v) may be from the same taxon.
The prearticulars UMNH 13505 and 13531 (Fig. 11u) bear few notable features, except that the coronoid process is directed dorsomedially and terminates in an obtuse point. UMNH 13527 is fragmentary, but some features suggest its coronoid process is similar in shape to the coronoid process on UMNH 13531. UMNH 13489 differs in that its coronoid process is widely rounded (not forming a point) and directed dorsally.

The majority of urostyles are monocondylar. UMNH 13549 (Fig. 11ii-1-3) has a pair of comparatively robust and dorsoventrally compressed transverse processes and the roof of the neural canal terminated in a point reaching the level of the dorsal margin of the condyloid fossa. It is similar to UMNH 13524 (Fig. 11jj-1-3), which is slightly smaller. The transverse processes continue posteriorly for a short distance as a narrow, gradually disappearing ledge on the lateral surface of the bone. UMNH 13526 (Fig. 1111-1,2) is also monocondylar, but the condyloid fossa is of the same diameter as the neural canal and its transverse processes are located anteriorly, at the level of the roof of the neural canal. UMNH 13530 (Fig. 11kk) has its condyloid fossa subdivided in its ventral portion by a small median partition (but the sacro-urostylar articulation could still be considered monocondylar), the roof of the neural canal reaches the level of the dorsal margin of the condyloid fossa, and the transverse processes are subtle and located anteriorly. UMNH 13533 (Fig. 11nn) is much larger and its condyloid fossa is completely subdivided by a prominent median partition terminating in a point. Its dorsal part is broken off. Finally, the urostyle UMNH 13502 (Fig. 11mm) is still larger and its condyloid fossa is completely separated into two cotyles. Unfortunately, the dorsal part is missing.

The scapula 13476 (Fig. 11t) has an extremely large glenoid cavity (the pars acromialis is broken away), a thin cylindrical connection between the medial portion of the bone and the pars suprascapularis, and broadly expanded pars suprascapularis. If this scapula really belongs to an anuran, it is unique among these amphibians. In contrast, the scapula UMNH 13477 is much larger and robust than UMNH 13476, but it is too fragmentary to provide any further information.

Among the humeri, UMNH 13474 (Fig. 11z) is large and relatively symmetrical compared to others in the sample. The rounded ridge on the ventral surface of the bone originating from the crista ventralis is only slightly declined medially (it does not continue onto the medial epicondyle) and it is separated from the caput humeri only by a short groove; no fossa cubitalis is developed. The lateral epicondyle is prominent, although not to the same degree as the medial one. The medial and lateral cristae are nearly symmetrical and not extensive.

In contrast to UMNH 13474, the humerus UMNH 13491 (Fig. 11aa) is clearly asymmetrical in that its rounded ridge 


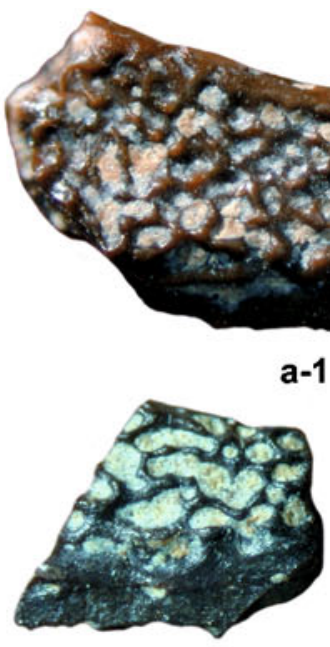

b-1

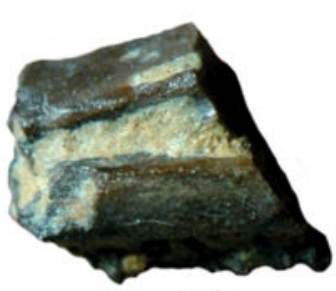

b-2

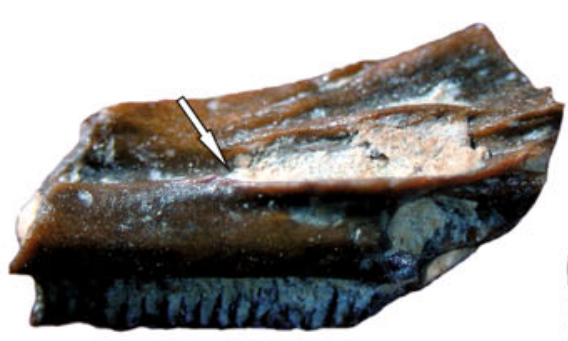

a-2

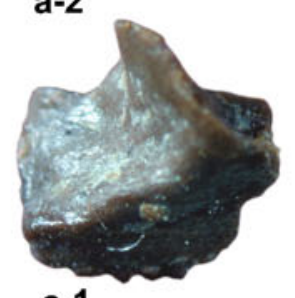

c-1

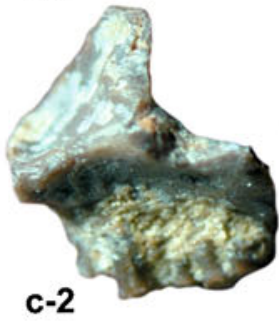

c-2

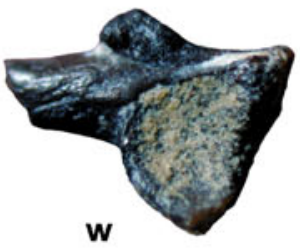

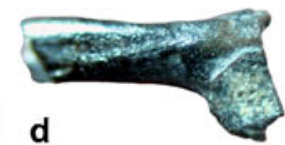
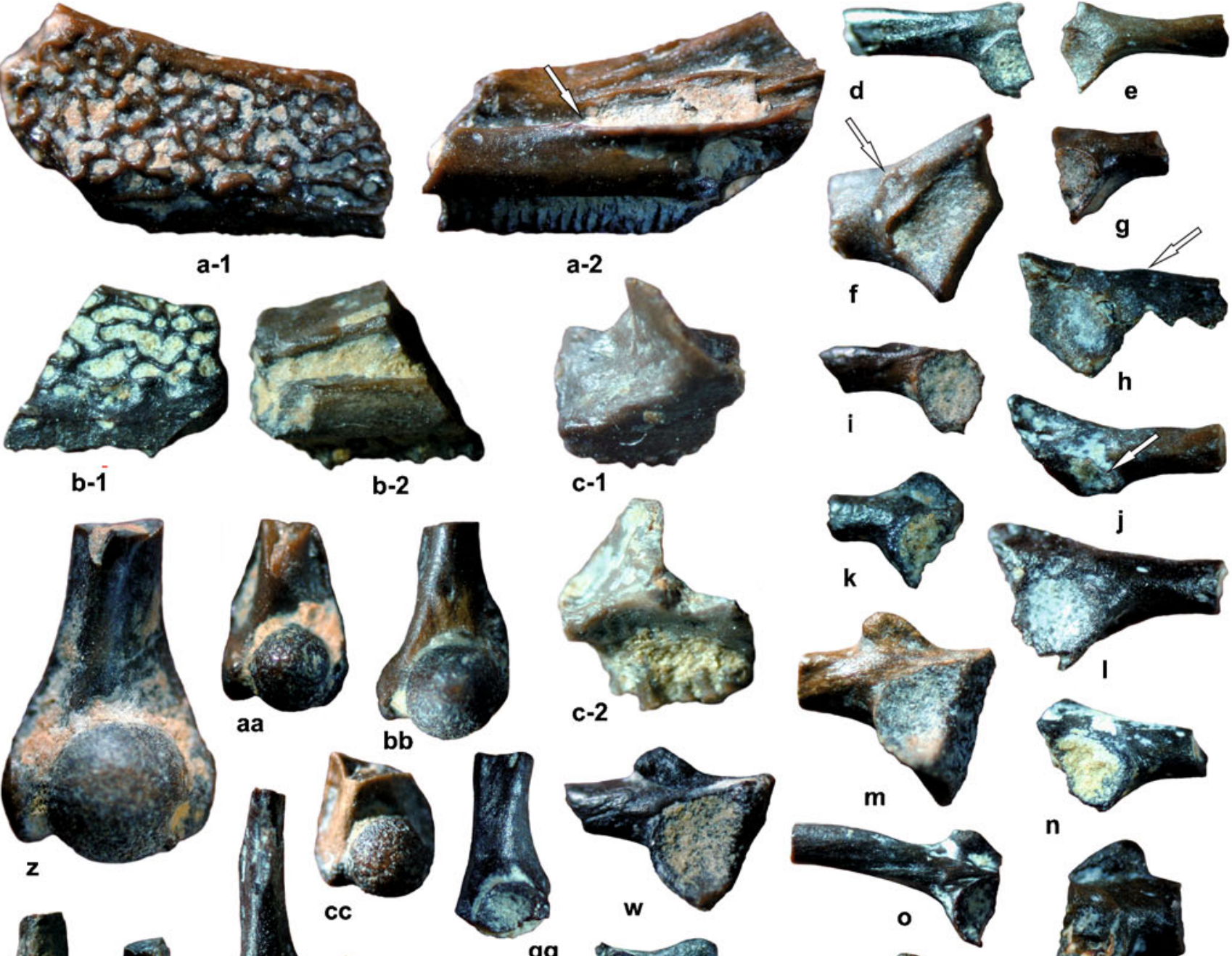

n
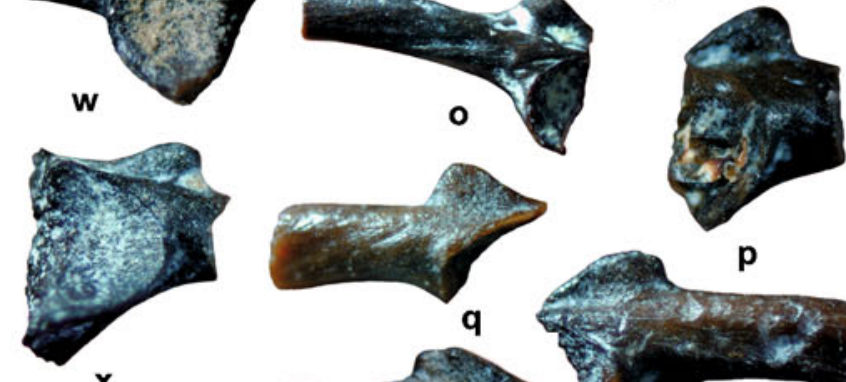

hh

dd

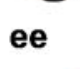

ff
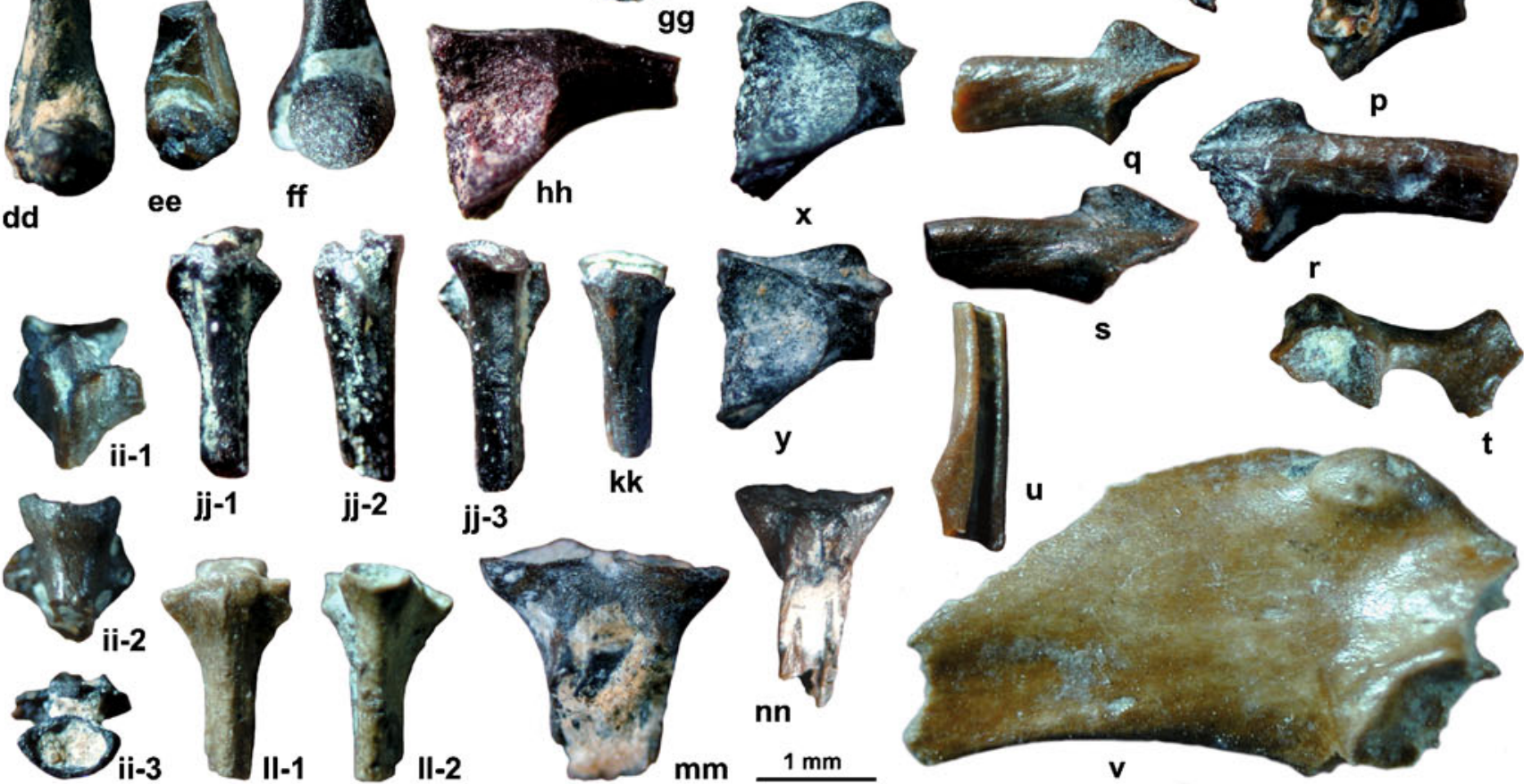
Fig. 11 Paul's Locality, late Santonian or early Campanian. a Maxilla (13486) in outer (a-1) and inner (a-2) views. b Maxilla (13548) in outer (b-1) and inner (b-2) views. c Right praemaxilla (13547) in outer (c 1) and inner (c 2) views. d Left ilium (13480). e Right ilium (13487). f Left ilium (13493). g Right ilium (13523). h Right ilium (13485). i Left ilium (13511). j Right ilium (13498). k Left ilium (13501). I Right ilium (13484). m Left ilium (13481). n Right ilium (13495). o Left ilium (13500). p Right ilium (13496). q Left ilium (13499). $\mathbf{r}$ Right ilium (13488). s Left ilium (13504). t Left scapula (13476) in ventral view. u Right prearticular (13531) in dorsal view. v Left ilium (13551). w Left ilium (13483). x Right ilium (13482). y Right ilium (13494). z Left humerus (13474). aa Left humerus (13491). bb Left humerus (13492). cc Left humerus (13521). dd Left humerus (13510). ee Right humerus (13528). ff Left humerus (13478). gg Left humerus (13506). hh Right ilium (13497). ii Urostyle (13549) in dorsal (ii-1), ventral (ii-2) and anterior (ii-3) views. jj Urostyle (13524) in dorsal (jj-1), left lateral (jj-2) and ventral (jj-3) views. kk Urostyle (13530) in dorsal view. Il Urostyle (13526) in dorsal (Il-1) and ventral (ll-2) views. mm Urostyle (13502) in dorsal view. nn Urostyle (13533) in dorsal view. Humeri in ventral view, ilia in lateral view. All at the same scale

extends onto the well-developed medial epicondyle and the lateral crista extends onto the lateral surface of the caput humeri. Both lateral and medial cristae tend to expand beyond the outlines of the bone. The fossa cubitalis is developed as an elongated depression adjacent to the dorsolateral margin of the caput. Disregarding variation in the sizes of their lateral crista, six other humeri are similar: UMNH 13479, 13492 (Fig. 11bb), 13521 (Fig. 11cc), 13516, 13517, and 13518. UMNH 13478 (Fig. $11 \mathrm{ff}$ ) is also clearly asymmetrical, but its medial rounded ridge originating from the ventral crista disappears at the level of the caput and, thus, does not reach the medial epicondyle. The medial crista is entirely absent, whereas the lateral crista is only moderately developed and it disappears before reaching the lateral surface of the caput.

The following two humeri are distinctly smaller although, judging by the ossification of their heads, they belonged to mature individuals. UMNH 13510 (Fig. 11dd) has no lateral epicondyle, the medial one is only moderately developed, and both cristae are distinct. UMNH 13528 (Fig. 11ee) is imperfectly preserved but it is clearly asymmetrical and lacks a medial epicondyle. UMNH 13506 (Fig. 11gg) is also asymmetrical, but the medial epicondyle and part of the articular head are worn off. UMNH 13514 is the distalmost part of an asymmetrical humerus. It has a relatively small caput with a smooth surface, which suggests the caput was ossified and covered by only a thin layer of cartilage. UMNH 13475 is also only the distalmost part of the humerus; however, it is characterized by a large medial epicondyle (approximately one-third the width of the bone) and a well-developed, though much smaller, lateral epicondyle.

UMNH 13519 and 13564 are the shafts of humeri with the crista ventralis, which in both specimens is prominent and only slightly thickened along its margin. The isolated shafts cannot be associated with other humeri.

Among the ilia from Paul's locality (Fig. 11), two principal types can be distinguished - those without a dorsal tubercle and those with the tubercle. Within the first category, there are ilia in which the dorsal margin is more or less straight. The ilium UMNH 13480 (Fig. 11d) has a comparatively large acetabulum. The dorsal margin of the bone between the shaft and pars ascendens is only moderately depressed. On its inner surface is a rounded ridge descending from the pars ascendens, but it soon disappears on the shaft. On its outer side is an oblique ridge running from the area dorsal to the acetabulum towards the lower margin of the shaft. UMNH 13487 (Fig. 11e) is similar, but slightly different in that the margins of the shaft are divergent anteriorly. In this feature it recalls many caudate ilia; however, in all other characteristics (including the asymmetrical position of the acetabulum) it is typically anuran. UMNH 13523 (Fig. 11g) is similar, but its acetabulum is smaller. UMNH 13485 (Fig. 11h) has the dorsal margin of the shaft clearly separated from the dorsal margin of the pars ascendens by a dorsal convexity (marked by arrow in Fig. 11h); a similar convexity is found in UMNH 13554.

The following ilia also lack the dorsal tubercle, but the dorsal margin of their pars ascendens is inclined posterodorsally. UMNH 13484 and 13495 (Fig. 111 and n) correspond to each other both in the shape and size of their acetabula. On the inner surface, they have an elevated symphysial area. UMNH 13498 (Fig. 11j) is similar but its acetabulum is extremely large (judging by preserved part of its anterodorsal margin; see arrow in Fig. 11j). There are two shallow, parallel grooves obliquely crossing its dorsal surface. The outer surface of the pars ascendens is rugose (it bears several comparatively large pits) and also its inner surface is slightly elevated and rugose in the area of symphysis with the opposite ilium. Disregarding details which can be due to imperfect preservation, the three ilia can be attributed to the same taxon. UMNH 13493 (Fig. 11f) also belongs among the ilia in which the dorsal tubercle is not developed; however, its acetabulum is a mere depression demarcated anterodorsally by a short elevated ridge. The ridge is paralleled by an elongated mound (see arrow in Fig. 11f).

The second principal group of ilia is characterized by a prominent dorsal tubercle which, if observed in lateral view, is declined anteriorly. The most characteristic specimen is UMNH 13481 (Fig. $11 \mathrm{~m}$ ) in which the dorsal tubercle is laterally compressed and prominent raised above the straight dorsal margin. The acetabulum is large and extends anteroventrally beyond the margin of the bone, almost up to its dorsal margin. In addition, the ventral margin of the acetabulum is well-developed 
laterally and a distinct oblique groove, delimited by rounded ridges, runs on the lateral surface of the shaft anteroventrally. UMNH 13483 (Fig. 11w) is similar, but differs in lacking the groove on the outer surface of the shaft and in having a rather knob-like dorsal tubercle. UMNH 13500 (Fig. 11o) may be related to the taxon represented by UMNH 13481, but it is much smaller. UMNH 13488 (Fig. 11r) and 13504 (Fig. 11s) are similar; however, the dorsal tubercle is lower but more elongated along its anterior-posterior diameter. UMNH 13499 (Fig. 11q) and 13496 (Fig. 11p) are similar, but fragmentary.

UMNH 13482 (Fig. 11x), 13494 (Fig. 11y) and, probably, 13566 clearly belong to a single taxon. In each, the acetabulum is large, vertically extending over the whole lateral surface of the acetabular region, and the posterodorsal and ventral margins protrude a considerable distance laterally. Because of the straight posterior suture, they can be associated with the ischia UMNH 13560. The ilium UMNH 13501 (Fig. 11k) has a large and triangular dorsal tubercle, with a flat anterior surface; however, it is not clear whether this may be due to breakage of the anterior margin of the dorsal tubercle. The acetabulum was obviously large. UMNH 13551 (Fig. 11v) differs from all others in the sample not only by its large size but also by its convex dorsal margin in the transition between the shaft and the acetabular portion. The knob-like dorsal tubercle is only slightly raised relative to the outline of the bone. The dorsal margin slants down posteriorly and, because it is broken off posteriorly, it is not clear whether the pars ascendens was prominent or not. The preserved part of the acetabular margin suggests that the acetabulum was comparatively small and shifted ventrally. The shaft is markedly compressed laterally, but it does not bear a dorsal crest. UMNH 13497 (Fig. 11hh) is characterized by its large acetabulum, which extends over nearly the whole dorsoventral diameter of the posterior part of the bone, and by its markedly thin shaft. The dorsal margin of the bone is moderately convex at the transition between the pars ascendens and the shaft. UMNH 13511 (Fig. 11i) has its dorsal margin broken off, so it is not clear whether this ilium bore a dorsal tubercle or not. Its acetabulum is also extremely large.

The ilia from Pinto Flats (Fig. 12), although represented by a limited number, are all very small and lack a dorsal tubercle. UMNH 18553 and 18555 (Fig. 12a and d) are each characterized by their acetabulum, which is shallow, circular in shape, and moderately declined posterodorsally because of its prominent anteroventral margin. Also, typical for these ilia is a sharp, straight edge that splits from the anteroventral section of the acetabular rim; between them, this edge and the acetabular margin delimit a deep triangular fossa (see Fig. 12d). Moreover, the ventral portion of the acetabular rim is curved posterodorsally along the posterior margin of the bone which suggests that the entire or at least a major part of the acetabulum was located on the ilium. The acetabular region is comparatively thick. The shaft is slender, oval in cross-section, and straight. The anterior margin of the pars ascendens is only slightly declined posterodorsally.

The other two ilia are different. UMNH 18552 (Fig. 12b) has the anterior margins of the pars ascendens and pars descendens markedly divergent. Even though the acetabulum is not greatly enlarged, it is shifted far enough ventrally that it extends beyond the anteroventral margin of the bone. On the inner surface of the bone there is a well-defined oblique groove running from the dorsal surface of the pars ascendens. UMNH 18554 (Fig. 12c) is slightly larger and it differs markedly in having a large acetabulum that extends nearly to the dorsal margin of the acetabular region. Its shaft is curved medially and has an oblique groove on its inner surface.

Early to Middle Campanian (Figs. 13 and 14)

Wahweap Formation, Wahweap Creek, locality 25; White Flats Road, locality 82; Bulldog Hollow, locality 1074; Mill Creek, locality 83; Barker Reservoir Rd., locality 130; Johnson Bench, locality 78; Campbell Canyon, localities 77 and 80. Formation uncertain, Websters Flat, locality 11

Material: 1 frontoparietal (18127); 2 premaxillae (18257; 18346); 10 maxillae $(18076 ; 18136 ; 18141 ; 18169 ; 18306$, Fig. $14 v-1,2 ; 18345 ; 18347-18349 ; 18502$, Fig. 14q-1,2); 12 prearticulars (18120, Fig. 13aa; 18128, Fig. 13dd; 18171; 18185, Fig. 14o; 18254, Fig. 13bb; 18255; 18258; 18260; 18271; 18280; 18291, Fig. 13z; 18292, Fig. 13cc); 2 atlases $(18111 ; 18190)$; 1 presacral vertebra (18092, Fig. 13hh); 3 urostyles (18115, Fig. 13jj-1,2; 18181, Fig. 14m-1,2; 19344, Fig. 13ii-1-3); 1 coracoid (18157); 4 scapulae (18116, Fig. 13kk; 18118, Fig. 1311; 18123; 18265); 17 humeri $(18078 ; 18090 ; 18091 ; 18093 ; 18110$;

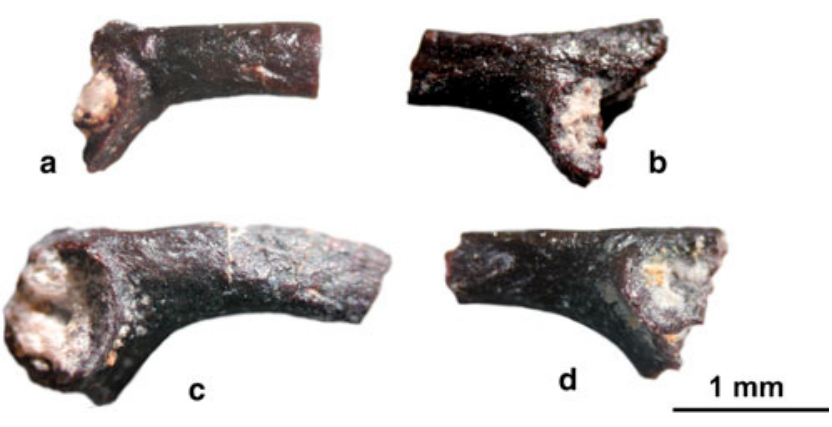

Fig. 12 Pinto Flats, ?Campanian. a Right ilium (18553). b Left ilium (18552). c Right ilium (18554). d Left ilium (18555). All are in lateral view and at the same scale 
$18125 ; 18126 ; 18129 ; 18130 ; 18132 ; 18149 ; 18174$, Fig. $14 n$; 18279; 18290; 18322; 18328; 19351, Fig. 13ff); 35 radioulnae $(18067 ; 18071 ; 18074 ; 18075 ; 18079$; $18081-18083$; 18085; 18142; 18143; 18145; 18147; 18148 ; 18158 ; 18160 ; 18256 ; 18266-18270, 18278; $18311-18313$; 18329-18331; 18334; 18337; 1934619348; 19354); 63 ilia (18088, Fig. 13ee; 18095, Fig. 13h; 18096; 18097; 18098, Fig. 13p; 18099, Fig. 131; 18100, Fig. 13i; 18101, Fig. 13u; 18102, Fig. 13r; 18103, Fig. 13w; 18104, Fig. 13s; 18105; 18106, Fig. 13v; 18108, Fig. 13m; 18112, Fig. 13gg; 18113, Fig. 13k; 18114, Fig. 13n; 18117; 18121, Fig. 13t; 18122, Fig. 13j; 18124; 18134, Fig. 14h; 18137; 18138; 18139, Fig. 14d; 18140, Fig. 14f; 18150; 18154, Fig. 14b; 18176; 18180, Fig. 14j1,2; 18182, Fig. 141-1,2; 18183, Fig.14e; 18184, Fig. 14g; 18188, Fig.14c; 18247, Fig. 13x; 18251; 18252; 18253, Fig. 13o; 18263, Fig. 13a-1,2; 18264, Fig. 13b-1,2; 18282, Fig. 13f; 18283, Fig. 13d-1,2; 18284, Fig. 13g-1,2; 18285; 18286, Fig. 13e-1,2; 18287, Fig. 13c; 18288, Fig. 13q; 18289; 18303, Fig. 14r-1,2; 18304, Fig. 14s-1,2; 18305, Fig. 14u; 18307, Fig. 14t-1,2; 18319, Fig. 14p-1-3; 18320, Fig. 14a; 18321, Fig. 14i; 18332; 18335; 18336; 18338, Fig. 14k-1,2; 19345, Fig. 13y; 19349; 19350; 19352; 19353); 2 pairs of ischia $(18069 ; 18094) ; 5$ femora (18068; 18072; 18073; 18077; 18170); 25 tibiofibulae $(18070 ; 18080 ; 18144 ; 18146 ; 18159 ; 18164 ; 18246$; 18249 ; 18261 ; 18262; 18272-18277; 18308-18310; 18323-18327; 18333).

Description: The frontoparietal UMNH 18127 is fragmentary, but preserves a portion of the incrassation on its inner surface and its outer surface is smooth.

The premaxilla 18257 has its medial part broken off, so it is not possible to determine whether there was a fossa in the base of the inner surface of its pars frontalis or what was the shape of its medial margin. Its outer surface is smooth and, at least on the lateral part of the bone, it continues without any discernable break in the dorsal surface of the pars horizontalis. UMNH 18346 is a small fragment of a premaxilla that corresponds in size to the maxilla UMNH 18347. Its medial part is broken off, so the contact with its counterpart cannot be restored.

The maxilla UMNH 18076 has its pterygoid process broken off, but it is obvious that the horizontal lamina is very thin posteriorly and that the tooth row extends beyond the posterior end of the lamina. The posterior section of the margo orbitalis slants down medially and bears several short ridges parallel to the orbital margin. The outer surface of the bone bears irregular pit-and-ridge sculpture which, however, is absent along the ventral part of the bone. This smooth strip on outer surface of the bone is separated from the sculptured surface by a distinct indentation. UMNH 18345 is the middle part of a maxilla that includes the processus palatinus and adjacent fossa maxillaris. The lamina horizontalis is thick and widely rounded along its margin, and its outer surface is entirely smooth. UMNH 18347 and 18348 are fragments of much larger maxillae than UMNH 18345, corresponding in size to the premaxilla UMNH 18346. Both fragments are irregularly wrinkled horizontally on the posterior part of their outer surface, but are smooth anteriorly. UMNH 18349 is a fragment from the middle part of a maxilla; it has a narrow, but thick and widely rounded horizontal lamina, and an extended and flattened orbital margin partly roofing the groove for the palatoquadrate bar dorsally. On its outer surface is irregular pit-and-ridge sculpture, which becomes less prominent ventrally, and the lower portion of the bone is entirely smooth. UMNH 18306 (Fig. 14v-1,2) has a narrow horizontal lamina that thins moderately towards its anterior end. The outer surface of the bone is smooth, although there is a hint of rudimentary sculpture on its upper part. UMNH 18136 and 18141 are similar, except their outer surfaces are entirely smooth. UMNH 18169 is very small (estimated length of the bone is about $4 \mathrm{~mm}$ ); it has a comparatively broad and thick horizontal lamina, with a rounded margin. The outer surface of the bone is smooth.

The maxilla UMNH 18502 (Fig. 14q-1,2) differs markedly from all other specimens in the sample by its larger size. It has a narrow, but deep horizontal lamina with a rounded margin. Its outer surface is covered by pustular sculpture, except for a smooth strip along the lower margin of the bone.

The prearticular 18128 (Fig. 13dd) has its coronoid process as a large, thin, horizontal lamina, with a widely arch-like, moderately raised, and rather swollen margin. Consequently, its dorsal surface is a shallow depression. The dorsal margin of Meckel's groove is curved medially at its posterior section, which results in the groove being open dorsally. UMNH 18291 (Fig. 13z) and 18292 (Fig. 13cc) also have an extensive coronoid process with a shallow depression on its dorsal surface, with a portion of its medial margin straight; this straight section is swollen, clearly indicating that it served for muscle insertion. UMNH 18271 and 18280 are fragmentary, but their coronoid process was a thin horizontal lamina that extends medially and has a shallow depression on its dorsal surface. In both specimens, the shape of the medial margin was widely convex. UMNH 18171 is badly damaged, but it is obvious that the coronoid process was moderately declined ventrally and that its dorsal surface, which was flat and slightly depressed in its posterior part, was declined accordingly. The dorsal margin of Meckel's groove follows the course of the ventral margin, so the groove is roofed over the entire extent of the coronoid process. UMNH 18185 (Fig. 14o) has a long and narrow coronoid process, with its dorsal surface flat and horizontal. Meckel's groove opens laterally along the whole length of the process. 

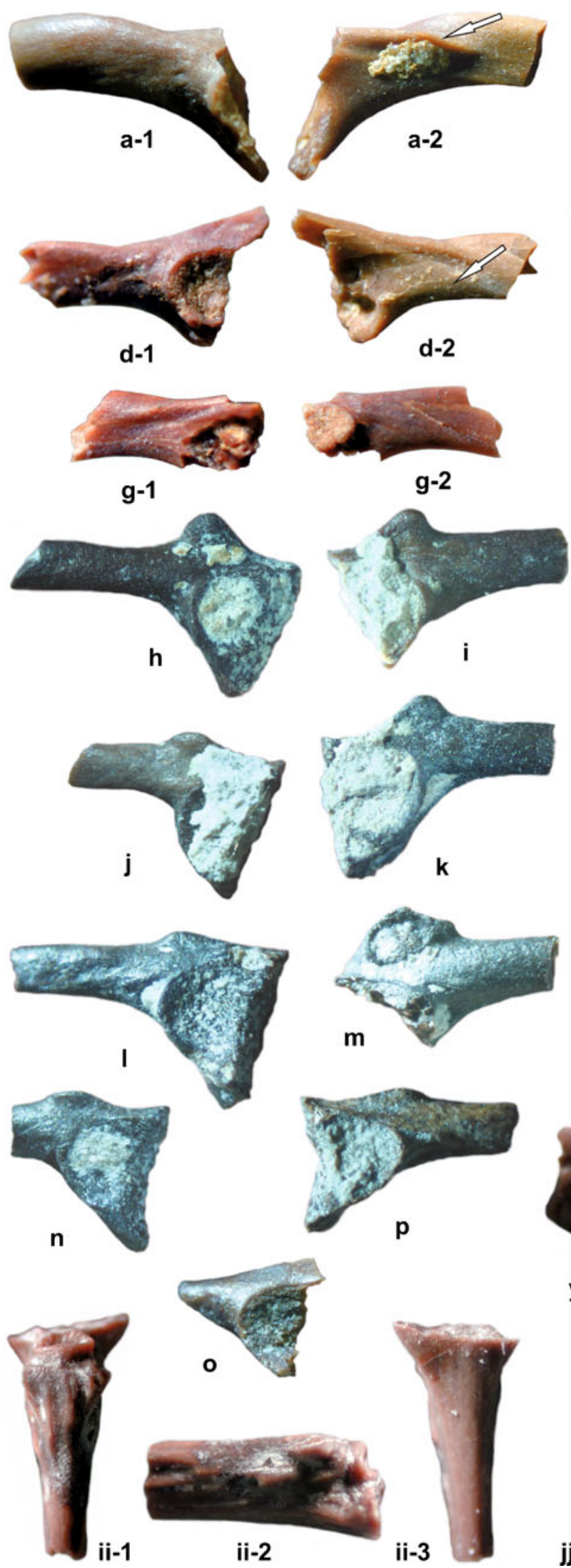
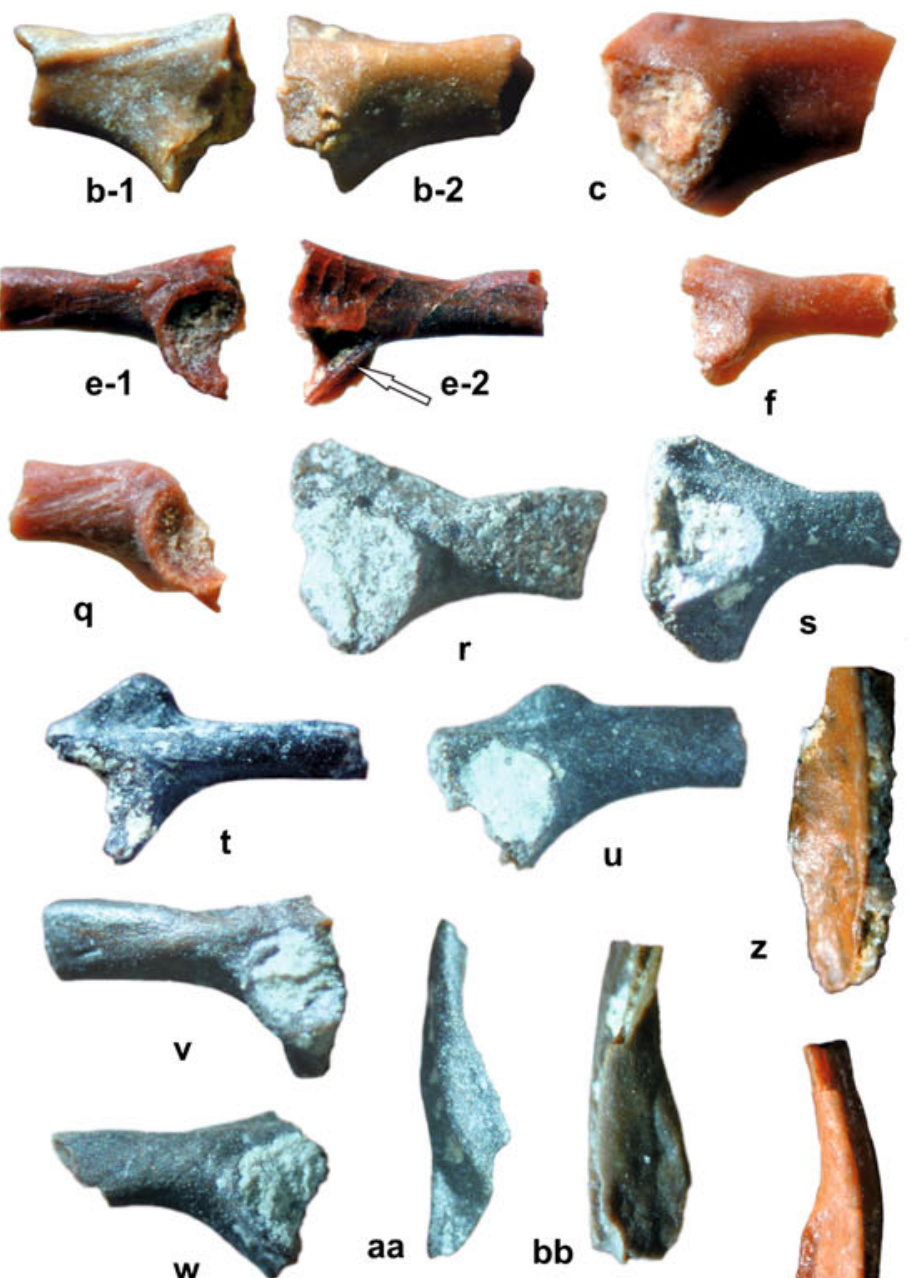

bb

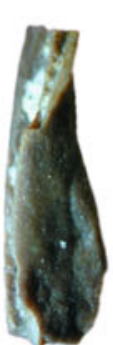

z
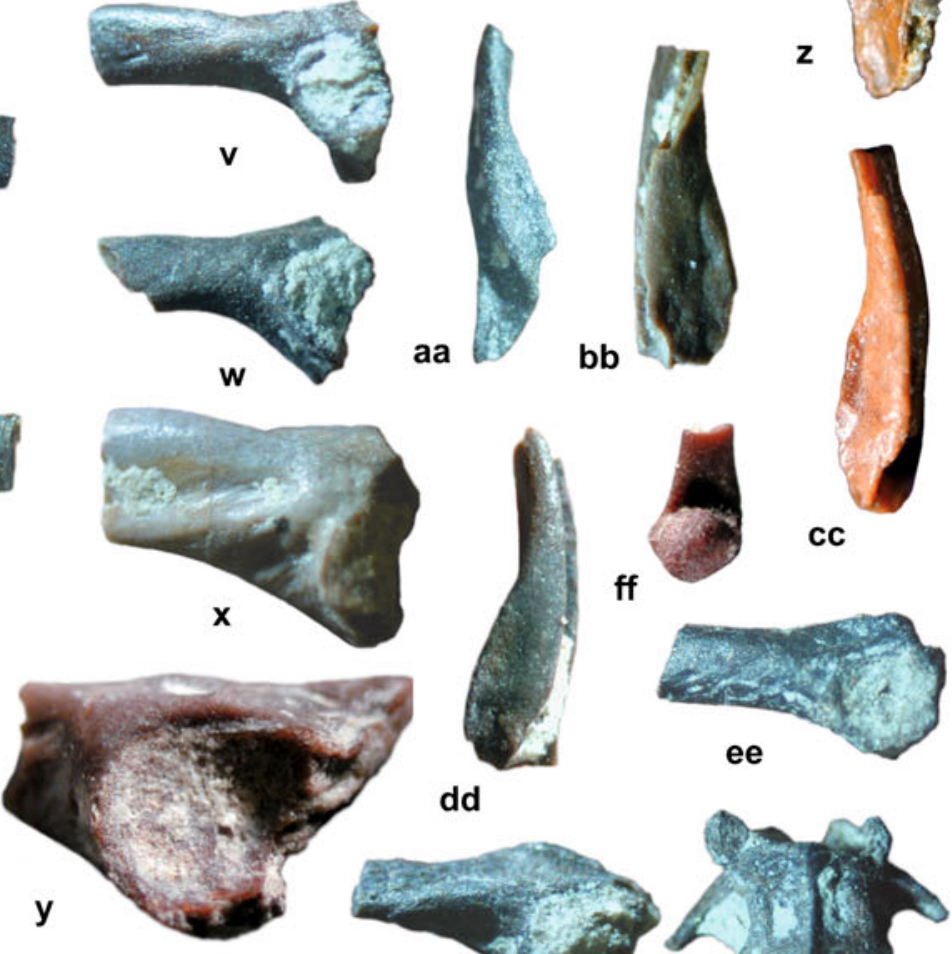

dd
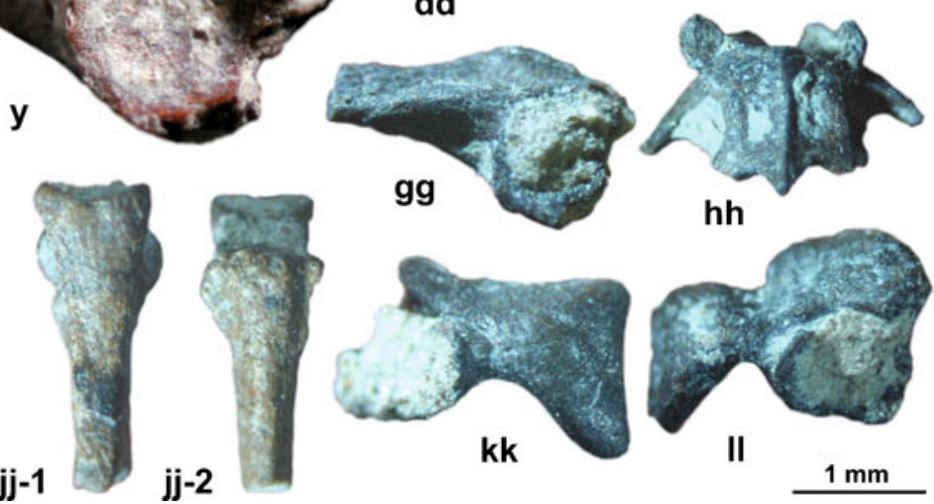
Fig. 13 Bulldog Hollow, Wahweap Creek, White Flats Rd., Mill Creek, Barker Reservoir Rd., Johnson Bench, early Campanian. a Scotiophryne pustulosa. Left ilium (18263) in lateral (a-1) and medial (a-2) views. b Scotiophryne pustulosa. Right ilium (18264) in lateral (b-1) and medial (b-2) views. c Right ilium (18287) in lateral view. d Scotiophryne pustulosa. Left ilium (18283) in lateral (d-1) and medial (d-2) views. e Left ilium (18286) in lateral (e-1) and medial (e-2) views. f Right ilium (18282) in lateral view. $\mathbf{g}$ Right ilium (18284) in medial (g-1) and lateral (g-2) views. h Left ilium (18095) in lateral view. i Right ilium (18100) in lateral view. j Left ilium (18122) in lateral view. k Right ilium (18113) in lateral view. I Left ilium (18099) in lateral view. m Right ilium (18108) in lateral view. $\mathbf{n}$ Left ilium (18114) in lateral view. o Left ilium (18253) in lateral view. p Right ilium (18098) in lateral view. q Left ilium (18288) in lateral view. $\mathbf{r}$ Right ilium (18102) in lateral view. s Right ilium (18104) in lateral view. t Left ilium (18121) in lateral view. u Right ilium (18101) in lateral view. v Left ilium (18106) in lateral view. w Scotiophryne pustulosa. Left ilium (18103) in lateral view. x Left ilium (18247) in lateral view. y Left ilium (19345) in lateral view. $\mathbf{z}$ Right prearticular (18291) in dorsal view. aa Left prearticular (18120) in dorsal view. bb Left prearticular (18254) in dorsal view. cc Right prearticular (18292) in dorsal view. dd Right prearticular (18128) in dorsal view. ee Right humerus (18088) in ventral view. ff Left humerus (19351) in ventral view. gg Left humerus (18112) in ventral view. hh Praesacral vertebra (18092) in dorsal view. ii Urostyle (19344) in dorsal (ii-1), right lateral (ii-2), and ventral (ii-3) views. jj Urostyle (18115) in ventral (jj-1) and dorsal (jj-2) views. kk Left scapula (18116) in outer view. Il Right scapula (18118) in outer view. All are at the same scale

In UMNH 18120 (Fig. 13aa) Meckel's groove opens widely onto the dorsal surface of the bone and its dorsal margin (which continues as the crista paracoronoidea) is curved medially. The coronoid process is long and its dorsal surface is horizontal and flat. UMNH 18254 (Fig. 13bb) also has its coronoid process arch-like, but its medial margin is a sharp edge and its dorsal surface is flat and even moderately convex anteriorly. The dorsal margin of Meckel's groove is abruptly bent medially so in the posterior part of the bone it was not roofed. UMNH 18255 is basically the same as 18120 and 18254 but different in that the coronoid process is declined dorsomedially and that the dorsal margin of Meckel's groove is bent medially as a regular arch, so it is open dorsally in its posterior part.

The prearticular UMNH 18258 (and perhaps the more fragmentary UMNH 18260) differs from other prearticulars in the sample by having the coronoid process sharply bent dorsally in a vertical position and is thickened in its middle (i.e., the highest) part. The upper margin of Meckel's groove is only moderately bent medially, so the groove opens laterally. The posterior part of the ventral surface of the bone runs out in a crista, thus it is not regularly rounded as is the case with other prearticulars in the sample.

The atlas UMNH 18111 has both anterior articular cavities circular and widely separated. Because the median portion is broken away anteriorly, it is apparent in the broken surface that the centrum is pierced by a narrow notochordal canal. The posterior cotyle is rather compressed ventrally. It was probably articulated with an amphicoelous or opisthocoelous second vertebra. The neural arches are broken off. UMNH 18190 is large, with two articular cotyles facing anterolaterally (thus indicating large occipital condyles) and separated by a narrow groove. On the ventral surface of the centrum is a low, but distinct median keel. The posterior condyle indicates that the centrum belonged to a column consisting of procoelous vertebrae.

The presacral vertebra UMNH 18092 (Fig. 13hh) is probably from the middle of the vertebral column, because its diapophyses are declined posteriorly and are laterally compressed, which suggests those processes did not bear ribs. The vertebra was probably slightly non-imbricate, because its zygapophyses extend well beyond the margins of the neural arches. On the dorsal surface, there is a welldeveloped although not very prominent median ridge extending from the anterior margin of the neural arches to the tip of the short neural spine. The centrum is broken away, so it is not possible to reconstruct its shape.

The urostyle UMNH 18115 (Fig. 13jj-1,2) is monocondylar, although the articular cavity is broadly oval and the ventral surface of the bone is rather flat. There is a small triangular transverse process on either side. The dorsal surface is rounded, without median crista. UMNH 19344 (Fig. 13ii-1-3) also has its articular cotyle broadly oval in a horizonal plane. Its dorsal margin somewhat constricts the neural canal, which is dorsoventrally compressed and much narrower that the condyloid fossa. There is one pair of transverse processes on the proximal part of the bone, and two sagittal, low cristae on its dorsal surface. The posterior part of the bone is rounded on its dorsal and ventral surfaces; however, on its lateral surfaces there are two horizontal grooves on each, which begin either in or near small foramina for spinal nerves. UMNH 18181 (Fig. 14m-1,2) also has its condyloid fossa as a horizontally elongated oval. Although it is filled with matrix, the fossa seems to be subdivided by a low median partition. The bone bears no transverse processes.

The scapulae UMNH 18116 (Fig. 13kk) and 18123 are similar to one another; they are characterized by a large medial portion consisting of the glenoid process and acromial portion reaching nearly to the middle of the posterior margin of the bone. In contrast, UMNH 18118 (Fig. 1311) has large pars acromialis and processus glenoidalis, whereas the pars suprascapularis represents only a minor portion of the bone. The sinus interglenoidalis is absent and both parts of the bone are confluent. In inner aspect, the pars acromialis is a thin lamina, whereas the glenoid process is thick. The pars suprascapularis is markedly curved medially. UMNH 18365 is represented only by its middle part and bears no diagnostic features.

The coracoid UMNH 18157 has its posterior margin nearly straight. The posterior half of its medial margin is 
also straight. The lateral end of the bone is damaged, but it was obviously moderately expanded.

The humerus UMNH 18078 is damaged, but it is clear that the medial epicondyle was large (despite the medial crista not being developed) and that the lateral crista extended laterally beyond the level of the articulation head; the latter implies that the lateral epicondyle could have been present. The fossa cubitalis is also developed. UMNH 18125 also has a large medial epicondyle and only a very short medial crista; the epicondyle reaches the level of the distal margin of the caput humeri. The lateral crista (narrow, but longer than the medial crista) joins the lateral and distal surface of the caput. UMNH 18129, although its distal end is broken off, is similar. UMNH 18126 is a distal portion of the humerus with a big medial epicondyle reaching the same level as the caput humeri, whereas the lateral margin of the bone is confluent with the lateral surface of the caput. Neither the medial nor lateral cristae are developed. UMNH 18279 is also fragmentary, but it seems that the lateral epicondyle was entirely absent, as it was in UMNH 18126. UMNH 19351 (Fig. 13ff) is small and its medial epicondyle reaches only the middle of the caput (this is similar to the lateral crista, which joins the lateral surface of the caput at the same level), but extends medially, which makes this humerus also asymmetrical. The fossa cubitalis is well developed. The humerus UMNH 18174 (Fig. 14n) is preserved only as a fragment of the distal part of the bone; however, it is remarkable for lacking the fossa cubitalis.

UMNH 18093 is preserved only as a shaft and its distal portion is broken off. The crista ventralis is thin and prominent, however, it disappears distally on the surface of the bone and does not continue as a rounded ridge towards the medial epicondyle, as is often the case with other humeri. UMNH 18110 is preserved as a distal portion of the shaft (its ventral crista is not included) but differs in that its ventral surface is prominent and continues towards the medial epicondyle as a rounded ridge. The fossa cubitalis is shallow. The lateral and medial cristae are narrow and slightly swollen along their margins.

The ilium 18263 (Fig. 13a-1,2) is a typical representative of the ilia without a dorsal tubercle. It is characterized by a broad oblique groove crossing the dorsal surface of the bone anteromedially. On its inner surface, the groove is delimited by a thin osseous lamina (see arrow in Fig. 13a-2) which, however, disappears after a short distance. This is also characteristic of the holotype ilium of Scotiophryne pustulosa (Estes 1969, Fig. 1d). Parallel to the lamina runs a less prominent ridge, thus delimiting a less developed groove. The acetabulum does not seem to be extensive, but its margins protrude well above the surface of the bone. UMNH 18097 is similar in that its oblique groove makes, in the lateral view, a distinct depression, when seen in lateral view, in the dorsal margin of the bone. The acetabulum is rather small, not reaching the level of the anteroventral margin of the bone. However, the crista on the medial surface is not as prominent as in UMNH 18263 (see Fig. 13a-2). UMNH 18283 (Fig. 13d-1,2) is also similar, but it is smaller. Its osseous lamina continues posteriorly as the rising dorsal margin of the acetabular portion of the ilium and terminates on the tip of the pars ascendens. UMNH 18264 (Fig. 13b-1,2), 18103 (Fig. 13w) and, possibly, also UMNH 18096 are similar to UMNH 18283 , except that in each their osseous lamina is weakly developed and their acetabulum is shallow and prominent from the surrounding bone. All these ilia may also be referred to Scotiophryne.

UMNH 18106 (Fig. 13v) is similar in lateral view to UMNH 18263, but its acetabulum has a prominent, vertical anteroventral flange that continues onto the posterior part of the bone and, consequently, the acetabulum is located completely (including its posterior margin) on the ilium. A sharp perpendicular crista splits from its ventral margin posteroventrally and runs towards the lower margin of the pars descendens. Between this crista and the margin of the acetabulum there is a deep triangular fossa (which, however, was undoubtedly filled with cartilage of the pubis in the living animal). The dorsal rim of the acetabulum is just a margin of a depression in the bone and is not continuous with the anterior flange of the acetabulum. Instead, the anterior flange terminates on the inner surface of the acetabulum. The iliac shaft is moderately convex dorsally and is separated from the pars ascendens by a shallow depression which, however, does not continue as a groove (delimited posteroventrally by a crista) onto the medial surface.

UMNH 19345 (Fig. 13y) has its pars ascendens only slightly declined dorsally and its dorsal margin is nearly a straight prolongation of the dorsal margin of the shaft. Both are separated by only an indistinct elevation. The acetabulum is large, with its margins (including the dorsal portion) very prominent above the surface of the surrounding bone. On the medial surface of the bone, a distinct though low and rounded oblique crista runs down from the dorsal margin of the pars ascendens onto the medial surface of the shaft, and a similar, parallel crista runs down from the low elevation on the dorsal margin of the bone. In this respect, the specimen is similar to UMNH 18264 (see Fig. 13b-1). UMNH 18247 (Fig. 13x) has a small but anteroventrally prominent acetabulum that is shallow and declined posteriorly. A rounded ridge runs from the anterior margin of the acetabulum towards the lower margin of the shaft. Above this ridge is a shallow but distinct depression. The dorsal margin of the bone is broad and depressed between the pars ascendens and the shaft. A clear, although not well developed pair of parallel ridges, similar to those in UMNH 18264 (Fig. 13b-1), runs obliquely on the inner 
surface. UMNH 18284 (Fig. 13g-1,2), although rather fragmentary, may also be attributed to this group. UMNH 18117 has a large pars ascendens and rather small acetabulum that does not exceed the anteroventral margin of the bone. Its acetabulum is elevated, shallow and horizontally ellipsoid, and its dorsal margin is markedly prominent. Similar, though fragmentary, are UMNH 18252, 18285, and 18287 (Fig. 13c). UMNH 18286 (Fig. 13e-1,2) is also similar to UMNH 18284 (Fig. 13g-1,2), especially in having the oblique groove crossing the dorsal surface and the osseous lamina (although this is not as prominent as on UMNH 18263; Fig. 13a-2), but UMNH 18286 differs from them by its large acetabulum that extends past the anteroventral margin of the bone (marked by arrow in Fig. 13e-2). UMNH 18288 (Fig. 13q) is similar in the general shape of the bone and the anteroventral margin of its acetabulum is markedly raised above the level of the surrounding bone.

The ilium UMNH 18102 (Fig. 13r) is characterized by its prominent but shallow acetabulum and by its robust and thick pars ascendens. As is the case with many other ilia without a dorsal tubercle, the dorsal margin of the shaft is separated from the pars ascendens by a broad depression that continues as a shallow oblique groove onto the medial surface of the bone.

UMNH 18282 (Fig. 13f) is small, but generally similar to other ilia in the sample. Anteromedially, its rather small acetabulum is raised above the surface of the bone, whereas dorsally it is a mere depression in the bone. Potentially the bone could be attributed to a juvenile, but its well-ossified nature contradicts such an interpretation.

Still among the ilia without a dorsal tubercle, UMNH 18104 (Fig. 13s) is characterized by its pars ascendens and pars descendens whose dorsal and ventral margins are strongly divergent from the long axis of the bone. The acetabular region is extremely compressed which indicates that the ilia of the left and right side were close to each other. The acetabulum is, compared with other ilia, very small. UMNH 18088 (Fig. 13ee) is also different from other ilia without a dorsal tubercle in that it has a small and shallow acetabulum located ventrally on the acetabular region. The dorsal margin of the pars ascendens is moderately declined from the long axis of the bone. UMNH 18253 (Fig. 13o) is very fragmentary, but peculiar in its large acetabulum and extremely slender shaft (directed to the left in Fig. 13o). It also belongs to the category of the ilia without a dorsal tubercle.

Nearly all ilia from Campbell Canyon lack the dorsal tubercle, and if there is some protuberance on the dorsal margin of the ilium (e.g., in UMNH 18137), it is low, indistinct, and located posteriorly, not at the level of the anterior margin of the acetabulum. The ilium UMNH 18134 (Fig. 14h) is fragmentary, but characterized by having its acetabulum located nearly completely on the ilium (apparently not extending onto the ischium); the acetabulum has prominent margins, including its dorsal portion, so it is slightly declined ventrally. The dorsal margin of the bone is straight, except for the tip of the pars ascendens which is moderately declined dorsally. The inner surface of the bone is smooth. UMNH 18137 is similar, but with a small tubercle on its dorsal margin, above the acetabular flange. In contrast, UMNH 18138 has a comparatively small acetabulum whose dorsal margin is not elevated and its pars ascendens is clearly, although not greatly, declined dorsally. The inner surface of its acetabular region is flat and smooth. UMNH 18139 (Fig. 14d) is only a small fragment, but the anterior margin of its acetabulum was prominent and there was an oblique crista on the outer surface of the proximal section of the shaft. The inner surface is smooth. UMNH 18140 (Fig. 14f) is small and it seems that in lateral view the margins of its shaft diverge slightly. UMNH 18150 has its shaft tapering moderately anteriorly, the acetabulum is small with rounded margins not prominent in its dorsal portion, and a shallow, oblique groove running on its inner surface. The pars ascendens is only moderately inclined dorsally. UMNH 18154 (Fig. 14b) is an iliac shaft that is markedly convex dorsally. The dorsal margin of the pars ascendens continues as a rounded ridge onto the medial surface of the bone where it disappears. Anterior to this rounded ridge is an oblique groove that does not continue onto the medial surface of the bone. UMNH 18180 (Fig. 14j-1,2) is similar to UMNH 18154 in that it has an oblique groove crossing the dorsal margin of the bone; however, that groove is accompanied posteriorly by a double crista reaching the medial surface of the bone. There are also several fragments of iliac shafts in the sample, e.g., UMNH 18177, 18335, 18338 (Fig. 14k-1,2), all of which are similar to UMNH 18154 (Fig. 14b) in that they are convex dorsally and they have more or less distinct oblique crista coming from the margin of the pars ascendens and extending onto the medial surface. In some (e.g., UMNH 18182, Fig. 141-1,2), this crista can be prominent and the groove broad and deep (see arrow in Fig. 141-2), because its anterolateral margin is formed by a robust mound coming from the anterodorsal margin of the acetabulum (Fig. 14l-1); this mound continues anteriorly as the dorsal margin of the shaft. By contrast, in UMNH 18183 (Fig. 14e), the oblique crista coming from the pars ascendens is less prominent.There are also ilia (e.g., UMNH 18184, Fig. 14g) that are similar in general morphology to those just described, except their inner surface is smooth and they have no oblique crista.

UMNH 18320 (Fig. 14a) has its dorsal surface nearly straight; the pars ascendens is only moderately declined dorsally and there is an indistinct, shallow oblique groove separating it from the dorsal surface of the shaft. The 

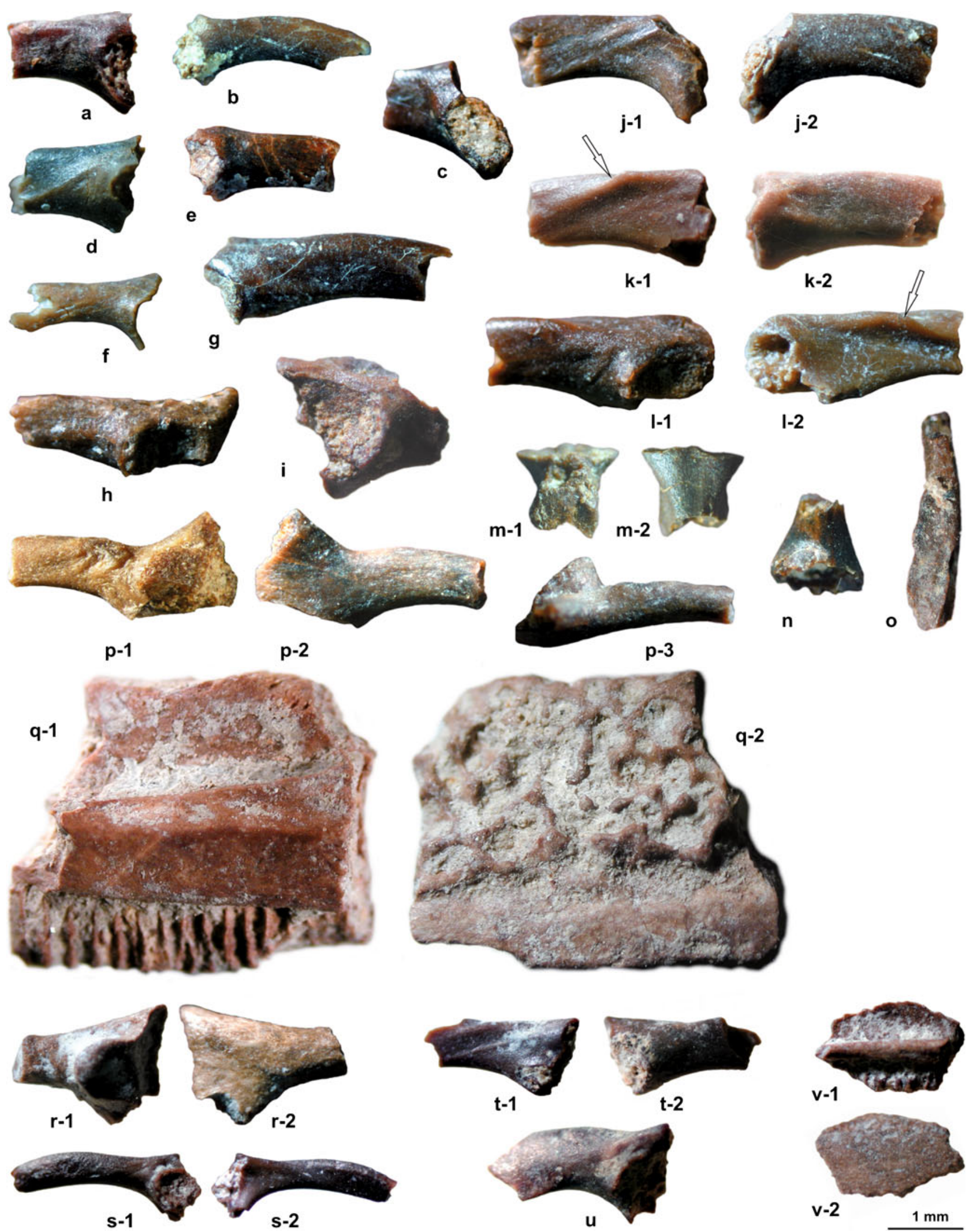
Fig. 14 Campbell Canyon and Websters Flat, early or middle Campanian. a Left ilium (18320). b Right ilium (18153). c Left ilium (18188). d Left ilium (18139). e Right ilium (18183). f Left ilium (18140). g Right ilium (18184). h Left ilium (18134). i Right ilium (18321). j Right ilium (18180) in inner (j-1) and outer (j-2) views. $\mathbf{k}$ Scotiophryne pustulosa. Right ilium (18338) in inner (k-1) and outer (k-2) views. I - Scotiophryne pustulosa. Left ilium (18182) in outer (l1) and inner (l-2) views (position of the oblique groove marked by arrow). m - Urostyle (18181) in dorsal (m-1) and ventral (m-2) views. $\mathbf{n}$ - Humerus (18174). $\mathbf{0}$ - prearticular (18185) in dorsal view. $\mathbf{p}$ - cf. Nezpercius dodsoni. Left ilium (18319) in lateral (p-1), medial (p-2) and dorsal (p-3) views. q - Left maxilla (18502) in inner (q-1) and outer (q-2) views. $\mathbf{r}-$ cf. Nezpercius sp. Left ilium (18303) in outer (r-1) and inner (r-2) views. s - Left ilium (18304) in outer (s-1) and inner (s-2) views. $\mathbf{t}$ - Scotiophryne pustulosa. Right ilium (18307) in inner (t-1) and outer (t-2) views. $\mathbf{u}$ - Left Ilium (18305) in lateral view. $\mathbf{v}$ - Maxilla (18306) in inner (v-1) and outer (v-2) views. All are at the same scale

acetabulum does not extend beyond the anteroventral margin of the bone, as is also the case with UMNH 18321 (Fig. 14i), 18332, and 18336.

UMNH 18319 (Fig. 14p-1-3) differs markedly from all other ilia from Campbell Canyon in that the anterior part of the acetabulum is extremely prominent, so that the acetabulum is strongly declined posteriorly and very shallow. Moreover, the anterodorsal surface of the shaft bears an elevated tuberosity separated from the anterior margin of the acetabulum by a broad depression. The acetabular region of the bone is thick, which is especially evident in posterior view. The anterodorsal margin of the pars ascendens is strongly declined from the long axis of the bone. The shaft is convex dorsally and moderately oval in cross-section. The inner surface of the bone is smooth and devoid of any ridges or scars. UMNH 18303 (Fig. 14r$1,2)$, from Websters Flat, also has the anterior portion of the acetabulum extremely prominent and its surface convex. Due to this, the acetabulum is declined posteroventrally. The proximal section of the iliac shaft is slender, and the pars ascendens and descendens are subequal. The posterior side of the bone is concave which suggests that it was completed by cartilage. In dorsal view, the acetabular region is convex medially. The medial surface of the bone is smooth. These two ilia bear some characters of Nezpercius (Blob et al. 2001). The ilia UMNH 18105 and 18109 (both unfigured) from Barkers Reservoir Road are similar in the shape of their acetabulum, which is horizontally elongate and unusually shallow, yet anteriorly and dorsally it is very prominent.

UMNH 18304 (Fig. 14s-1,2) is a tiny ilium with a flat acetabulum that does not extend neyond the outlines of the bone. Its shaft is convex both dorsally and laterally. The pars ascendens is rather prominent and its anterodorsal margin continues onto the medial surface of the bone as a low rounded ridge which, however, does not delimit any groove. UMNH 18307 (Fig. 14t-1,2) is larger and its acetabulum is shallow and declined posteriorly. The dorsal margin of the bone is nearly straight and the medial surface is almost flat, with two low parallel ridges running anteroventrally towards the lower margin of the shaft.

Among the ilia with a dorsal tubercle, UMNH 18095 (Fig. 13h) is a typical representative. It is characterized by its straight and slender iliac shaft and by its dorsal margin of the pars ascendens being parallel to the long axis of the bone. The acetabulum is large, extending close to the dorsal margin of the bone and to, or slightly beyond, its anteroventral margin. The dorsal tubercle is large, triangular, slightly declined anteriorly, and laterally compressed. Its medial surface is smooth. UMNH 18121 (Fig. 13t) is similar in proportions of the shaft and shape of the dorsal tubercle, but its acetabulum is extremely large, covering nearly the entire acetabular region and its dorsal tubercle is compressed into a thin lamina. UMNH 18100 (Fig. 13i) seems to belong to these ilia as well, although its shaft is not as slender. UMNH 18113 (Fig. 13k), 18101 (Fig. 13u), 18122 (Fig. 13j), and 18099 (Fig. 131) also each have a triangular dorsal tubercle and a large acetabulum (although the acetabulum is not so large in UMNH 18113 and 18101 that it extends beyond the anteroventral margin of the bone), but the dorsal margin of their pars ascendens is slightly declined posteroventrally. Their medial surface is smooth, but with a deep triangular depression near the posterior margin of the bone. UMNH 18112 (Fig. 13gg) is similar to UMNH 18099 (Fig. 131) except for having prominent rounded ridge that runs from the anterior margin of the acetabulum towards the lower margin of the shaft. In UMNH 18101, the dorsal margin of the acetabulum is prominently developed as a sharp crista.

UMNH 18098 (Fig. 13p) is unique among all other ilia in having a large acetabulum that extends almost to the dorsal margin of the bone and slightly beyond its anteroventral margin. The acetabulum is narrower anteriorly and it extends this narrow anterior part onto the proximal portion of the shaft. The dorsal tubercle is low but extensive antero-posteriorly; its anterior margin continues on the medial surface of the bone as an oblique rounded ridge. The pars ascendens seems not to be divergent from the long axis of the bone. UMNH 18114 (Fig. 13n) is similar in that it also has a large acetabulum with prominent dorsal margin, and in that the pars ascendens is a straight continuation of the dorsal margin of the shaft. The dorsal tubercle is moderate in size. The medial surface of the bone is smooth, except for the extensive contact area for the opposite ilium.

The ilium UMNH 18108 (Fig. 13m) is fragmentary, but remarkable because it differs from all other anuran ilia considered in this study by the combination of a large acetabulum with a prominent sharp margin (including its 
dorsal section), a large dorsal tubercle with a rugose lateral surface, and flat medial surface that continues onto the dorsal tubercle without any distinct border. The inner surface of the preserved proximal section of the shaft is also flat, so the shaft is " $\mathrm{D}$ " shaped in cross-section.

The ilium UMNH 18305 (Fig. 14u) from Websters Flat is characterized by a shaft which is markedly convex dorsally and compressed laterally and by an extremely thick acetabular region. The acetabulum is not preserved. Judging by the thick acetabular region, which might be a contact surface for the puboischiadic cartilage, this ilium may belong to a caudate.

\section{Late Campanian (Figs. 15A, B and 16A, B)}

Kaiparowits Formation, Blue Wash Quarry, localities 24 and 25; Fossil Ridge, localities 51, 54, 56; The Blues, locality 108; South Rim, MNA locality 1004; Howard's uppermost Kaiparowits locality, locality 1078

Material: 1 sphenethmoid (13279, Fig. 15Bd-1-3); 2 frontoparietals (13225, Fig. 15Aj-1,2; 18444, Fig. 16Ae1,2); 3 premaxillae (13216; 13306, Fig. 15Am-1,2; 19316, Fig. 16Ai-1,2); 21 maxillae (13217; 13224, Fig. 15Ah; 13254, Fig. $15 \mathrm{Al} 1,2 ; 13267$, Fig. 15Ak-1,2; 13268, Fig. 15Bb-1,2; 13269, Fig. 15Be-1,2; 13270, Fig. 15Ba1,$2 ; 13278 ; 13338$, Fig. 15Ao-1,2; 13352; 13353, Fig. 15An-1,2; 18437, Fig. 16Ak-1,2; 18438, Fig. 16Am1,2; 18446, Fig. 16Al-1,2; 18447, Fig. 16Aj-1,2; 18448, Fig. 16An-1,2; 18449, Fig. 16Aa-1,2; 18450; 18452, Fig. 16Bd-1,2; 19310, Fig. 16Ab-1,2; 19339); 8 prearticulars (13201; 13204, Fig. 15Ac; 13207, Fig. 15Aq; 13326, Fig. 15Aw; 18340, Fig. 15Ar; 19315, Fig. 16Ac; 19324, Fig. 16Ad; 19334); 2 presacral vertebrae (13333, Fig. $15 \mathrm{Ag} ; 18343)$; 5 urostyles (13307, Fig. 15At; 13318, Fig. 15Au; 13328, Fig. 15Av; 13342, Fig. 15Ap; 13385, Fig. 16Ba-1-4); 3 scapulae (13273; 13312, Fig. 15Ai-1,2; MNA V7716, Fig. 15As-1,2); 15 humeri (13228; 13272, Fig. 15Ab; 13281, Fig. 15Bf; 13283; 13303; 13308, Fig. 15Ax; 13320; 13322, Fig. 15Ay; 13331; 13341, Fig. 15Aaa; 13356, Fig. 15Az; 18339, Fig. 15Bc; 18431, Fig. 16Ag; 18452, Fig. 16Ah; 19317); 11 radioulnae (13192; 13193; 13197; 13205; 13296; 13297; 13319; 13329; 13330; 13423; 19322); 13 ilia (13206; 13209; 13282; 13323, Fig. 15Af; 13334, Fig. 15Ae; 13336, Fig. 15Aa; 13424; 18342; 18435, Fig. 16Af; 19311, Fig. 16Bb; 19313; 19314, Fig. 16Bc; 19330, Fig. 15Ad$1,2)$; 1 pair of ischia (18445, Fig. 16Ao-1,2); 8 femora (13187; 13188; 13191; 13194; 13298; 13299; 13340; 19329); 15 tibiofibulae $(13185 ; 13186 ; 13189 ; 13190$; 13294 ; 13295 ; $13314 ; 13315 ; 13332 ; 13383$; 13384; $18189 ; 18192 ; 19325 ; 19331)$.
Description: The sphenethmoid UMNH 13279 (Fig. 15Bd1-3) belongs to a larger anuran, perhaps the same taxon represented by the medium-sized maxillae (e.g., UMNH 13270; Fig. 15Ba-1,2). As indicated by its nasal septum, the sphenethmoid was well ossified. The anterior portion of the frontoparietal foramen is preserved; that foramen does not correspond to the frontoparietal incrassation in UMNH 13225 (Fig. 15Aj-1,2). Judging by a pair of articular facets on the dorsal surface of the bone, the complementary frontoparietals were paired.

Two frontoparietals are available. UMNH 13225 (Fig. 15Aj-1,2) is smooth and flat on its dorsal surface, which passes into the lateral, vertical part with a sudden break. A distinct frontoparietal incrassation is on its inner surface. In contrast, UMNH 18444 (Fig. 16Ae-1,2) belongs to a much larger anuran. It preserves the lateral portion of the bone, the dorsal surface of which is covered by a pitand-ridge sculpture. On the inner surface, there is a perpendicular crista for articulation with the lateral wall of the braincase.

The premaxillae UMNH 13306 (Fig. 15Am-1,2) and 13216 are very small and have thin horizontal lamina, with the medial margin forming a sharp edge. On the inner surface of the bone, there is a distinct rounded ridge in the middle of extensive pars facialis and, where the ridge meets the horizontal lamina, there is a well-developed fossa on the side where the pars facialis is declined. The outer surface of the bone is smooth, but with several large pits. In contrast, UMNH 19316 (Fig. 16Ai-1,2) is different in that the horizontal lamina is represented by a break between the inner vertical surface of the bone and the horizontal lower surface. The number of tooth positions is 11 or 12 . There is a small but rather deep depression delimited by rounded ridges on either side of the frontal process. The outer surface of the bone is smooth.

The maxilla UMNH 13338 (Fig. 15Ao-1,2) has its horizontal lamina widely rounded, but it narrows and tapers towards the anterior end. Its outer surface is almost smooth, except for being covered anteroventrally by irregular, tiny horizontal grooves. In UMNH 13353 (Fig. 15An-1,2) the horizontal lamina is broad and widely rounded, slightly concave dorsally where it supported the palatoquadrate bar in the living animal, and it terminates posteriorly as a thin lamina perpendicular to the vertical portion of the bone. Because its posterior margin seems to be damaged, it is not clear whether the horizontal lamina was terminated by a pterygoid process. The dorsal margin of the vertical part of the bone does not extend in the processus zygomaticomaxillaris. The ventral part of the outer surface of the bone is smooth, whereas the dorsal part is covered by a vermicular net of tiny grooves. UMNH 13224 (Fig. 15Ah) and 13263 are small, with the horizontal lamina broad, thin, and with a rounded margin. Their outer surfaces are smooth. UMNH 
18449 (Fig. 16Aa-1,2) and 18450 may also be from the same taxon as UMNH 13224 and 13263.

UMNH 13254 (Fig. 15Al-1,2) has a horizontal lamina with a widely rounded and swollen margin and is moderately tapered posteriorly. The dorsal surface of the lamina slants down posteriorly as a groove separating the margin of the horizontal lamina from the vertical part of the bone. Consequently, the margin of the lamina continues posteriorly as a short process (marked by arrow in Fig. 15Al-1). The orbital margin is a sharp edge. The outer surface of the bone is smooth.

UMNH 13267 (Fig. 15Ak-1,2) is a fragment of a long and slender maxilla. The horizontal lamina is rather extended horizontally at its posterior end, thus producing a sort of the pterygoid process. On the inner surface of the bone, at the level of the anterior border of the orbit, there is an oblique crista (Fig. 15Ak-1). The outer surface of the bone is smooth.

UMNH 13268 (Fig. 15Bb-1,2), 13269 (Fig. 15Be-1,2) and, probably, also 19339 represent large and robust maxillae. In each the horizontal lamina is narrow, but deep and widely rounded along its margin, extends horizontally and is markedly compressed dorsoventrally at its posterior end. The groove for the palatoquadrate bar runs along the line of attachment of the horizontal lamina to the vertical part of the bone. On the inner surface of the zygomaticomaxillar process are irregular grooves and ridges oriented parallel with the orbital margin. The dorsal surface of the horizontal lamina slants down from the zygomaticomaxillar process towards its extended posterior part (Fig. 15Be-2). The main articular facet for attachment with the pterygoid is on its posterior surface (see arrow in Fig. 15Be-2). The outer surface of the bone, except for its lowermost part, is covered by a pit-and-ridge sculpture. The posterior end of the bone is a rounded point. UMNH 13270 (Fig. 15Ba-1,2) is similar but smaller and more gracile. Its orbital section is very low and the orbital margin is rounded. On its outer surface, the pits of the sculpture tend to fuse into posteriorly oriented grooves.

There is a group of large maxillae in the sample from the Blues locality that are characterized by pustular sculpture. UMNH 18437 (Fig. 16Ak-1,2) has irregular ridges that run parallel with the orbital margin along the inner surface of the zygomaticomaxillar process and a deep and narrow horizontal lamina that extends medially along its posterior section, but does not extend posteriorly to produce a pterygoid process. The posterior end of the tooth row is slightly behind the level of the posterior end of the horizontal lamina. The bone does not extend posteriorly in a posterior process. UMNH 18446 (Fig. 16Al-1,2) is similar, but has a comparatively large foramen piercing the posterior surface of the horizontal lamina near its junction with the vertical part of the bone. In UMNH 18437
(Fig. 16Ak-2) that foramen is obscured by matrix. UMNH 18447 (Fig. 16Aj-1,2) is similar; moreover, below the orbital margin the horizontal lamina is deep and narrow (so it appears merely as a longitudinal convexity on the vertical part of the bone), and a horizontal crista extends anteriorly from the lowest point of the orbital margin (see arrow in Fig. 16Aj-2). UMNH 18451 (Fig. 16Bd-1,2) may also be associated with this group of maxillae because of its pustular sculpture and a narrow, deep horizontal lamina whose dorsal surface is confluent with, and not clearly distinguishable from, the inner surface of the vertical part of the bone. The pustular sculpture is absent along the anteriormost and ventral portions of the bone, which instead are smooth. These maxillae are referrable to Scotiophryne pustulosa, a taxon described by Estes (1969) from a locality (Bug Creek Anthills; now interpreted as containing a mix of latest Maastrichtian and earliest Paleocene fossils) in the Hell Creek Formation, Montana. UMNH 19310 (Fig. 16Ab-1,2) bears pustular sculpture similar to that in UMNH 18437, 18446, and 18447; however, it is smaller and morphology of its inner surface is different.

Another group of large maxillae from the Blues locality bear pit-and-ridge sculpture, but part of the outer surface remains smooth. UMNH 18438 (Fig. 16Am-1,2) has thin horizontal lamina, with a deep horizontal groove above the line of attachment with the vertical part of the bone. It is comparatively low along its orbital section. UMNH 18448 (Fig. 16An-1,2) is a fragment of the anterior part of a maxilla in which the horizontal lamina is deep, narrow and widely rounded, and the anterior part of the bone is smooth.

The prearticulars are preserved as fragments from different parts of the bone, so their comparisons are limited. UMNH 13326 (Fig. 15Aw) has its coronoid process elongated, with the dorsal surface flat anteriorly and rather convex posteriorly. The crista paracoronoidea is gradually curved medially, without a sudden break. The lower surface of the bone is rounded, without any longitudinal crista. UMNH 13207 (Fig. 15Aq) differs from UMNH 13326 in that within the extent of the coronoid process the sulcus Meckeli is not roofed, and that the paracoronoid crista is developed only in its posterior part where it joins the medial margin of the bone. On the lateral surface of the bone, there is a distinct depression the ventral margin of which forms a protruding crista. UMNH 18340 (Fig. 15Ar) has its posterior part, including Meckel's groove, slender and narrow, and the medial margin of the coronoid process is not prominently extended beyond the medial surface of the bone. Its dorsal surface is a shallow concavity. UMNH 13204 (Fig. 15Ac) has an elongated and narrow coronoid process, with its surface flat anteriorly and deeply concave posteriorly. The roof of Meckel's groove is slightly curved medially in its posterior section, so the groove is exposed. 
This part of Meckel's groove is separated from the posterior depression of the coronoid process by the crista paracoronoidea which, however, does not reach the posterior margin of the bone. UMNH 19315 (Fig. 16Ac) and 19324 (Fig. 16Ad) also have an elongated coronoid process; however, its dorsal surface is concave and the medial margin is thickened and slightly raised. Both differ from one another only by size.

Only a fragment of the presacral vertebra preserving fused neural arches was recovered (UMNH 13333, Fig. $15 \mathrm{Ag}$ ) and indicates the occurrence of a mediumsized anuran. The posterior margin runs out into a slender process extending beyond the level of the postzygapophyses. On the dorsal surface midline is a rounded ridge that does not extend posteriorly. UMNH 18343 is an amphicoelous centrum with its notochordal canal obliterated.

The urostyle UMNH 13307 (Fig. 15At) has the condyloid fossa horizontally oval, with its dorsal margin along the midline widely depressed; this results in the condyloid fossa partly subdivided. The vertebral canal is also dorsoventrally compressed. There are a pair of transverse processes that are thick anteriorly, but thin posteriorly. Their line of attachment to the bone is slightly declined posteroventrally and they continue posteriorly as low, horizontal ledges similar to the longitudinal keel on the dorsal side of the bone. Its lower surface is smooth and widely rounded. UMNH 13318 (Fig. 15Au) is basically similar, except the transverse processes are not prominent laterally and the dorsal surface of the bone is rounded. UMNH 13328 (Fig. 15Av) is larger than the previous two urostyles. It also has a horizontally oval condyloid fossa, with its lower margin extending anteriorly. The vertebral canal is dorsoventrally compressed and its dorsal flange is turned up. The transverse processes are triangular laminae that taper posteriorly. On the midline, there is a narrow dorsal keel. UMNH 13342 (Fig. 15Ap) has its neural part broken off, but because its condyloid fossa is horizontally oval, it can be associated with the urostyles UMNH 13307 and 13318. The condyloid fossa in UMNH 13385 (Fig. 16Ba-1-4) is only slightly compressed dorsoventrally and lacks a median partition. The vertebral canal is nearly the same diameter as the condyloid fossa. UMNH 13385 also includes two postsacral vertebrae, which are partly separated from each other by a constriction. The anterior postsacral vertebra has a pair of lateral swellings, with a tiny spinal process between them and with a large, posteriorly facing foramen on each side. The second postsacral vertebra has a pair of triangular diapophyses directed laterally, with small foramina below them. The spinal process is a low rounded keel that continues posteriorly on the laterally compressed bone. Several irregular foramina on either side open into horizontal grooves running posteriorly.
Fig. 15 A Fossil Ridge, South Rim, Howards uppermost Kaiparowits locality, late Campanian. a Right ilium (13336) in lateral view. b Left humerus (13272) in ventral view. c Right prearticular (13204) in dorsal view. d Right ilium (19330) in inner (d-1) and outer (d-2) views. e Left ilium (13334) in lateral view. f Right ilium (13323) in lateral view. g Presacral vertebra (13333) in dorsal view. h Left maxilla (13224) in inner view. i Left scapula (13312) in dorsal (i-1) and ventral (i-2) views. j Right frontoparietal (13225) in dorsal (j-1) and ventral (j-2) views. k Maxilla (13267) in inner (k-1) and outer (k2) views. I Right maxilla (13254) in inner (l-1) and outer (l-2) views. $\mathbf{m}$ Left premaxilla (13306) in inner (m-1) and outer (m-2) views. $\mathbf{n}$ Right maxilla (13353) in outer (n-1) and inner (n-2) views. o Left maxilla (13338) in outer (o-1) and inner (o-2) views. p Urostyle (13342) in dorsal view. q Left prearticular (13207) in dorsal view. $\mathbf{r}$ Right prearticular (18340) in dorsal view. s Scapula (MNA V7716) in inner (s-1) and outer (s-2) views. t Urostyle (13307) in dorsal view. u Urostyle (13318) in dorsal view. v Urostyle (13328) in dorsal view. w Left prearticular (13326) in dorsal view. Position of Meckel's groove is marked by arrow on the left side, margin of the coronoid process by arrow on the right side. $\mathbf{x}$ Left humerus (13308) in ventral view. y Left humerus (13322) in ventral view. $\mathbf{z}$ Right humerus (13356) in ventral view. aa Right humerus (13341) in ventral view. All are at the same scale. B Fossil Ridge, late Campanian. a Right maxilla (13270) in outer (a-1) and inner (a-2) views. b Right maxilla (13268) in outer (b-1) and inner (b-2) views. c Right humerus (18339) in ventral view. d Sphenethmoid (13279) in ventral (d-1), dorsal (d-2) and anterior (d-3) views. e Right maxilla (13269) in outer (e-1) and inner (e-2) views. f Humerus (13281) in ventral view. All are at the same scale

The scapula UMNH 13312 (Fig. 15Ai-1,2) has a vertical glenoid cavity, oriented obliquely to the long axis of the bone. The sinus interglenoidalis was not developed. On the inner side of the bone there is a prominent mound in the midline, whereas the anterior and posterior parts of the bone are thin.

MNA V7716 (Fig. 15As-1,2) is, according to its flattened lateral portion and bipartite medial portion, presumably a tiny anuran scapula. Its medial part is bifurcated in two subequal parts, each of them terminated by a flat articular facet. The anterior one is oriented outside, the posterior one inside. The outer surface of the bone is moderately convex, whereas the inner surface is concave.

The humerus UMNH 13308 (Fig. 15Ax) has a comparatively large caput, with the medial epicondyle reaching only to the level of three-quarters of its proximo-distal diameter. The medial crista is absent and the lateral one joins the lateral surface of the caput. At the level where the lateral crista reaches the surface of the caput is a hook-like structure (marked by arrow in Fig. 15Ax) pointing ventrally and slightly distally. At the base of the caput, the bone is dorsoventrally thin; consequently, the caput is prominent ventrally and the fossa cubitalis is open laterally. UMNH 13322 (Fig. 15Ay) is similar, but its medial epicondyle is more prominent distally so that it reaches nearly to the distalmost end of the caput. The hook-like thickening is also developed. UMNH 13356 (Fig. 15Az), although preserved only as the shaft lacking its distal portion, also belongs to this group, as indicated by the fossa cubitalis 


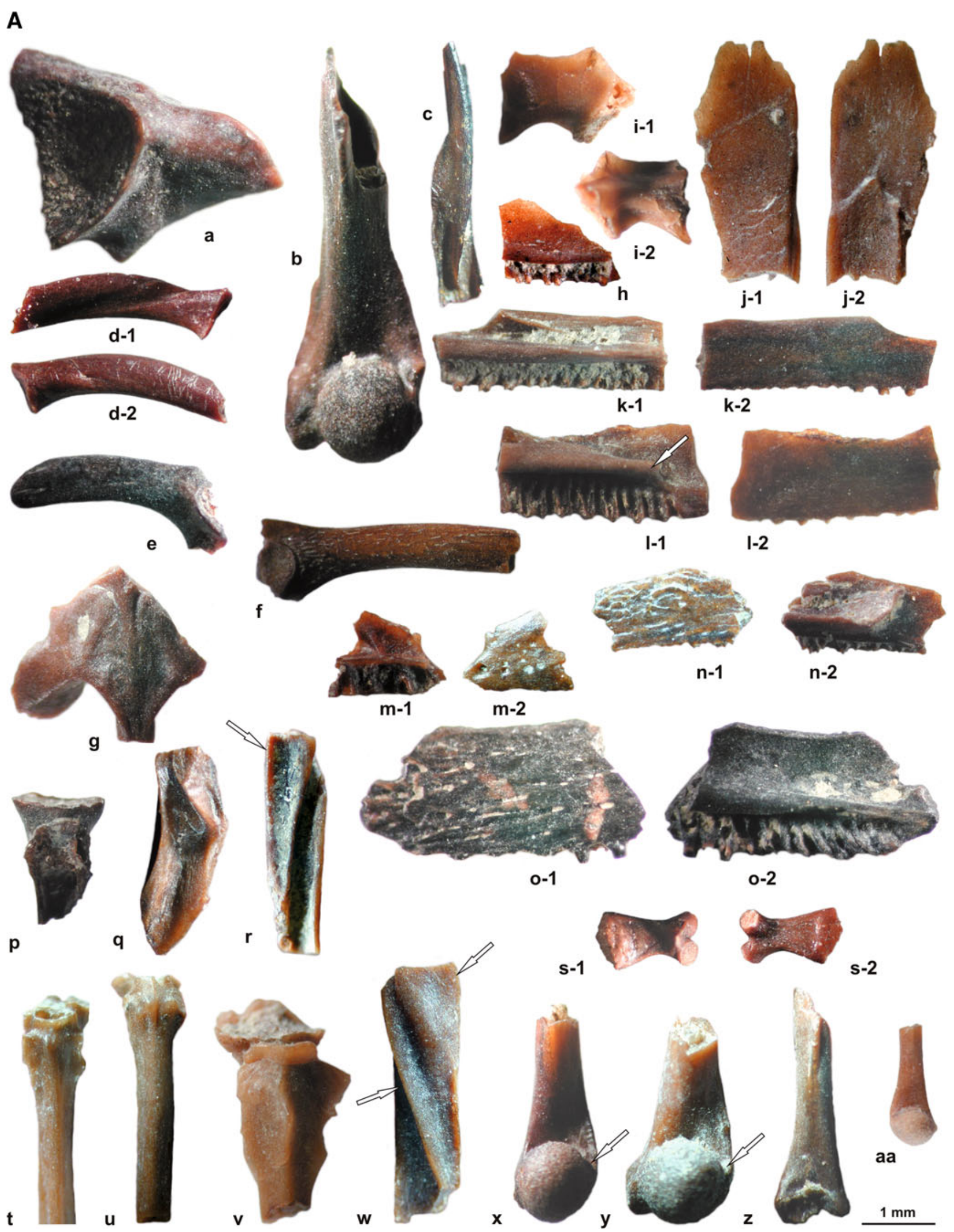



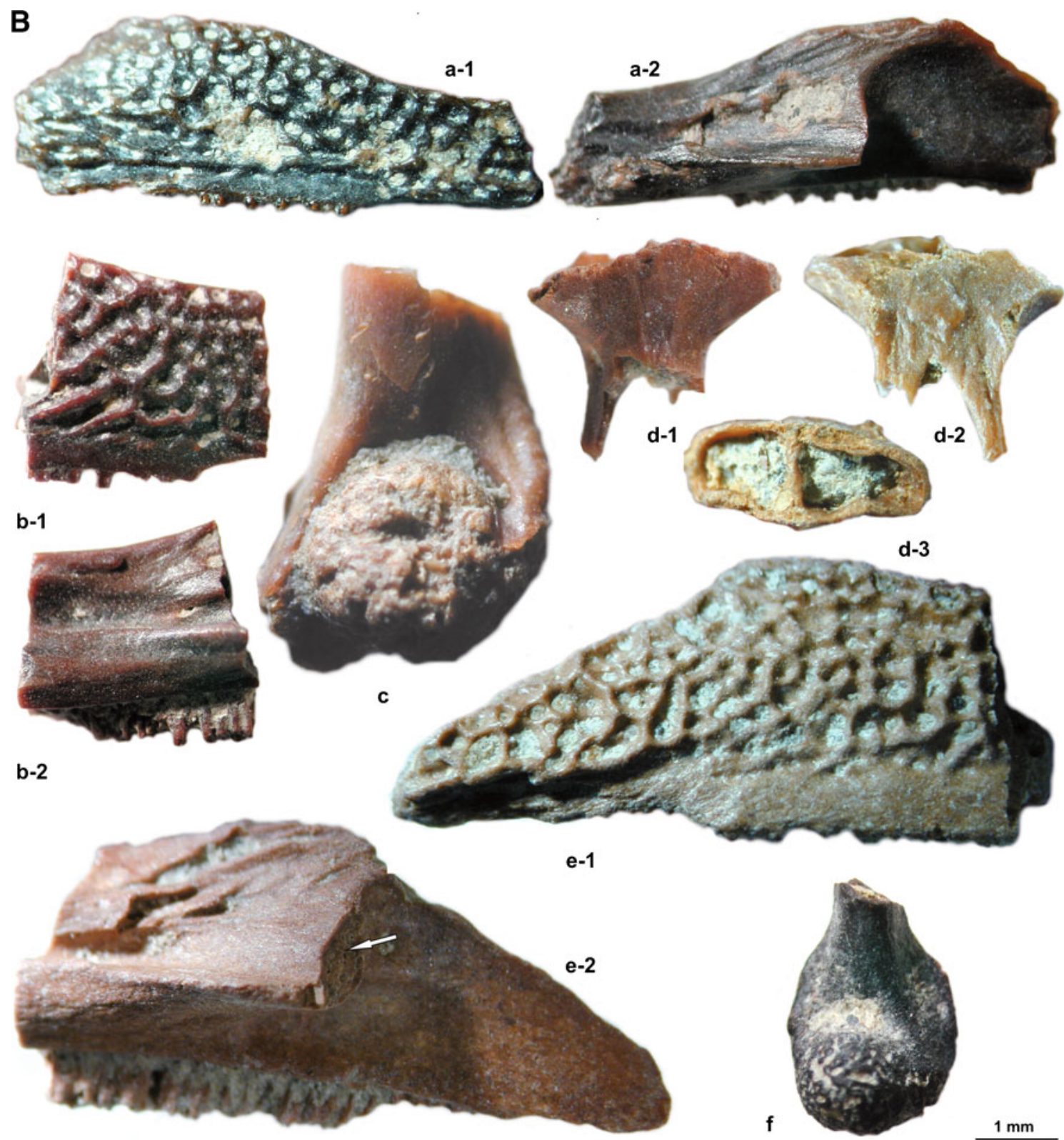

Fig. 15 (continued)

being open laterally, the presence of the lateral crista, and the absence of the medial crista. The ventral crista is short and weakly developed on the ventral surface of the proximal section of the bone. UMNH 13281 (Fig. 15Bf) is characterized by its arch-like expanded medial and lateral cristae. Both are confluent with the margin of the caput and, thus, do not produce epicondyles. The fossa cubitalis is shallow and is open laterally and, to a lesser extent, also medially.

UMNH 18339 (Fig. 15Bc) is large but its caput is comparatively small. Its medial epicondyle extends beyond the distal margin of the caput, and runs out dorsomedially in a small knob-like process (this feature is not shared with any other Late Cretaceous anuran; see arrow in Fig. 15Bc).
The distalmost process on the medial epicondyle continues onto its dorsal surface, where it disappears. The lateral crista joins the lateral surface of the caput and even extends onto its laterodistal part. The fossa cubitalis is narrow, but deep and well isolated from the lateral surface of the bone. UMNH 13272 (Fig. 15Ab) is also comparatively large, with its medial epicondyle reaching nearly the level of the distal surface of the caput. Both the medial and lateral cristae are developed. The lateral crista is rather swollen at the point where it joins the caput, and extends onto its laterodistal surface. The fossa cubitalis is a narrow depression along the proximal surface of the caput and it opens both medially and laterally. UMNH 18431 (Fig. 16Ag), 19317, and 18452 (Fig. 16Ah) are also quite large, but on each their caput is 
relatively small. The medial epicondyle is much larger than the lateral one. The medial and lateral cristae are short and declined dorsally; the fossa cubitalis is poorly developed and opens both laterally and medially. The distal section of the shaft is comparatively thin, although it is moderately thicker in UMNH 18452.

In contrast to the above described humeri, UMNH 13341 (Fig. 15Aaa) is extremely small. However, the following features allow this tiny humerus to be associated with larger humeri from this sample: medial epicondyle large and prominent medially, but with no medial crista; lateral crista well developed and reaching lateral surface of caput; and fossa cubitalis open laterally.

The ilium UMNH 13323 (Fig. 15Af) has an acetabulum that is shallow, moderately convex along its anteroventral margin, and well delimited by a thin, continuous line. The pars ascendens is large and its dorsal margin is moderately declined from the long axis of the bone, which results in a shallow depression between the pars ascendens and the dorsal margin of the shaft. The surface of the bone is slightly wrinkled. Disregarding this delicate rugosity, the inner surface of the bone is smooth. UMNH 13206, 13209 and 13334 (Fig. 15Ae) are similar, but in each the margin of their acetabulum is more prominent. UMNH 13282 has a small acetabulum shifted ventrally, with its surface almost flat and its anteroventral margin is prominent. The dorsal margin of the bone is straight, but there is a rounded crista running from the dorsal margin of the bone onto its medial surface. UMNH 19330 (Fig. 15Ad-1,2) and 19314 (Fig. 16Bc) are similar in that the rounded crista runs down from the dorsal margin of the pars ascendens onto the medial surface of the bone, delimiting a distinct oblique groove on the dorsal surface of the bone. Because the pars ascendens is prominent and the shaft is convex dorsally, the oblique groove appears as a distinct depression on the dorsal margin of the bone. The outer surface of the bone is smooth, but it is pierced in UMNH 19330 by a foramen that continues anteriorly for a short distance as a groove. UMNH 19311 (Fig. 16Bb) is basically the same (although only the shaft is preserved), except that the oblique crista is extremely well developed and the outer surface is smooth.

The ilium UMNH 13336 (Fig. 15Aa) differs from the previous two in that it is much larger and its acetabulum is more extensive, reaching nearly to the dorsal margin of the pars ascendens. The anterior margin of the acetabulum is very prominent. UMNH 18435 (Fig. 16Af) also has the anteroventral portion of its acetabulum markedly prominent, but does not extend beyond the outlines of the bone. Its shaft is rather thin, with a depression on the lateral side of its posterior section. The dorsal margin of the acetabular portion is slightly declined dorsally; in an opposite direction, it runs down anteroventrally onto the medial surface of the shaft, parallel with a shallow groove which runs posterior to it.
The pair of ischia UMNH 18445 (Fig. 16Ao-1,2) is well preserved, but except for its comparatively large size, it does not display any significant diagnostic features.

\section{Evolutionary trends}

The relatively continuous middle Cenomanian to late Campanian record of anuran assemblages documented herein from a geographically limited area in southern Utah provides a unique opportunity to infer some anatomical trends in the evolution of Mesozoic anurans and to examine changes in anuran assemblages during the Late Cretaceous in the North American Western Interior.

\section{Size}

Although we used the same washing methods at all localities, there are pronounced size differences in bones through the sampled interval. The average sizes of bones from the Cenomanian through to the early Campanian was small, and larger bones became more frequent only in the late Campanian. We used ilia for size comparisons, because it is possible 1) to make relatively accurate estimates of the complete length of that bone from preserved fragments and 2) to use actual or estimated iliac lengths to estimate the principal body dimension, i.e. snout-vent length (SVL). As a basis for these comparisons we used the primitive Recent anuran Ascaphus truei (Fig. 17) because of its presumably similar anatomy. In Ascaphus, SVL is approximately 3.5 times the length of its ilium.

The smallest ilium recovered in the middle? Cenomanian Cedar Canyon samples (UMNH 12936, Fig. 4r-1,2) is a fragment $1.6 \mathrm{~mm}$ long, the total length of which can be estimated to about $4 \mathrm{~mm}$. If this reconstructed length of the ilium is then multiplied by 3.5 , the resulting SVL of the frog would be $14 \mathrm{~mm}$. On the basis of this estimated SVL, the urostyle UMNH 12932 (Fig. 4t) and, possibly, the humerus UMNH 13006 (Fig. 4b) could also belong to a frog of similar body size. This is the smallest of the sampled Cedar Canyon frogs. The other anurans are somewhat larger, and the largest frog present in the Cedar Canyon samples - as indicated by the maxillae UMNH 12910 (Fig. 4f-1,2) and 18427 (Fig. 4g-1,2), the prearticular UMNH 12933 (Fig. 4q), the sacral vertebra UMNH 18418 (Fig. 4x-1-3), and the humeri UMNH 12894 (Fig. 4a) and 12934 (Fig. 4e) - reached an SVL approximately 3 times larger, i.e. about $42 \mathrm{~mm}$.

The middle and late Santonian samples also include a high percentage of tiny ilia; by contrast, larger ilia or any other large skeletal elements are rare. For instance, in the middle Santonian (Fig. 9), the smallest ilium from 
Henderson Canyon is UMNH 18233 (Fig. 9t); when complete, the total length of that specimen would have been about $4 \mathrm{~mm}$ which, in turn, yields an estimated SVL of only about $14 \mathrm{~mm}$. Most of the other ilia are only slightly larger and the SVLs of those frogs are estimated to be $20-25 \mathrm{~mm}$. Most of other skeletal elements correspond to anurans of that size range (e.g., frontoparietal UMNH 19288, Fig. 9e-1,2; prearticular UMNH 18217, Fig. 9g; humerus UMNH 18223, Fig. 9cc). Only a few ilia (e.g., UMNH 18539, Fig. 9w) and maxillae (UMNH 19279, Fig. 9f-1,2) indicate the presence of slightly larger anurans, with SVLs of about $40 \mathrm{~mm}$.

A similar situation is found at Paul's locality (Fig. 11), which is a sample from a highly diversified local anuran assemblage of late Sanatonian or early Campanian age. Of the 34 ilia from that locality, there is only one large ilium: UMNH 13551 (Fig. 11v) has an estimated length of about $18 \mathrm{~mm}$. Paul's locality has yielded a few other large bones, namely the humerus UMNH 13474 (Fig. 11z) and the bicondylar urostyle UMNH 13502 (Fig. $11 \mathrm{~mm}$ ), that could be associated with the ilium UMNH 13551 based on their similarly large size.

In the late Campanian, however, the pattern is reversed. Small ilia (e.g., UMNH 19311, Fig. 16Bb and UMNH 19314, Fig. 16Bc) and other small skeletal elements representing tiny frogs are present (e.g., humerus UMNH 13341, Fig. 15Aaa), but they are few in number. Instead, the majority of the bones are from large frogs.

To summarize the above, in the study area small-bodied anuran taxa prevailed from the middle Cenomanian until the early Campanian, then larger-bodied anurans began to dominate in the late Campanian. When complete, the holotype ilium of Scotiophryne pustulosa (Estes 1969, Fig. 1c,d) from the Hell Creek Formation, Montana, is estimated to be about $15 \mathrm{~mm}$ in total length, which represents a frog whose SVL reached slightly more than $50 \mathrm{~mm}$. Our Scotiophryne ilium UMNH 18263 (Fig. 13a1,2), from the early Campanian of White Flats Road, is estimated to have been $7.8 \mathrm{~mm}$ long when intact, which corresponds to an SVL of about $27.5 \mathrm{~mm}$. Other Scotiophryne ilia in our samples are from frogs with body sizes that are both smaller (e.g., UMNH 18307, Fig. 14t-1,2, from Websters Flat) and larger (e.g., UMNH 18338, Fig. 14k-1,2 and UMNH 18182, Fig. 141-1,2, both from Campbell Canyon). If the ilium UMNH 18484 (Fig. 10Bl), from the late Santonian North Side of Pasture Wash locality, is correctly assigned to Scotiophryne, it is from an even smaller frog-the length of the intact ilium is estimated at $4.2 \mathrm{~mm}$ and the SVL as $14.5 \mathrm{~mm}$, which is within the size range of the tiny frogs from the middle Cenomanian.

The holotype ilium of Paradiscoglossus americanus (Estes and Sanchíz 1982, Fig. 1A-B, Gardner 2008,
Fig. 13.2 K-L) from the late Maastrichtian of Wyoming is consistent with the presence of larger anurans in the latest Cretaceous. Its total length is estimated to be $20 \mathrm{~mm}$ and the SVL of the frog would have been about $70 \mathrm{~mm}$. Paradiscoglossus was part of a diverse late Maastrichtian anuran assemblage in the Lance Formation (Gardner 2008); at least one member of that assemblage, Theatonius lancencis (Fox 1976a), was considerably smaller than Paradiscoglossus, although body sizes of the two cannot be compared directly because ilia are unknown for Theatonius.

It is worth noting that compared to size ranges reported above for Late Cretaceous anurans, the Early Jurassic (and earliest known) anuran Prosalirus bitis was a medium-sized frog. Two of the referred Prosalirus ilia were probably about 10 mm (MNA V 8725; Jenkins and Shubin 1998, Fig. 3D) and $12.5 \mathrm{~mm}$ (MCZ 9324A; Jenkins and Shubin 1998, Fig. 2O) long when complete, which yields an estimated SVL of $35-43 \mathrm{~mm}$.

\section{Vertebrae and urostyles}

Although it may be expected that vertebrae of small anurans are too delicate to be preserved, some nearly complete specimens were recovered. In the late Santonian North Side of Pasture Wash locality, there are seven tiny vertebrae, each with centra less than $1 \mathrm{~mm}$ long: six presacrals (UMNH 18386, Fig. 10Al-1-3; UMNH 18388, Fig. 10Am-1-3; UMNH 18390, Fig. 10Ak-1,2; UMNH 18392, Fig. 10Ah-1,2; UMNH 18479, Fig. 10Ai-1-3; UMNH 18472, Fig. 10Aj-1-4) and one sacral (UMNH 18391, Fig. 10Ag-1,2). Judging by their small size and morphology, two nearly complete urostyles (UMNH 18384, Fig. 10Bcc-1-3; 18385, Fig. 10Bdd-1-3) might originate from the same kind of frog as the small vertebrae. In the same locality, large vertebrae are scarce and fragmentary. Only one large sacral centrum (UMNH 18500, Fig. 10Af1-3) is present and both neural arches are broken off the specimen. This sacral vertebra may be from the same kind of anuran represented by large maxillae (e.g., UMNH 19341, Fig. 10Ab-1,2) at the same locality. The scarcity of large vertebrae at the North Side of Pasture Wash locality is consistent with the pattern identified above (see previous section) of small anurans prevailing in the study region from the Cenomanian through to the late Santonian.

The majority of small praesacral vertebrae in our samples are amphicoelous (UMNH 18388, 18390, 18470, 18472). Although their articular cavities are sometimes obscured by matrix, there is no clear indication that any of them are pierced by a notochordal canal. These can be compared with the atlas UMNH 18516 (Fig. 9y-1-3) from the middle Santonian Casey's Shell Hash locality; that atlas has a small pit in the midline between both anterior articular 
cotyles, but no notochordal canal. Unfortunately, although the presacral vertebra UMNH 18092 (Fig. 13hh) is nicely preserved dorsally, its centrum is missing.

Based on specimens documented herein and previously reported in the literature, it appears that all Late Cretaceous anurans with amphicoelous vertebrae had their notochordal canal already infilled by bone. The only early anurans with disarticulated vertebral centra are Eodiscoglossus oxoniensis from the Middle Jurassic (Bathonian) of Watton Cliff in England (Evans and Milner 1994, Fig. 18.2I-K) and Prosalirus (Jenkins and Shubin 1998, Fig. 3A-C). In both of these Jurassic taxa, the notochordal canal opens widely both anteriorly and posteriorly and extends completely through the centrum. In tadpoles of the Early Cretaceous pipoid frog Shomronella (Estes et al. 1978, Fig. 6C; Roček and Van Dijk, 2006), opisthocoelous type centra develop from amphicoelous type centra in late stages of metamorphosis. The geological age of Shomronella indicates that opisthocoely appeared in anurans by at least the earliest Cretaceous, if not earlier. Therefore it is not surprising that opisthocoelous vertebrae are present in the late Santonian North Side of Pasture Wash locality (UMNH 18386, Fig. 10Al-1-3 and UMNH 18392, Fig. 10Ah-1,2).

Although only two examples are available and neither preserves any significant amount of the neural arch, there are pronounced differences between sacral vertebrae from the North Side of Pasture Wash locality. UMNH 18391 (Fig. 10Ag-1,2) has a biconvex centrum bearing welldeveloped, knob-like articular condyles both anteriorly and posteriorly. This same sacral condition occurs in extant Discoglossidae, all of which have opisthocoelous presacrals; Barbourula and Bombina even retain a monocondylar sacro-urostylar articulation. The second specimen, UMNH 18500 (Fig. 10Af-1-3), differs in that its centrum has a concave anterior surface and a bicondylar posterior surface. In frogs retaining the amphicoelous condition (e.g., Recent Ascaphus and Late Cretaceous Gobiates; Roček 2008), all their post atlantal vertebrae, including the sacrum, have biconcave centra. The distinct structure of its centrum means that UMNH 18500 cannot be from a frog with either amphicoelous or opisthocoelous vertebrae; thus, although no examples of procoeolous anuran presacral vertebrae were recovered from the North Side of Pasture Wash locality, UMNH 18500 must be from a frog with a procoeolous vertebral column.

It follows from these considerations that monocondylar urostyles (i.e., those that articulate with the sacral vertebra by a single, undivided condyloid fossa) either belonged to an anuran with an amphicoelous or opisthocoelous vertebral column. Such simple urostyles occur in the middle Cenomanian (UMNH 12954, Fig. 4v-1-4), Santonian/ Campanian (UMNH 13526, Fig. 111l-1,2) and, disregarding size, also in the late Campanian (UMNH 13385, Fig. 16Ba-
1-4). However, as early as in the middle Cenomanian there were anurans in which the condyloid fossa was horizontally oval (UMNH 12944, Fig. 4u), suggesting restricted movement in the vertical plane at the sacro-urostylar joint (see Emerson and De Jongh 1980, Figs. 8, 9). Most of the urostyles in our samples have the condyloid fossa horizontally oval (e.g., Fig. 11ii-3). Moreover, some of them (UMNH 13530 and 13533 from the Santonian/Campanian boundary) have their condyloid fossa partly subdivided by an incomplete vertical partition arising from the ventral margin. This reflects a partly subdivided posterior condyle on the sacral vertebra. Ultimately, this trend resulted in the complete subdivision of the condyloid fossa into two cotyles. A range of undivided to completely divided sacro-urostylar joints is recorded in our collection of urostyles from the Late Cretaceous; however, the derived condition obviously first appeared even earlier, because bicondylar urostyles and sacral vertebrae (UMNH 18418, Fig. 4x-1-3 and UMNH 12932, Fig. 4t, respectively) were already present by the Cenomanian.

The presence of procoelous sacral vertebrae in frogs from the Cenomanian (UMNH 18418, Fig. 4x-1-3) and late Santonian (UMNH 18500, Fig. 10Af-1-3) of Utah and from the middle to late Campanian Judith River Formation of Montana (Sahni 1972) indicates the existence of anurans with procoelous vertebral centra during the Late Cretaceous in North America. Procoelous anuran vertebrae have been reported elsewhere in North American from the Early Cretaceous (Albian) of central Texas (Winkler et al. 1990). However, procoely in anuran vertebrae is evidenced as early as from the lowermost Cretaceous (possibly Berriasian) of Morocco (Jones et al. 2003: 79, Fig. 6, 11C-E; see also Rage and Dutheil 2008). Procoelous sacral vertebrae similar to the Utah specimens also have been identified from the Late Cretaceous of Central Asia (Roček and Nessov 1993, text-Fig. 14). These geographically widespread occurrences suggest that procoelous anuran vertebrae originated at the beginning of the Cretaceous at the latest.

Ilia

Ilia are the most abundant and easily recognizable elements in all our anuran samples. The anuran ilium consists of two parts: an anteriorly elongate shaft, which is an anuran autapomorphy, and a broader posterior portion, called the acetabular region, that laterally bears a bowl-shaped acetabulum. Anuran ilia bear various combinations of grooves and processes that serve as attachment points for pelvic and hindlimb muscles and, thus, are functionally linked to locomotion. Specimens from Utah provide an opportunity to examine trends in three of these featuresthe dorsal tubercle, oblique groove, and dorsal crest. 
The dorsal tubercle is variably present in anurans. Where present, the dorsal tubercle arises from the upper surface of the ilium, dorsal to the anterior margin of the acetabulum. In extant anurans, the dorsal tubercle serves as the area of origin for the glutaeus maximus and iliofibularis/iliofemoralis muscles (Přikryl et al. 2009). The glutaeus maximus muscle extends across the hip and knee joints. It serves as a knee extensor that is important for the take-off phase during jumping and also has a flexion action at the hip joint when the frog is in a crouched position during the preparatory phase (i.e. just before it leaps) of the jump (Calow and Alexander 1973). The iliofemoralis and iliofibularis muscles collectively function to retract the thigh, which is also important in the take-off phase of the jump, and separately as the adductor of the thigh (iliofemoralis) and flexor of the knee (iliofibularis). Thus, all three muscles have important functions during both the preparatory and take-off phases of the jump. In late stage tadpoles of taxa that have a dorsal tubercle as adults (Green 1931) and in extant anurans whose adults lack the dorsal tubercle (e.g., Ascaphus), the above-described trio of muscles originate on the dorsolateral surface of the ilium, above the anterior part of the acetabulum (Prikryl et al. 2009, Fig. 3-2B); in other words, the three muscles originate in approximately the same position on the ilium, regardless of whether a dorsal tubercle is present or not.

In our geologically older samples from Utah, ilia lacking the dorsal tubercle are prevalent. Ilia that have a prominent dorsal tubercle or those in which the dorsal tubercle is only a low protuberance occur even in very small samples (e.g., from the late Cenomanian Bulldog Bench locality, Fig. 5), but they are never common. Ilia with a well-developed dorsal tubercle become relatively more common in younger samples from Utah. This stratigraphic pattern might suggest that the dorsal tubercle is a derived feature of anurans that become more prominent (both in its development and frequency of occurrence) through the Late Cretaceous, but when older occurrences are considered the situation becomes confused. The basal anuran Prosalirus lacks a dorsal tubercle (see Jenkins and Shubin 1998, Fig. 2O, 3D). Isolated, indeterminate anuran ilia reported by Curtis and Padian (1999) from the spoil pile at the Prosalirus quarry appear to represent at least two different morphs (MCZ 9020, 9021 versus MCZ 9022, 9023), both of which lack a dorsal tubercle. The condition in Prosalirus and the indeterminate, contemporaneous ilia from the Kayenta Formation imply that the dorsal tubercle was absent in the earliest frogs. However, a dorsally-projecting, knob-like structure on the dorsal margin of the ilium in the Early Triassic proanurans Triadobatrachus (Rage and Roček 1989, text-Fig. 3) and Czatkobatrachus (Evans and Borsuk-Białynicka 1998, Fig. 2A) has been widely interpreted as a dorsal tubercle. If these identifications are
Fig. 16 A The Blues, late Campanian. a Right maxilla (18449) in outer (a-1) and inner (a-2) views. b Right maxilla (19310) in outer (b1) and inner (b-2) views. c Right prearticular (19315) in dorsal view. d Right prearticular (19324) in dorsal view. e Right frontoparietal (18444) in ventral (e-1) and dorsal (e-2) views. f Left ilium (18435) in lateral view. g Right humerus (18431) in ventral view. h Right humerus (18452) in ventral view. i Right premaxilla (19316) in anterodorsal (i-1) and posterior (i-2) views. j Scotiophryne pustulosa. Right maxilla (18447) in outer (j-1) and inner (j-2) views. $\mathbf{k}$ Scotiophryne pustulosa. Right maxilla (18437) in outer (k-1) and inner (k-2) views. I Scotiophryne pustulosa. Right maxilla (18446) in outer (l-1) and inner (l-2) views. m Left maxilla (18438) in outer (m$1)$ and inner (m-2) views. $\mathbf{n}$ Right maxilla (18448) in outer (n-1) and inner (n-2) views. o Ischia (18445) in ventral (o-1) and right lateral (o2) views. All are at the same scale. B The Blues, late Campanian. a Urostyle (13385) in dorsal (a-1), right lateral (a-2), left dorsolateral (a3), and ventral (a-4) views. b Left iliac shaft (19311) in medial view. c Right ilium (19314) in lateral view. d Scotiophryne pustulosa. Right maxilla (18451) in outer (d-1) and inner (d-2) views. All are at the same scale

correct, they would instead support the alternative hypothesis that the dorsal tubercle is primitive for salientians. We note, however, that the structure identified as the dorsal tubercle in the Triassic taxa is positioned further to the anterior compared to anurans (i.e., well onto the base of the shaft and well anterior to the level of the anterior margin of the acetabulum versus on the dorsal edge of the acetabulum and approximately in line with the level of the anterior margin of the acetabulum); these positional differences might indicate that the "dorsal tubercle" in proanurans and anurans are not homologous.

The oblique groove ("spiral groove" of some authors) is variably present in anurans. Where present, the oblique groove originates on the lateral surface of the acetabular region, above and parallel to the dorsal margin of the acetabulum. The groove extends forward and upwards to cross over the dorsal edge of the bone at the depression formed by the junction between the acetabular region and the base of the shaft, and continues forward and downwards for a short distance before grading into the medial surface of the proximal portion of the shaft. In Scaphiopus and Pelobates, which are the only extant frogs in which the oblique groove is known, the portion of the groove on the medial surface of the shaft is the area of origin for the medial head of the iliacus externus muscle; the lateral head of that muscle originates on the opposite or lateral surface of the shaft. The medial head wraps over the dorsal surface of the ilium, where it joins the lateral head and then both extend onwards to insert onto the dorsal surface of the proximal part of the femur (Prrikryl et al. 2009). The iliacus externus muscle is an important protractor of the thigh that helps draw the legs into a crouched position.

An oblique groove is present in a minority of ilia through the sampled sequence in Utah: for example, in the Cenomanian (UMNH 12936, Fig. 4r-1,2; UMNH 13156, Fig. 5j), Turonian (UMNH 13461, Fig. 6x-1,2), Coniacian 


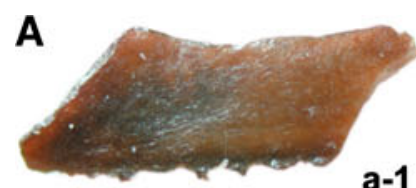

a-1 a-2
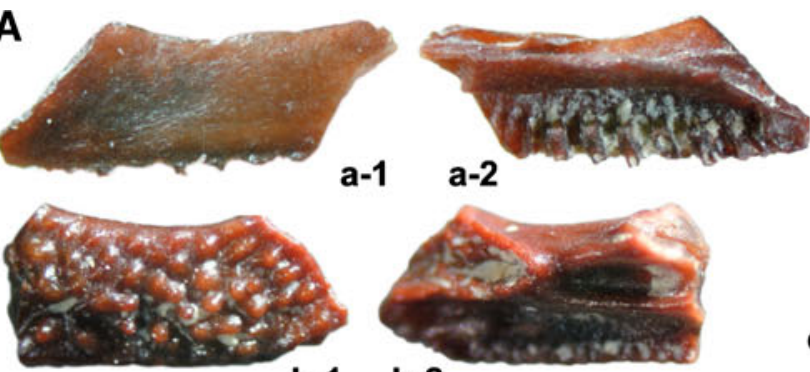

b-1

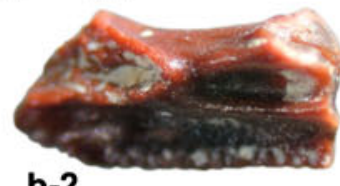

c
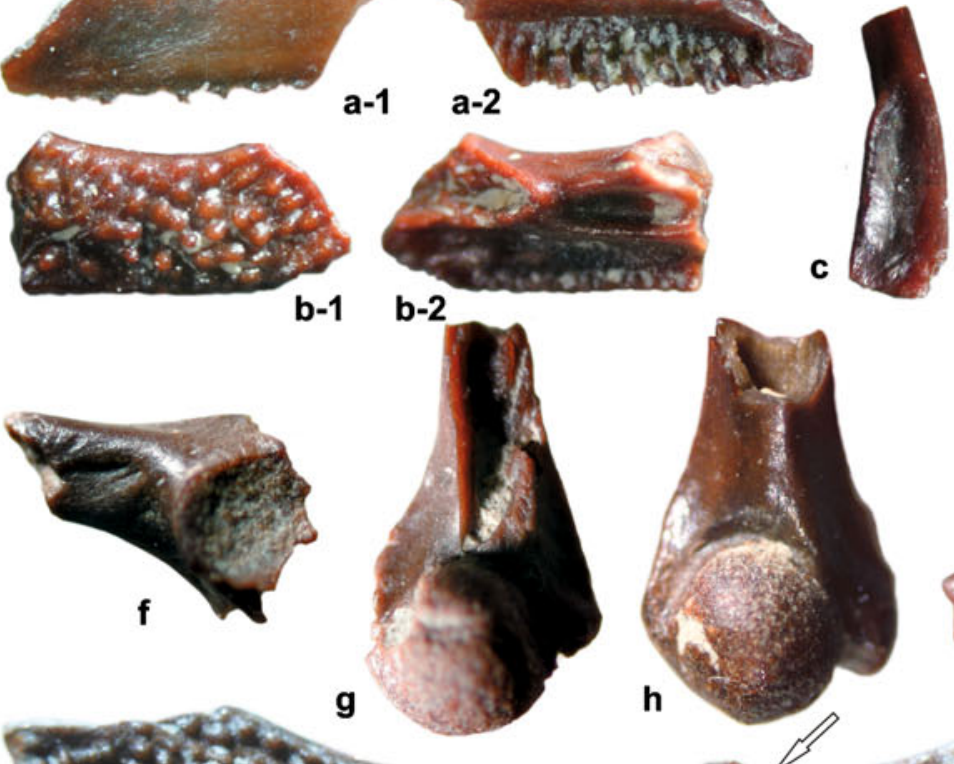

d
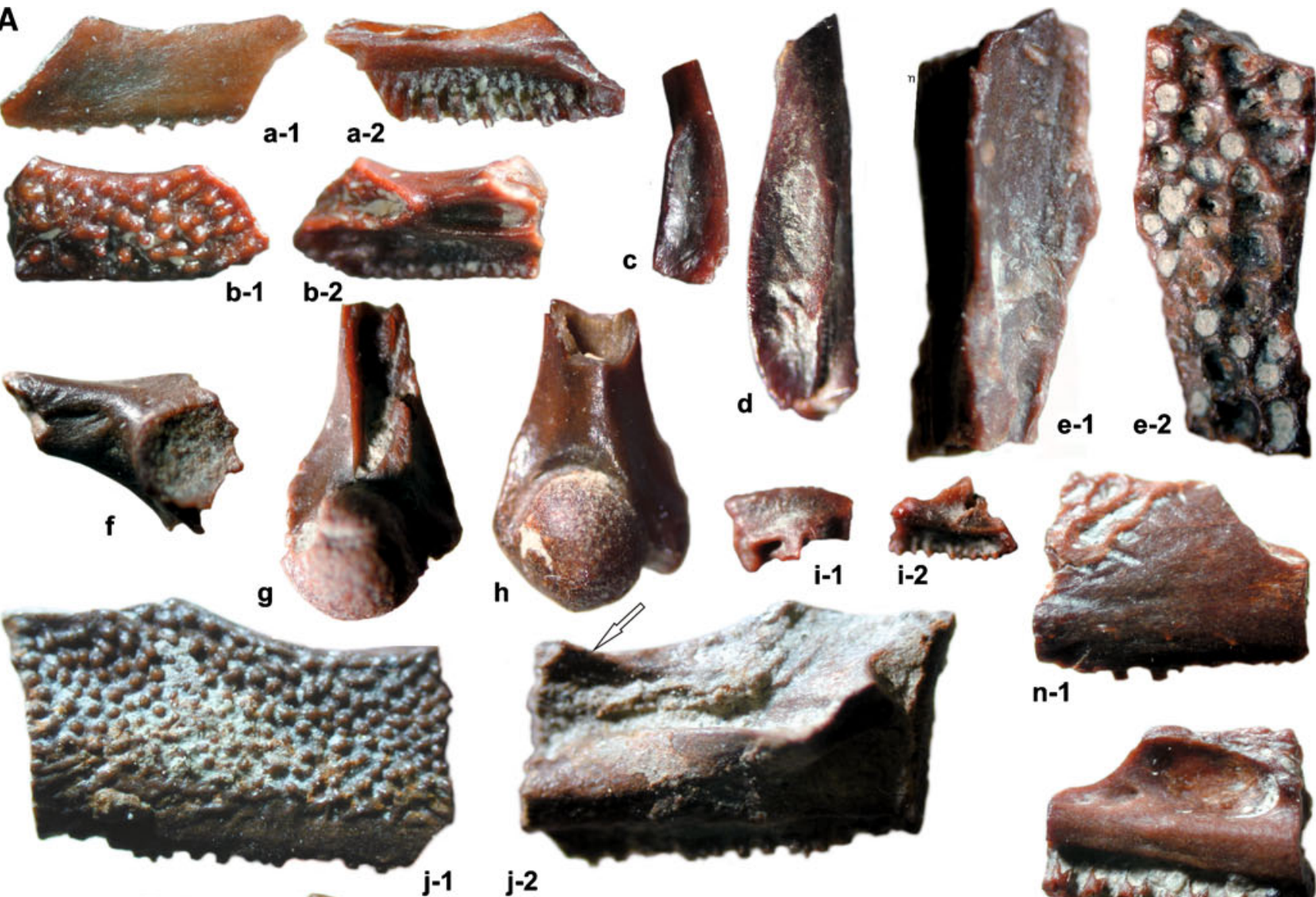

j-2
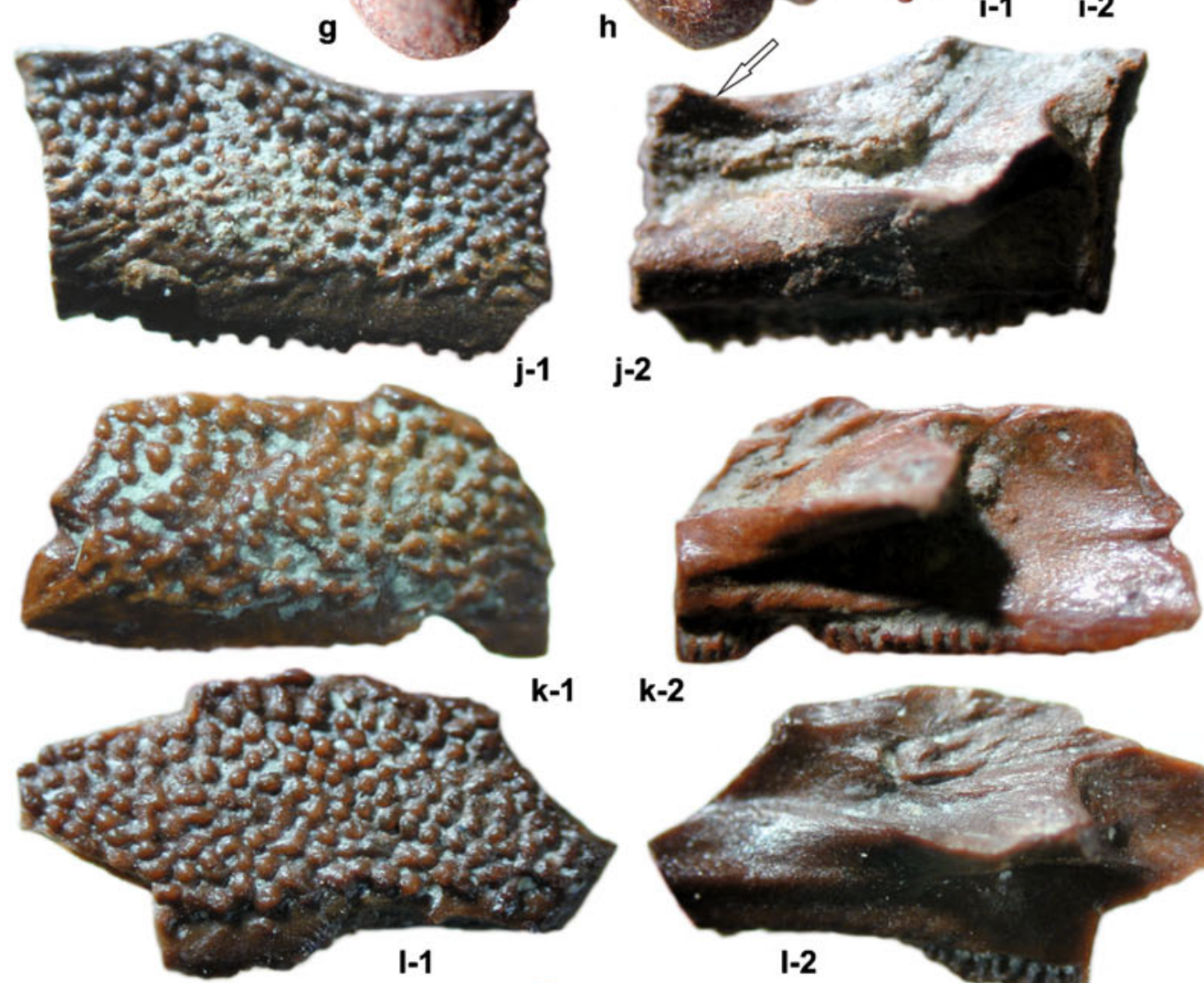

k-2
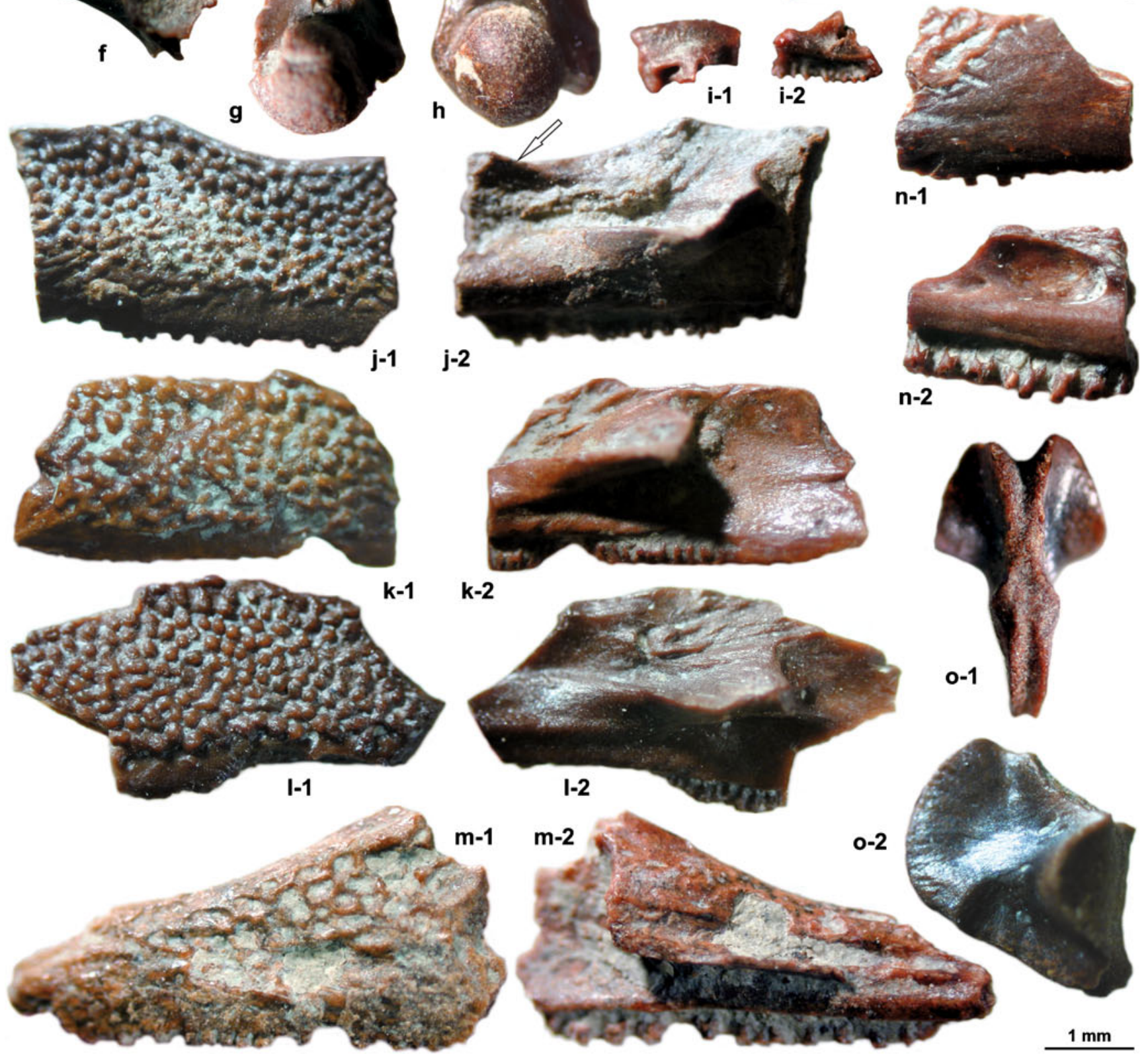

$1 \mathrm{~mm}$ 
B

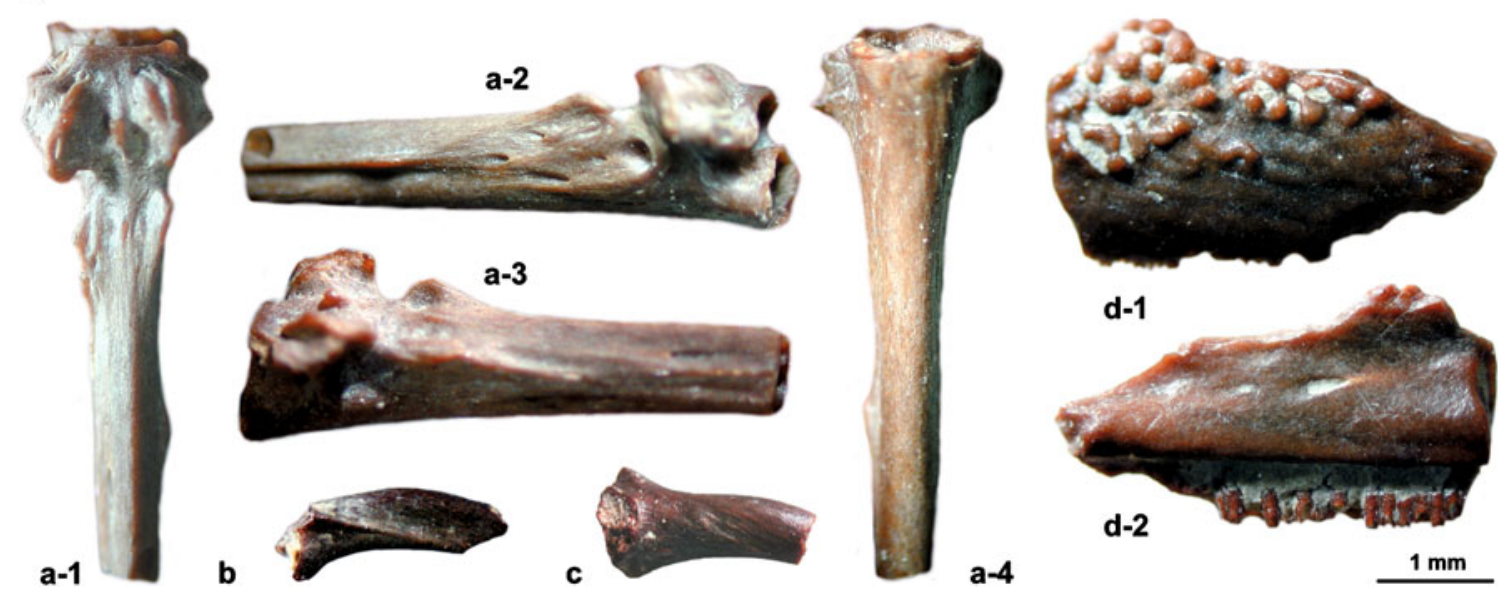

Fig. 16 (continued)

(UMNH 19371, Fig. 7a-2), early Santonian (UMNH 18293 , Fig. 8f-1; UMNH 19271), late Santonian (UMNH 18344, Fig. 10Bd-2; UMNH 18476; UMNH 18480; UMNH 18484, Fig. 10Bl; UMNH 18486; UMNH 18506 , Fig. 10By), late Santonian or early Campanian (UMNH 13480, Fig. 11d; UMNH 18552, Fig. 12b), early Campanian (UMNH 18097; UMNH 18102, Fig. 13r; UMNH 18103, Fig. 13w; UMNH 18154, Fig. 14b; UMNH 18180 , Fig. 14j-1; UMNH 18182, Fig. 141-2; UMNH 18263, Fig. 13a-1,2; UMNH 18264, Fig. 13b-1,2; UMNH 18283, Fig. 13d-1,2; UMNH 18284, Fig. 13g-1; UMNH 18286, Fig. 13e-1,2; UMNH 18320, Fig. 14a; UMNH 19345, Fig. 13y), and late Campanian (UMNH 18435, Fig. 16Af; UMNH 19311, Fig. 16Bb; UMNH 19314, Fig. 16Bc; UMNH 19330, Fig. 15Ad-1,2). Oblique grooves have been reported in some Late Jurassic anuran ilia (e.g., Evans and Milner 1993), but the presence of an oblique groove in the Early Jurassic anuran Prosalirus cannot be verified by direct observation. Many of the Prosalirus ilia have a comparatively deep depression along the dorsal margin, between the acetabular region and the dorsally convex shaft (Jenkins and Shubin 1998, Fig. 3D; Gardner et al., in press, Fig. 4J); in other anurans having a similarly deep depression at that point, a well-developed oblique groove is often present. This suggests that an oblique groove may occur in Prosalirus. As an aside, it is worth noting that the isolated ilium with a relatively straight dorsal margin illustrated by Jenkins and Shubin (1998, Fig. 2O) consists of several fragments glued together and, thus, probably does not accurately reflect the original shape of the bone. There is no indication of an oblique groove in Triadobatrachus (Rage and Roček 1989, text-Fig. 3) or Czatkobatrachus (Evans and Borsuk-Białynicka 2009, Fig. 8). It seems unlikely that all the Upper Cretaceous ilia from Utah and previously reported, geologically older ilia with an oblique groove would be closely related to Pelobates and Scaphiopus. Rather than being solely a taxonomic feature, we suggest it is more probable that the oblique groove is also functionally significant. However, as noted above, what the function of that groove may have been in Mesozoic anurans remains unknown.

In extant anurans, the dorsal tubercle and oblique groove never co-occur on the same ilium. If the dorsal tubercle is present, the oblique groove and any structures (parallel cristae, ridges or grooves) associated with it are absent, and vice versa. Although this pattern holds true for most of the fossil ilia from the Utah localities, both structures are present in at least two specimens-UMNH 13461 (Fig. 6x1,2) from Jimmy Canyon (Turonian) and UMNH 13481 (Fig. 11m) from Paul's locality (late Santonian or early Campanian). Based on our current state of knowledge, it is uncertain why typically only the dorsal tubercle or the oblique groove are present, but it cannot be excluded that this pattern might be functionally related to different locomotor capabilities (e.g., jumping versus walking). On the other hand, many extant anuran taxa lack both structures and those individuals are capable of jumping, walking, or both.

The dorsal crest ("dorsal crista" of some authors) is a mediolaterally narrow bony flange, of variable height and length, that extends along the dorsal surface of the iliac shaft in some anurans. In extant anurans that have a dorsal crest, this structure forms an extended area for the insertion of the coccygeoiliacus muscle, which originates on the urostyle, and for the origin of the lateral head of the iliacus externus muscle. The dorsal edge of the dorsal crest is usually well palpable under the skin. Depending on the size of its area of insertion, the coccygeoiliacus muscle may facilitate anterior gliding of the ilium along the sacral diapophysis, helps rotate the urostyle ventrally or, during simultaneous hind leg 


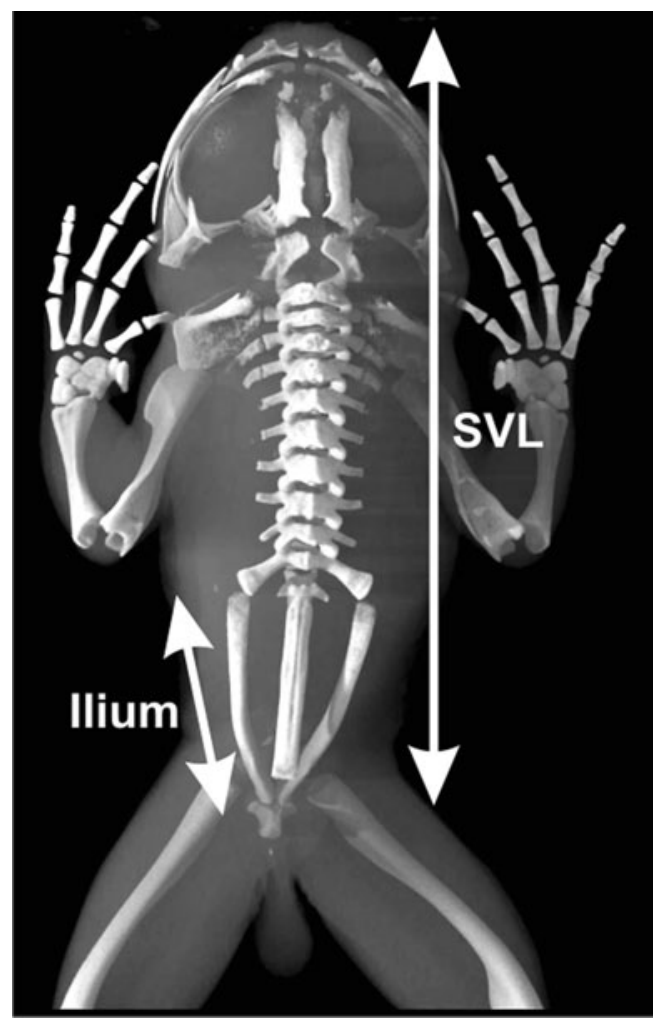

Fig. 17 Snout-vent length (SVL) compared to length of ilium, as exemplified in the primitive Recent anuran Ascaphus truei. Image with permission of DigiMorph Org

movement (as occurs when jumping), helps shift the pelvis posteriorly. The iliacus externus muscle helps flex the hip joint. The importance of the dorsal crest for jumping may be inferred from the observation that this crest is well developed in strong jumpers such as Rana and Discoglossus. Where the dorsal crest is absent, the inner head of the iliacus externus muscle wraps across the dorsal surface of the iliac shaft and cushions the dorsal surface of the shaft so it is not palpable under the skin. Because the proximal portion of the dorsal crest extends to the very base of the shaft, its presence can usually be detected in isolated ilia that preserve even just the posterior portion of the shaft. Even so, none of the ilia from our Utah localities have a dorsal crest. Iliac shafts are more nearly completely preserved in the Triassic proanurans Triadobatrachus and Czatkobatrachus and the earliest anuran Prosalirus, but none of those have a dorsal crest. Among North American Mesozoic anurans, the only one known to have a dorsal crest on its iliac shaft is Paradiscoglossus americanus from the Late Cretaceous (late Maastrichtian) Lance Formation (Estes and Sanchíz 1982; see also Gardner 2008).

Structures on the lateral surface of the proximalmost portion of the iliac shaft are unknown in extant anurans, but we have identified several specimens-e.g., UMNH 13158 (Fig. 5k) from the late Cenomanian Bulldog Bench locality and UMNH 19366 (Fig. 7b) from the Coniacian Heward Creek locality - that each have a low, moderately elongate ridge extending anteroventrally-posterodorsally along the lateral surface of the shaft, just in front of the acetabulum. These are clearly anuran ilia, based on the characteristic form of their acetabula (subcircular, bowl-shaped, with a convex articular surface and enclosed by a laterally raised rim) and, in UMNH 13158, by the presence of a dorsal tubercle. More problematic are two early or middle Campanian ilia-one from Campbell Canyon (UMNH 18319, Fig. 14p-1-3) and one from Websters Flat (UMNH 18304, Fig. 14r-1,2) - that have a raised bony patch on the lateral surface of the shaft just in front of the acetabulum and a ramp-like acetabulum whose anterior portion projects laterally and bears a flattened to shallowly convex articular surface that is tilted posteriorly. Three similar ilia from the Judith River Formation (middle to late Campanian) of Montana were described by Blob et al. (2001) as belonging to the anuran Nezpercius; Holman (2003) subsequently questioned the anuran affinities of Nezpercius, but did not offer any alternatives. We will deal with the topotypic Nezpercius ilia and similar specimens elsewhere (Gardner et al., in press).

There are other peculiar ilia in our samples that are not restricted to a certain horizon. One of them is characterized by a prominent anterior margin of the acetabulum that is not continuous with the dorsal margin of the acetabulum (e.g., UMNH 13071, Fig. 5m, from the late Cenomanian). This discontinuous rim might indicate some peculiarities in the attachments of the circumacetabular muscles. A similar, but not identical pattern occurs in UMNH 13493 (Fig. 11f) from the Santonian/Campanian Paul's locality and in UMNH 18106 (Fig. 13v) from the early Campanian Barker Reservoir Road locality. A similar ilium has been previously reported from the early Cenomanian Khodzhakul Formation in Central Asia (Roček and Nessov 1993, text-Fig. 28E, pl. 8-2). Without understanding the reason(s) for this unusual acetabular margin condition, it is impossible to determine if they have any underlying functional or anatomical significance or if they are just anomalies.

\section{Taxonomic diversity}

Given that the same collection and processing methods were used at all 37 localities, potentially any element, providing that it was present in each locality, could be used to estimate taxonomic diversities. In practice, we found the ilium to be the most informative element because it is the most commonly recovered and easily recognizable anuran element and because distinct morphotypes can be identified. In order to make meaningful comparisons, we limited our assessment to the richest samples from single localities 
and refrained from using mixed samples from multiple localities, even when those localities were considered to be stratigraphically equivalent. In ascending stratigraphic sequence, we assessed taxonomic diversities based on ilia from the following five localities: Cedar Canyon, middle? Cenomanian (Fig. 4); Bulldog Bench, late Cenomanian (Fig. 5); Jimmy Canyon, Turonian (Fig. 6); Paul's locality, late Santonian or early Campanian (Fig. 11); and The Blues, late Campanian (Fig. 16A, B).

The two oldest localities are not especially informative, because each yielded only a few ilia. Considering that other anuran elements were more abundant at both localities, it appears that for reasons unknown ilia were under-represented at the two oldest localities. The Cedar Canyon sample contained only two fragmentary ilia, but based on differences in their structure each ilium probably belonged to a different taxon. The Bulldog Bench locality also yielded only rare ilia; however, even in that small sample three or four morphotypes that probably represent different taxa can be identified.

In Jimmy Canyon, the number of recovered ilia seems to be more representative because it roughly corresponds to the number of recovered humeri. Among the eight best preserved ilia, seven morphotypes are present that, potentially, each pertain to a different taxon. Six morphotypes are each known by just one specimen, whereas the seventh is represented by two specimens (UMNH 13458, Fig. 6w-1,2 and UMNH 13460, Fig. 6y).

Paul's locality yielded 21 comparatively well-preserved ilia; this count far exceeds the number of any other anuran elements at this locality, so here ilia are over-represented. Among these ilia, about 14 morphotypes can be identified. The Blues locality yielded only a few ilia, yet at least three morphotypes can be recognized. Judging by the number of other bones in the sample, ilia appear to be underrepresented at this locality.

Although ilia appear to be under-represented in samples from the Cedar Canyon, Bulldog Bench, and The Blues localities, several morphotypes were identified at locality and this indicates at least some local diversity in the anuran assemblages from each of those localities. Ilia appear to be properly represented at Jimmy Canyon, and a moderately diverse assemblage is recognized for that locality. Ilia are abundantly represented (perhaps overly so) in the sample from Paul's locality and about 14 iliac morphotypes are recognized. If each of those morphotypes represents a different taxon, this indicates that the anuran community in the geographically limited area around Paul's locality was remarkably diverse. If one takes into account that most diagnostic taxonomic differences are found in the skull, whereas the postcranial skeleton is usually more uniform, the number of taxa actually present might be even higher. Although ilia are useful for estimating taxonomic diversities in the Late Cretaceous of Utah, this is not the situation everywhere. In a study of isolated anuran bones from nine Albian-Campanian localities in Central Asia, Roček and Nessov (1993) found that postcranial bones (including ilia) were much more uniform, so instead they based their estimates of taxonomic diversities exclusively on differences in cranial bones.

Acknowledgements We are greatly indebted to Janet Gillette, Museum of Northern Arizona, Flagstaff, and Farish A. Jenkins, Jr., Museum of Comparative Zoology, Harvard University, for allowing one of us (Z.R.) to study material under their care and for their general hospitality. Comments from Jean-Claude Rage, Laboratoire de Paléontologie, Muséum d'Histoire naturelle, Paris, France, and from Márton Venczel, Țării Crișurilor Museum, Oradea, Romania, considerably improved the text. Specimens from Bryce Canyon National Park were collected with funding from the National Park Service and the Bryce Canyon Natural History Association. Funds for collecting all other specimens were provided by grants to Eaton from the Petroleum Research Fund (ACS-PRF\# 30989-GB8; ACS-PRF\# 34595-B8), the National Science Foundation (EAR-9004560), and the National Geographic Society. This research was funded by the Ministry of Education, Youth and Sports of the Czech Republic grant No. ME08066 through the American Science Information Center, Prague.

Open Access This article is distributed under the terms of the Creative Commons Attribution Noncommercial License which permits any noncommercial use, distribution, and reproduction in any medium, provided the original author(s) and source are credited.

\section{References}

Armstrong-Ziegler JG (1980) Amphibia and Reptilia from the Campanian of New Mexico. Fieldiana Geol (New Series) 4:1-39

Blob RW, Carrano MT, Rogers RR, Forster CA, Espinoza NR (2001) A new fossil frog from the Upper Cretaceous Judith River Formation of Montana. J Vertebr Paleontol 21:190-194

Bohor BFD, Dalrymple B, Triplehorn D, Kirschbaum M (1991) Argon/argon dating of tonsteins from the Dakota Formation, Utah. Geol S Am, Abstracts with Programs 23:A85

Borsuk-Białynicka M, Evans SE (2002) The scapulocoracoid of an Early Triassic stem - frog from Poland. Acta Palaeont Pol 47:79-96

Braman DR (2002) Terrestrial palynomorphs of the upper Santonian-? lowest Campanian Milk River Formation, southern Alberta. Palynology 25:57-107

Breithaupt BH (1982) Paleontology and paleoecology of the Lance Formation (Maastrichtian), east flank of Rock Springs Uplift, Sweetwater County, Wyoming. Contrib Geol, University of Wyoming 21:123-151

Breithaupt BH (1985) Nonmammalian vertebrate faunas from the Late Cretaceous of Wyoming. Wyoming Geol Assoc, Thirty-sixth Annual Field Conference Guidebook:159-175

Brinkman DB (1990) Paleoecology of the Judith River Formation (Campanian) of Dinosaur Provincial Park, Alberta, Canada: evidence from vertebrate microfossil localities. Palaeogeogr Palaeocl 78:37-54

Bryant LR (1989) Non-dinosaurian lower vertebrates across the Cretaceous-Tertiary boundary in norteastern Montana. Univ Calif Publ Geol Sci 134:1-107

Calow LJ, Alexander RN (1973) A mechanical analysis of a hind leg of a frog (Rana temporaria). J Zool Lond 171:293-321

Cifelli RL, Gardner JD, Nydam RL, Brinkman DL (1997) Additions to the vertebrate fauna of the Antlers Formation (Lower 
Cretaceous), southeastern Oklahoma. Okla Geol Notes 57:124131

Cifelli RL, Nydam RL, Gardner JD, Weil A, Eaton JG, Kirkland JJ, Madsen SK (1999a) Medial Cretaceous vertebrates from the Cedar Mountain Formation, Emery County, Utah: the Mussentuchit local fauna. In: Gillette DD (ed) Vertebrate Paleontology in Utah. Miscellaneous Publication 99-1. Utah Geological Survey, Salt Lake City, pp 219-242

Cifelli RL, Nydam RL, Eaton JG, Gardner JD, Kirkland JI (1999b) Vertebrate faunas of the North Horn Formation (Upper Cretaceous-lower Paleocene), Emery and Sanpete counties, Utah. In: Gillette DD (ed) Vertebrate paleontology in Utah. Utah Geol Survey Misc Pub 99-1, Salt Lake City, pp 377-388

Cifelli RL, Eberle JJ, Lofgren DL, Lillegraven JA, Clemens WA (2004) Mammalian biochronology of the latest Cretaceous. In: Woodburne MO (ed) Late cretaceous and cenozoic mammals of North America: biostratigraphy and geochronology. Columbia University Press, New York, pp 21-42

Cobban WA (1984) Mid-Cretaceous ammonite zones, Western Interior, United States. Geol Soc Denmark B 33:71-89

Curtis K, Padian K (1999) An Early Jurassic microvertebrate fauna from the Kayenta Formation of northeastern Arizona: Microfaunal change across the Triassic-Jurassic boundary. PaleoBios 19:19-37

DeMar DG Jr, Breithaupt BH (2006) The nonmarine vertebrate microfossil assemblages of the Mesaverde Formation (Upper Cretaceous, Campanian) of the Wind River and Bighorn basins, Wyoming. N M Mus N H Sci Bull 35:33-53

DeMar DG Jr, Breithaupt BH (2008) Terrestrial and aquatic vertebrate paleocommunities of the Mesaverde Formation (Upper Cretaceous, Campanian) of the Wind River and Bighorn basins, Wyoming, USA. In: Sankey JT, Baszio S (eds) Vertebrate Microfossil Assemblages: Their Role in Paleoecology and Paleobiogeography. Indiana University Press, Bloomington, pp 78-103

Denton RK Jr, O'Neill RC (1998) Parrisia neocesariensis, a new batrachosauroidid salamander and other amphibians from the Campanian of eastern North America. J Vertebr Paleontol $18: 484-494$

Dyman TS, Cobban WA, Titus AL, Obradovich JD, Davis LE, Eves RL, Pollock GL, Takahashi KI, Hester TC (2002) New biostratigraphic and radiometric ages for Albian-Turonian Dakota Formation and Tropic Shale at Grand Staircase-Escalante National Monument and Iron Springs Formation near Cedar City, Parowan, and Gunlock in SW Utah. Geol Soc Am, Rocky Mountain Sec, Abstracts with Programs 34:13

Eaton JG (1990) Stratigraphic revision of Campanian (Upper Cretaceous) rocks in the Henry Basin, Utah. Mt Geol 27:27-38

Eaton JG (1991) Biostratigraphic framework for the upper Cretaceous rocks of the Kaiparowits Plateau, southern Utah. Geol Soc Am S $260: 47-63$

Eaton JG (1999) Vertebrate paleontology of the Paunsaugunt Plateau, Upper Cretaceous, southwestern Utah. In: Gillette DD (ed) Vertebrate paleontology in Utah. Utah Geol Survey Misc Pub 99-1, Salt Lake City, pp 335-338

Eaton JG (2002) Multituberculate mammals from the Wahweap (Campanian, Aquilan) and Kaiparowits (Campanian, Judithian) formations, within and near the Grand Staircase-Escalante National Monument, southern Utah. Miscellaneous Publication 02-4. Utah Geological Survey, Salt Lake City

Eaton JG (2004) New screen-washing approaches to biostratigraphy and paleoecology, Cretaceous of southwestern Utah. Carn Mus N H Bull 36:21-30

Eaton JG (2006a) Santonian (Late Cretaceous) mammals from the John Henry Member of the Straight Cliffs Formation, Grand Staircase-Escalante National Monument, Utah. J Vertebr Paleontol 26:446-460
Eaton JG (2006b) Late Cretaceous mammals from Cedar Canyon, southwestern Utah. New Mex Mus N H Sci Bull 35:373-402

Eaton JG (2010) Cenomanian (Late Cretaceous) mammals from Cedar Canyon, southwestern Utah, and a revision of Cenomanian Alphadon-like marsupials. Mus N Arizona Bull 65 (in press)

Eaton JG, Cifelli RL (1988) Preliminary report on the Late Cretaceous mammalian faunas of the Kaiparowits Plateau, Utah. Contrib Geol, University of Wyoming 26:45-51

Eaton JG, Cifelli RL, Hutchison JH, Kirkland JI, Parrish JM (1999a) Cretaceous vertebrate faunas from the Kaiparowits Plateau, south-central Utah. In: Gillette DD (ed) Vertebrate Paleontology in Utah. Miscellaneous Publication 99-1. Utah Geol Survey, Salt Lake City, pp 345-353

Eaton JG, Maldonado F, McIntosh WC (1999b) New radiometric dates from Upper Cretaceous rocks of the Markagunt Plateau, southwestern Utah, and their bearing on subsidence histories. Geol Soc Am, Abstracts with Programs 31:A-11.

Eaton JG, Laurin J, Kirkland JI, Tibert NE, Leckie RM, Sageman BB, Goldstrand PM, Moore DW, Straub AW, Cobban WA, Dalebout JD (2001) Cretaceous and Early Tertiary Geology of Cedar and Parowan canyons, western Markagunt Plateau, Utah. In: Erskine MC, Faulds JE, Bartley JM, Rowley PD (eds) The Geologic Transition, High Plateaus to Great Basin - A Symposium and Field Guide: Utah Geological Association Publication No 30. Utah Geological Association, Salt Lake City, pp 337-363

Eberth DA, Braman DR, Tokaryk TT (1990) Stratigraphy, sedimentology and vertebrate paleontology of the Judith River Formation (Campanian) near Muddy Lake, west-central Saskatchewan. B Can Petrol Geol 38:387-406

Eberth DA, Currie PJ, Brinkman DB, Ryan MJ, Braman DR, Gardner JD, Lam VD, Spivak DN, Neuman AG (2001) Alberta's dinosaurs and other fossil vertebrates: Judith River and Edmonton groups (Campanian-Maastrichtian). In: Hill CL (ed) Mesozoic and Cenozoic Paleontology in the Western Plains and Rocky Mountains. Museum of the Rockies, Bozeman, pp $47-75$

Emerson SB, De Jongh HJ (1980) Muscle activity at the ilio-sacral articulation of frogs. J Morphol 166:129-144

Estes R (1964) Fossil vertebrates from the Late Cretaceous Lance Formation, eastern Wyoming. Univ Calif Publ Geol Sci 49:1-180

Estes R (1969) A new fossil discoglossid frog from Montana and Wyoming. Breviora 328:1-7

Estes R (1970) Origin of the recent North American lower vertebrate fauna: an inquiry into the fossil record. Forma et Functio 3:139-163

Estes R, Sanchíz B (1982) New discoglossid and palaeobatrachid frogs from the Late Cretaceous of Wyoming and Montana, and a review of other frogs from Lance and Hell Creek Formations. J Vertebr Paleontol 2:9-20

Estes R, Berberian P, Meszoely C (1969) Lower vertebrates from the Late Cretaceous Hell Creek Formation, McCone County, Montana. Breviora 337:1-33

Estes R, Špinar ZV, Nevo E (1978) Early Cretaceous pipid tadpoles from Israel (Amphibia: Anura). Herpetologica 34:374-393

Evans SE, Borsuk-Białynicka M (1998) A stem group frog from the Early Triassic of Poland. Acta Palaeontol Pol 43:573-580

Evans SE, Borsuk-Białynicka M (2009) The Early Triassic stem-frog Czatkobatrachus from Poland. Palaeontol Pol 65:79-105

Evans SE, Milner AR (1993) Frogs and salamanders from the Upper Jurassic Morrison Formation (Quarry Nine, Como Bluff) of North America. J Vertebr Paleontol 13:24-30

Evans SE, Milner AR (1994) Middle Jurassic microvertebrate assemblages from the British Isles. In: Fraser NC, Sues H-D (eds) In the shadow of Dinosaurs. Cambridge University Press, pp 303-321

Fox RC (1972) A primitive therian mammal from the Upper Cretaceous of Alberta. Can J Earth Sci 9:1479-1494 
Fox RC (1976a) An edentulous frog (Theatonius lancensis, new genus and species) from the Upper Cretaceous Lance Formation of Wyoming. Can J Earth Sci 13:1486-1490

Fox RC (1976b) Upper Cretaceous and Paleocene vertebrate paleontology in Alberta. Geological and Mineralogical Association of Canada, Edmonton

Fox RC (1989) The Wounded Knee local fauna and mammalian evolution near the Cretaceous-Tertiary boundary, Saskatchewan, Canada. Palaeontogr Abt A 208:11-59

Gao K-Q, Wang Y (2001) Mesozoic anurans from Liaoning Province, China, and phylogenetic relationships of archaeobatrachian anuran clades. J Vertebr Paleontol 21:460-476

Gardner JD (1995) Lower Cretaceous anurans from Texas and Utah. J Vertebr Paleontol 15(suppl):31A

Gardner JD (2000) Systematics of Albanerpetontids and Other Lissamphibians from the Late Cretaceous of Western North America. Dissertation, University of Alberta

Gardner JD (2005) Lissamphibians. In: Currie PJ, Koppelhus EB (eds) Dinosaur Provincial Park. Indiana University Press, Bloomington, pp 186-201

Gardner JD (2008) New information on frogs (Lissamphibia: Anura) from the Lance Formation (late Maastrichtian) and Bug Creek Anthills (late Maastrichtian and early Paleocene), Hell Creek Formation, USA. In: Sankey JT, Baszio S (eds) Vertebrate Microfossil Assemblages. Indiana University Press, Bloomington, pp 219-249

Gardner JD, Roček Z, Eaton JG, Cifelli RL (2009) Amphibians from the Late Cretaceous of southwestern Utah. Advances in Western Interior Late Cretaceous Paleontology and Geology, Abstracts with Program, Grand Staircase-Escalante National Monument Cretaceous Symposium. St. George, Utah, p 20

Gardner JD, Roček Z, Přikryl T, Eaton JG, Blob RW, Sankey JT (in press) Comparative morphology of the ilium of anurans and urodeles (Lissamphibia) and a re-assessment of the anuran affinities of Nezpercius dodsoni Blob et al., 2001. J Vertebr Paleontol

Gradstein FM, Ogg JG, Smith AG (2004) A Geologic Timescale 2004. Cambridge University Press, Cambridge

Green TL (1931) On the pelvis of the Anura: a study in adaptation and recapitulation. Proc Zool Soc Lond 1931:1259-1291

Hecht MK (1963) A reevaluation of the early history of the frogs. Part II. Syst Zool 12:20-35

Hecht MK, Estes R (1960) Fossil amphibians from Quarry Nine. Postilla 46:1-19

Henrici AC (1998a) A new pipoid anuran from the Late Jurassic Morrison Formation at Dinosaur National Monument, Utah. J Vertebr Paleontol 18:321-332

Henrici AC (1998b) New anurans from the Rainbow Park Microsite, Dinosaur National Monument, Utah. Mod Geol 23:1-16

Holman JA (2003) Fossil Frogs and Toads of North America. Indiana University Press, Bloomington

Hunt AP, Lucas SG (1993) Cretaceous vertebrates of New Mexico. New Mex Mus N H Sci Bull 2:77-91

Jarošová J, Roček Z (1982) The incrassatio frontoparietalis in frogs, its origin and phylogenetic significance. Amphib-Reptil 3:111124

Jenkins FA Jr, Shubin NH (1998) Prosalirus bitis and the anuran caudopelvic mechanism. J Vertebr Paleontol 18:495-510

Jinnah ZA, Roberts EM, Deino AL, Larsen JS, Link PK, Fanning $\mathrm{CM}$ (2008) New ${ }^{40} \mathrm{Ar}-{ }^{39} \mathrm{Ar}$ and Detrital zircon U-Pb ages from the Upper Cretaceous Wahweap and Kaiparowits formations on the Kaiparowits Plateau, Utah: implications for regional correlation, provenance, and biostratigraphy. Cretaceous Res 30:287299

Jones MEH, Evans SE, Sigogneau-Russell D (2003) Early Cretaceous frogs from Morocco. Ann Carnegie Mus 72:65-97
Kielan-Jaworowska Z, Cifelli RL, Luo Z-X (2004) Mammals from the age of Dinosaurs: origins, evolution, and structure. Columbia University Press, New York

Kowallis BJ, Christiansen EH, Deino A (1989) Multi-characteristic correlation of Upper Cretaceous volcanic ash beds from southwestern Utah to central Colorado. Utah Geol Mineral Survey Misc Pub 89-5. Utah Geological Survey, Salt Lake City

Larson DW, Brinkman DB, Bell PR (in press) Faunal assemblages from the upper Horseshoe Canyon Formation, an early Maastrichtian cool-climate assemblage from Alberta, with special reference to the Albertosaurus sarcophagus bonebed. Can J Earth Sci

Lillegraven JA (1976) A new genus of therian mammals from the Late Cretaceous "El Gallo Formation," Baja California, Mexico. J Paleontol 50:437-443

Lofgren DL (1995) The Bug Creek problem and the CretaceousTertiary transition at McGuire Creek, Montana. University of California Publications in Geological Sciences 140. University of California Press, Berkley

Lynch JD (1971) Evolutionary relationships, osteology, and zoogeography of leptodactyloid frogs. Univ Kansas Mus Nat Hist Miscl Publ 53:1-238

Marsh O (1887) The American Jurassic mammals. Am J Sci 33:327_ 348

May FE, Traverse A (1973) Palynology of the Dakota Sandstone (Middle Cretaceous) near Bryce Canyon National Park, southern Utah. Geosci Man 7:57-64

Merewether EA, Cobban WA, Obradovich JD (2007) Regional disconformities in Turonian and Coniacian (Upper Cretaceous) strata in Colorado, Wyoming, and adjoining states; biochronological evidence. Rocky Mt Geol 42:95-122

Moodie RL (1912) An American Jurassic frog. Am J Sci 34:286-288

Moodie RL (1914) The fossil frogs of North America. Am J Sci 38:531-536

Moore DW, Nealey LD, Rowley PW, Hatfield SC, Maxwell DJ, Mitchell E (2004) Geologic Map of the Navajo Lake Quadrangle, Kane and Iron counties, Utah. Utah Geological Survey Map 199, scale 1:24,000. Utah Geol Survey, Salt Lake City

Obradovich JD, Cobban WA (1975) A time-scale for the Late Cretaceous of the Western Interior of North America. In: Caldwell WGE (ed) The Cretaceous System in the Western Interior of North America. Geol Assoc of Canada, St. John's, pp $31-54$

Payenberg THD, Braman DR, Davis DW, Miall AD (2002) Litho- and chronostratigraphic relationships of the Santonian-Campanian Milk River Formation in southern Alberta and Eagle Formation in Montana utilizing stratigraphy, U-Pb geochronology, and palynology. Can J Earth Sci 39:1553-1577

Pearson DA, Schaefer T, Johnson KR, Nichols DJ, Hunter JP (2002) Vertebrate biostratigraphy of the Hell Creek Formation in southwestern North Dakota and northwestern South Dakota. Geol Soc Am Spec Pap 361:145-167

Peng J, Russell AP, Brinkman DB (2001) Vertebrate microsite assemblages (exclusive of mammals) from the Foremost and Oldman formations of the Judith River Group (Campanian) of southeastern Alberta: an illustrated guide. Provincial Museum of Alberta, Edmonton

Peterson F (1969) Four new members of the Upper Cretaceous Straight Cliffs Formation in southeastern Kaiparowits region, Kane County, Utah. US Geol Survey Bull 1274-J:1-28

Přikryl T, Aerts P, Havelková P, Herrel A, Roček Z (2009) Pelvic and thigh musculature in frogs (Anura) and origin of anuran jumping locomotion. J Anat 214:100-139

Rage JC, Dutheil DB (2008) Amphibians and squamates from the Cretaceous (Cenomanian) of Morocco. A preliminary study, with 
description of a new genus of pipid frog. Palaeontogr, A, 285:122

Rage JC, Roček Z (1989) Redescription of Triadobatrachus massinoti (Piveteau, 1936) an anuran amphibian from the Early Triassic. Palaeontogr Abt A 206:1-16

Roberts EH (2007) Facies architecture and depositional environments of the Upper Cretaceous Kaiparowits Formation, southern Utah. Sed Geol 197:207-233

Roberts LNR, Kirschbaum MA (1995) Paleogeography of the Late Cretaceous of the Western Interior of middle North America coal distribution and sediment accumulation. US Geol Surv Prof Pap 1561, 115 p.

Roberts EM, Deino AL, Chan MA (2005) ${ }^{40} \mathrm{Ar}-{ }^{39} \mathrm{Ar}$ age of the Kaiparowits Formation, southern Utah, and correlation of contemporaneous Campanian strata and vertebrate faunas along the margin of the Western Interior Basin. Cretaceous Res 26:307-318

Roček Z (2000) Mesozoic anurans. In: Heatwole H, Carroll RL (eds) Amphibian Biology, vol 4, Palaeontology: the Evolutionary History of Amphibians. Surrey Beatty, Sydney, pp 1295-1331

Roček Z (2008) The Late Cretaceous frog Gobiates from Central Asia: its evolutionary status and possible phylogenetic relationships. Cretaceous Res 29:577-591

Roček Z, Nessov LA (1993) Cretaceous anurans from Central Asia. Palaeontogr Abt A 266:1-54

Roček Z, Van Dijk E (2006) Patterns of larval development in Cretaceous pipid frogs. Acta Palaeontol Pol 51:111-126

Rowe T, Cifelli RL, Lehman TM, Weil A (1992) The Campanian Terlingua local fauna, with a summary of other vertebrates from the Aguja Formation, Trans-Pecos Texas. J Vertebr Paleontol $12: 472-493$

Sahni A (1972) The vertebrate fauna of the Judith River Formation, Montana. B Am Mus Nat Hist 147:321-412
Sanchíz B (1998) Salientia. In: Wellnhofer P (ed) Encyclopedia of Paleoherpetology, Part 4. Friedrich Pfeil, München, pp 1-275

Shubin NH, Jenkins FA Jr (1995) An early Jurassic jumping frog. Nature 377:49-52

Tibert NE, Leckie RM, Eaton JG, Kirkland JI, Colin J-P, Leithold EL, McCormick M (2003) Recognition of relative sea-level change in Upper Cretaceous coal-bearing strata: a paleoecological approach using agglutinated foraminifera and ostracodes to detect key stratigraphic surfaces. In: Olson H, Leckie RM (eds) Microfossils As Proxies for Sea level Change and Stratigraphic Discontinuities. Soc Sed Geol, Tulsa, pp 263-299

Tokaryk TT (1997) Preliminary review of the non-mammalian vertebrates from the Frenchman Formation (late Maastichtian [sic]) of Saskatchewan. In: McKenzie-McAnally L (ed) Upper Cretaceous and tertiary stratigraphy and Paleontology of Southern Saskatchewan. Geol Assoc of Cananda, St. John's, pp 34-44

Wilson LE (2008) Comparative taphonomy and paleoecological reconstruction of two microvertebrate accumulations from the Late Cretaceous Hell Creek Formation (Maastrichtian) Eastern Montana. Palaios 23:289-297

Winkler DA, Jacobs LL (2002) Cenomanian vertebrate faunas of the Woodbine Formation, Texas. J Vertebr Paleontol 22(suppl 3):120A

Winkler DA, Murry PA, Jacobs LL (1989) Vertebrate paleontology of the Trinity Group, Lower Cretaceous of central Texas. In: Winkler DA, Murry PA, Jacobs LL (eds) Field Guide to the Vertebrate Paleontology of the Trinity Group, Lower Cretaceous of Central Texas. Institute for the Study of Earth and Man. Southern Methodist University, Dallas, pp 1-22

Winkler DA, Murry PA, Jacobs LL (1990) Early Cretaceous (Comanchean) vertebrates of central Texas. J Vertebr Paleontol 10:95-116

Zangerl R, Denison RH (1950) Discovery of Early Cretaceous mammals and frogs in Texas. Science 112:61 